\title{
Holistic Fisheries Management: Combining Macroecology, Ecology, and Evolutionary Biology
}

\author{
CHARLES W. FOWLER, ANDREA BELGRANO, and MICHELE CASINI
}

\section{Introduction}

Overfishing is recognized as a major challenge confronting management in marine environments (Jackson, 2008; Pitcher and Lam, 2010; Eikeset et al., 2011). Conventional measures of overfishing indicate that about $28 \%$ of the world's exploited stocks are either overfished or recovering (FAO, 2009). Comparisons with the consumption

Charles W. Fowler, corresponding author, is with the National Marine Mammal Laboratory, Alaska Fisheries Science Center, National Marine Fisheries Service, NOAA, 7600 Sand Point Way, NE, Seattle, WA 98115 (current address: Biology Department, Seattle University, 901 12th Ave, P.O. Box 222000, Seattle, WA 98122-1090; email: charles.fowler@noaa. gov). Andrea Belgrano is with the Swedish University of Agricultural Sciences, Department of Aquatic Resources, Institute of Marine Research, Turistgatan 5, SE-453 30 Lysekil, Sweden; and Swedish Institute for the Marine Environment (SIME), Box 260, SE-405 30 Göteborg, Sweden. Michele Casini is with the Swedish University of Agricultural Sciences, Department of Aquatic Resources, Institute of Marine Research, Turistgatan 5, SE-453 30 Lysekil, Sweden.

doi: dx.doi.org/10.7755/MFR.75.1_2.1 rates of other predators indicate that nearly all current commercial fishing rates are far from sustainable (Belgrano and Fowler, 2011a). Overfishing is a problem whether assessing fisheries with respect to harvests from individual species, species groups, ecosystems, or the entire marine environment (Fig. 1; App. 1).

It is widely acknowledged that confining fisheries management to the regulation of harvests from individual species is insufficient and fraught with risks. As a step toward more holistic management, efforts of the last few decades have made progress toward including ecosystems, mostly through substantiating a few of the critical principles involving ecosystems (e.g., interconnectedness). However, achieving ecosystem-based fisheries management is only one of many essential elements on the path toward developing an objective and holistic form of management-long seen as a major goal in the effort to solve problems associated with overfishing (NRC, 2004; Pitcher and Lam, 2010).

The multispecies systems from which we harvest resources involve both ecosystems and "evosystems"." In other words, these systems include food webs, trophic structure, complex population dynamics, and numerous predatory and competitive interactions, along with processes and interactions that involve evolution, coevolution, extinction, and speciation-thus evosystems. Within these systems, natural selection occurs at all levels and involves evolutionary interactions among species, including extinction and its selectivity, insofar as they contribute to the structure and functioning of ecosystems (Okasha, 2006; Damuth, 2007). In addition to the classically recognized forms of inheritance of genetic material within species (vertical transfer, or transfer

\footnotetext{
${ }^{1}$ See footnote 1 of Belgrano and Fowler (2011a) regarding the history of the concept and the term "evosystem."
}

ABSTRACT-Ecosystem-based management is one of many indispensable components of objective, holistic management of human impacts on nonhuman systems. By itself, however, ecosystem-based management carries the same risks we face with other forms of current management; holism requires more. Combining singlespecies and ecosystem approaches represents progress. However, it is now recognized that management also needs to be evosystem-based. In other words, management needs to account for all coevolutionary and evolutionary interactions among all species; otherwise we fall far short of holism. Fully holistic practices are quite distinct from the approaches to the management of fisheries that are applied today.
In this paper, we show how macroecological patterns can guide management consistently, objectively, and holistically. We present one particular macroecological pattern with two applications. The first application is a case study of fisheries from the Baltic Sea involving historical data for two species; the second involves a sample of 44 species of primarily marine fish worldwide. In both cases we evaluate historical fishing rates and determine holisticl systemic sustainable single-species fishing rates to illustrate that conventional fisheries management leads to much more extensive and pervasive overfishing than currently realized; harvests are, on average, over twenty-fold too large to be fully sustainable. In general, our approach involves not only the sustainability of fisheries and related resources but also the sustainability of the ecosystems and evosystems in which they occur. Using macroecological patterns accomplishes four important goals:

1) Macroecology becomes one of the interdisciplinary components of management.

2) Sustainability becomes an option for harvests from populations of individual species, species groups, ecosystems, and the entire marine environment.

3) Policies and goals are reality-based, holistic, or fully systemic; they account for ecological as well as evolutionary factors and dynamics (including management itself).

4) Numerous management questions can be addressed. 
from one generation to the next), and their evolutionary implications in natural selection, evosystems also involve the transfer of genetic material from one co-occurring species to another (horizontal transfer among species with its attendant field of science; see Woese, 2004). All such dynamics are important parts of the complexity to be accounted for in management.

The evolutionary impact of fishing is now recognized as one of many issues that must be taken into account to achieve holistic sustainability (Jørgensen et al., 2007). These effects are exemplified by changes in growth rates in response to size-selective fishing (Swain et al., 2007). However, the direct genetic impacts of harvesting are not alone. Indirect effects (including feedback) are ubiquitous. There are the indirect effects of secondary, tertiary, and higher-order reactions to fishing within ecosystems.

Thus, there are evolutionary ripple effects that involve higher-order interactions in evosystems. These effects include the various ways genetic information is transferred. Indirect effects are involved in the coevolutionary relationships among all species within the system. The fields of science involving evolutionary ecology and the study of horizontal genetic transfer emphasize the respective dynamics as a matter of principle. The dynamics of selectivity at all levels, and involving the impacts of all species (including influences by humans), contribute to the macroecological patterns observed within and among ecosystems.

To make progress toward greater holism, emphasis has often been placed on increasing the interdisciplinary nature of management. Simply including more disciplines, however, is counterproductive if the exercise perpetuates problems associated with conventional attempts to account for complexity. In contrast, each discipline of science can be relied upon to reveal empirical patterns identified by specific management questions. These are integrative patterns (Belgrano and Fowler, 2008) that are consonant $^{2}$, consistent, and isomorphic with a specific pattern matching each specific question (Fowler and Hobbs, 2009, 2011).

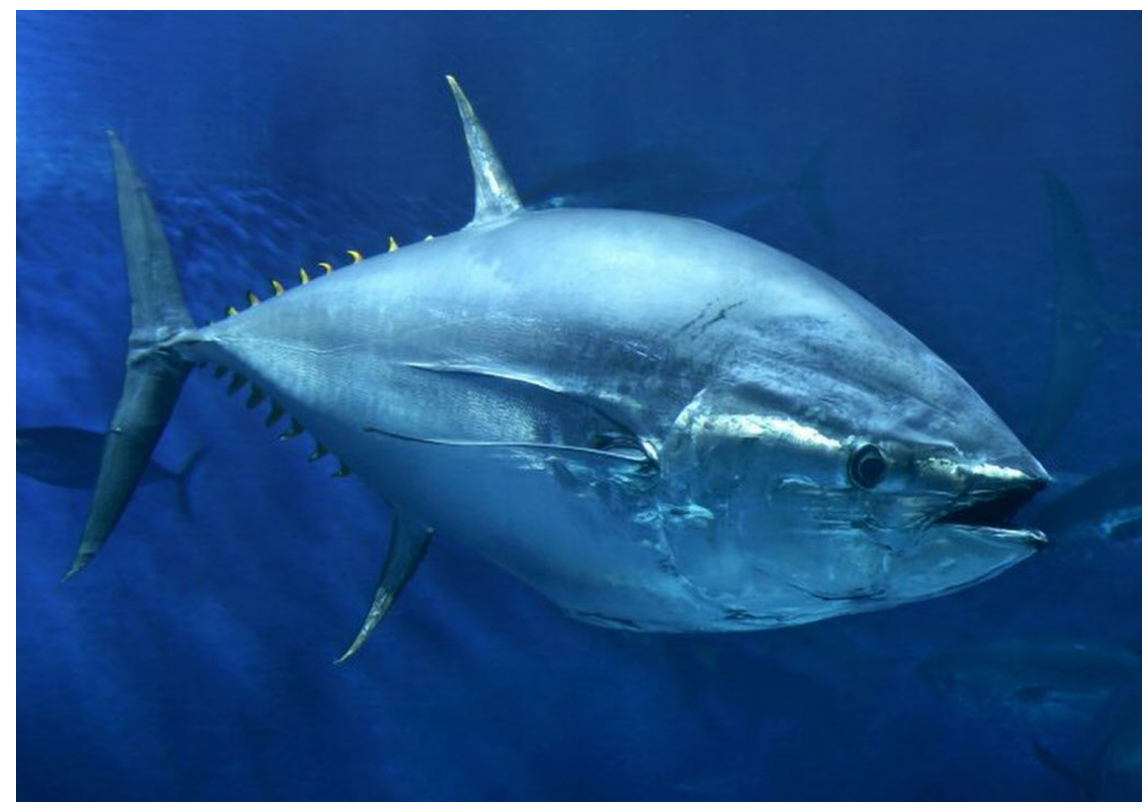

The Pacific Bluefin Tuna, Thunnus orientalis, is a species of marine fish for which fisheries management could regulate harvests based on the macroecological pattern relating sustainable harvest rates to total natural mortality rate $(M)$ (photo courtesy of Monterey Bay Aquarium/Randy Wilder).
Thus, bringing the field of macroecology into the realm of management allows for observing numerous patterns to address management questions that were impossible to answer objectively in the past. Management based on macroecological patterns achieves holism through the integrative nature of such patterns: macroecological patterns account for everything that contributed to their origin and all of their systemic influences-nothing is ignored (Belgrano and Fowler, 2008). ${ }^{3}$

With this in mind, in the following sections we provide examples of the use of macroecological patterns for objectively and holistically setting quantitative goals for management:

1) A selection of four published cases illustrate the use of macroecological patterns for assessing historical harvest rates for marine fisheries at various scales of organization from individual species to the full marine environment.

2) A presentation of data from the monitoring of two species of fish in the Baltic Sea covering several decades, plus information that does not include temporal variation for 44

\footnotetext{
${ }^{2}$ Consonance involves being isomorphic; i.e., there is a strict match between the management question being addressed and the pattern used to provide guidance; they involve the same thing. Both the pattern and the question involve the same units of measurement, are of the same logical type, and are otherwise congruent in nature. See Fowler and Hobbs $(2009,2011)$ for more detail.

${ }^{3}$ Management based on patterns (App. 1), whether macroecological or otherwise, involves information (App. 2) of an integrative nature (App. 3). These patterns reflect the results of a "laboratory" (reality, nature, or the universe) wherein an enormous number of "experiments" have already been performed through ecological and evolutionary trial and error processes. We get to see only those outcomes that are successful-temporary as such examples themselves may be. Consequently, the things that we do not see in the patterns of nature necessarily have a low probability of ecological success, at least on evolutionary time scales. Examples of abnormality in patterns can be considered unsustainable (running all of the risks of a failed "experiment"). Avoiding abnormality in natural patterns (especially by humans) is core to systemic management. For more detailed accounts and examples of this form of management, see Belgrano and Fowler (2008), Fowler (2003, 2009), and Fowler and McCluskey (2011).
} 
species of fish. In each case we exemplify the use of a macroecological pattern to assess historical harvests from individual species.

3 ) Further examples of the use of macroecological patterns to provide management advice regarding two applications:

- sustainable selectivity to deal directly with one aspect of the evolutionary impact of fishing, and

- an introduction to the use of macroecological patterns for establishing marine protected areas.

\section{Using Macroecological Patterns}

Assessing Historical Management:

\section{A Brief Review}

Realistic management starts with a very carefully posed management question (Fowler and Hobbs, 2009, 2011). Likewise, the assessment of any particular management practice (e.g., those of conventional management) begins with a seriously considered research question. For example: "How many tons of Walleye Pollock, Theragra chalcogramma, would have been taken each year, if taken sustainably from the eastern Bering Sea ecosystem, in the late 1980's?"

To answer this question requires a consonant natural pattern. The appropriate pattern is illustrated in Figure 1a. It is a macroecological pattern revealed by the kind of research that best provides objective answers to management questions.

The information presented in Figure 1a addresses the question just posed to assess management as practiced historically - thus helping demonstrate the general applicability of holism. The pattern represented by Figure 1a (as with all the patterns of Figure 1; see also Appendices 1 and 2) allows for achieving the objectives of:

1) measuring abnormality, especially on the part of humans,

2) maximizing the biodiversity of this system, (a)

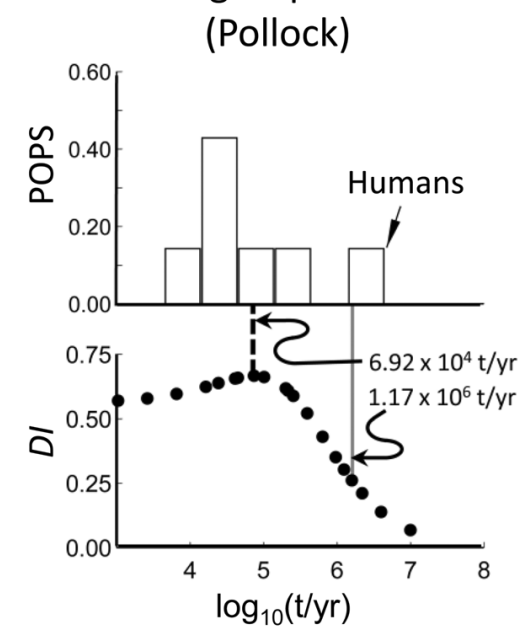

(c)
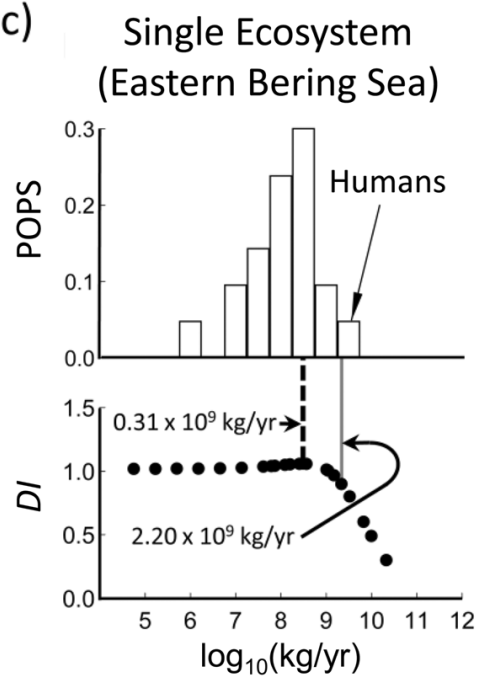

(b)

Multiple Species

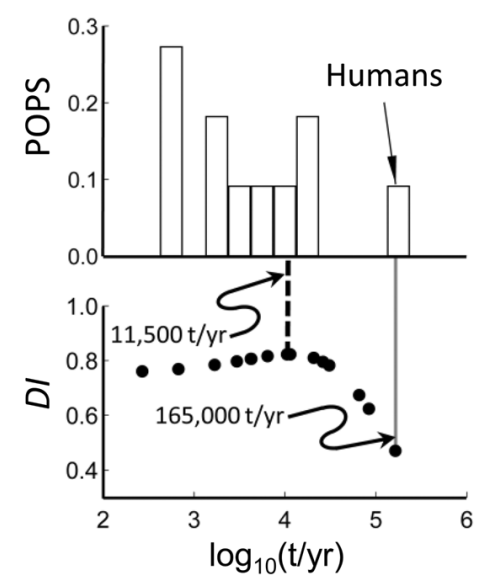

(d)
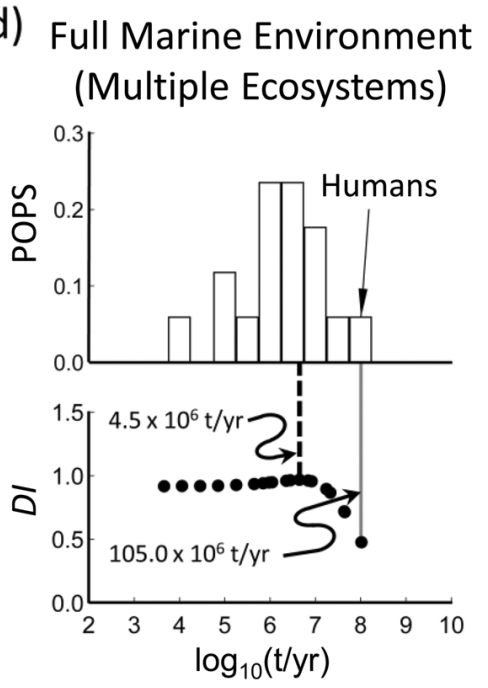

Figure 1.-Macroecological patterns in the rates at which biomass is consumed by varying numbers of predatory species from four hierarchically distinct biological systems, at distinct times, with biodiversity as a function of consumption by humans (fishing rates). POPS is the portion of the sample $(n)$ of predatory species represented by the top panel, and $D I$ is the corresponding diversity index plotted against corresponding fishing rates in the bottom panel. (a) Consumption from a stock of T. chalcogramma by six species of marine mammals (and fisheries) $(n=7)$ in the eastern Bering Sea during the late 1980's (Livingston, 1993; Fowler, 2008). (b) Consumption from three species of fish by 10 species of marine mammals (and fisheries) $(n=11)$, in the northwest Atlantic during the late 1980's (Overholtz et al., 1991; Fowler, 2009). (c) Consumption by 20 species of marine mammals (and fisheries) $(n=21)$, from the eastern Bering Sea ecosystem during the late 1980's (Fowler, 2009). (d) Consumption by 16 species of small cetaceans (and fisheries) $(n=17)$, from the world's oceans during the late 1990's (Tamura and Ohsumi, 1999). See Appendix 1 for a more detailed explanation of the construction and interpretation of this figure.

3) including humans as part of the ecosystem, and

4) taking advantage of the holistic information integral/inherent to the pattern itself (App. 3).
To achieve such objectives, the harvest rate in the pollock fishery in the late 1980's would have been about 69,200 metric tons $(\mathrm{t}$ ) per year (shown by the dashed vertical line, 4.84 in log scale). 


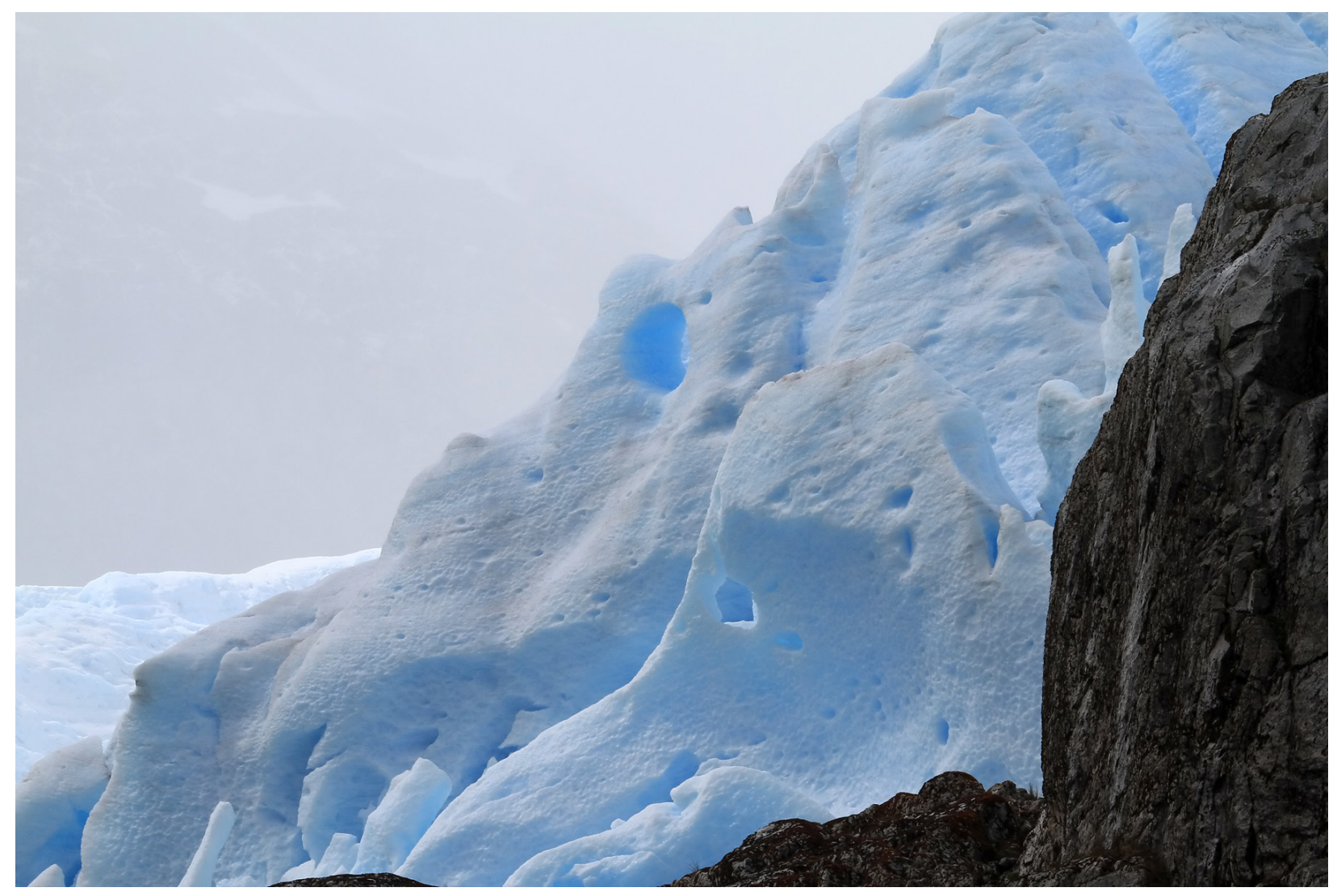

Habitat is one of the factors accounted for by the variability in natural patterns to offer the option of overt treatment in statistical analysis. Different species are expected to be represented differently in macroecological patterns as dependent on their habitat as that associated with glacial areas on Mt. Rainier in Washington State (opposite top), seasonal ice near Prudhoe Bay, Alaska (opposite bottom), and glaciers near Punta Arenas, Chile (above). Photos courtesy of and copyrighted by Amy Kennedy, www.WildKennedy.com.

This harvest rate occurs at the peak of the curve depicting the diversity/information $^{4}$ for this set of seven species (six nonhuman species plus humans) as a function of the harvest by the fishery. Thus, if 69,200 thad been taken each year, the diversity exhibited by the full set of seven species would have been maximized. This biodiversity would have been much greater than that observed for harvests actually taken (plotted at the lower end of the solid vertical gray line in the bottom panel of Figure 1a). In other words,

\footnotetext{
${ }^{4}$ The index of diversity/information $(D I)$ was measured by the Shannon-Weiner index. See Appendix 1 and Pielou (1974) regarding the use of this index and its connection to the field of information theory. See Appendices 1 and 2 for a more detailed explanation of finding maximized biodiversity.
}

the fishery, which was harvesting at a rate of $1,179,000$ t per year in the late 1980 's, was taking over 16 times too much pollock (Fowler, 2008).

"In the combined take of Silver Hake, Merluccius bilinearis; Atlantic Mackerel, Scomber scombrus; and Atlantic Herring, Clupea harengus; how many tons would have been harvested each year within the northwest Atlantic ecosystem during 1988-92 if the fishery had been managed sustainably?" Figure $1 \mathrm{~b}$ shows the observed commercial harvest rate ( $t /$ year) compared to the pattern in consumption rates observed among the marine mammal predators feeding on this multispecies complex.

As with the single-species example above (Fig. 1a), this multispecies pattern (Fig. 1b) exhibits consonance with the research question just posed to assess past management. In this case, the harvest to maximize biodiversity would have been about $11,500 \mathrm{t}$ each year instead of the $165,000 \mathrm{t}$ that were actually harvested (with data and ecosystem defined spatially by Overholtz et al., 1991); there was over 14 times too much biomass extracted from this multispecies complex for the combined set of all systems involved (including the ecosystem, evosystem, and the fisheries) to be sustainable.

"How many kilograms of biomass would have been harvested from the eastern Bering Sea ecosystem during the late 1980's, if the harvests had been managed sustainably?" Figure 1c illustrates the pattern consonant with this question, again a research question rather than a management 

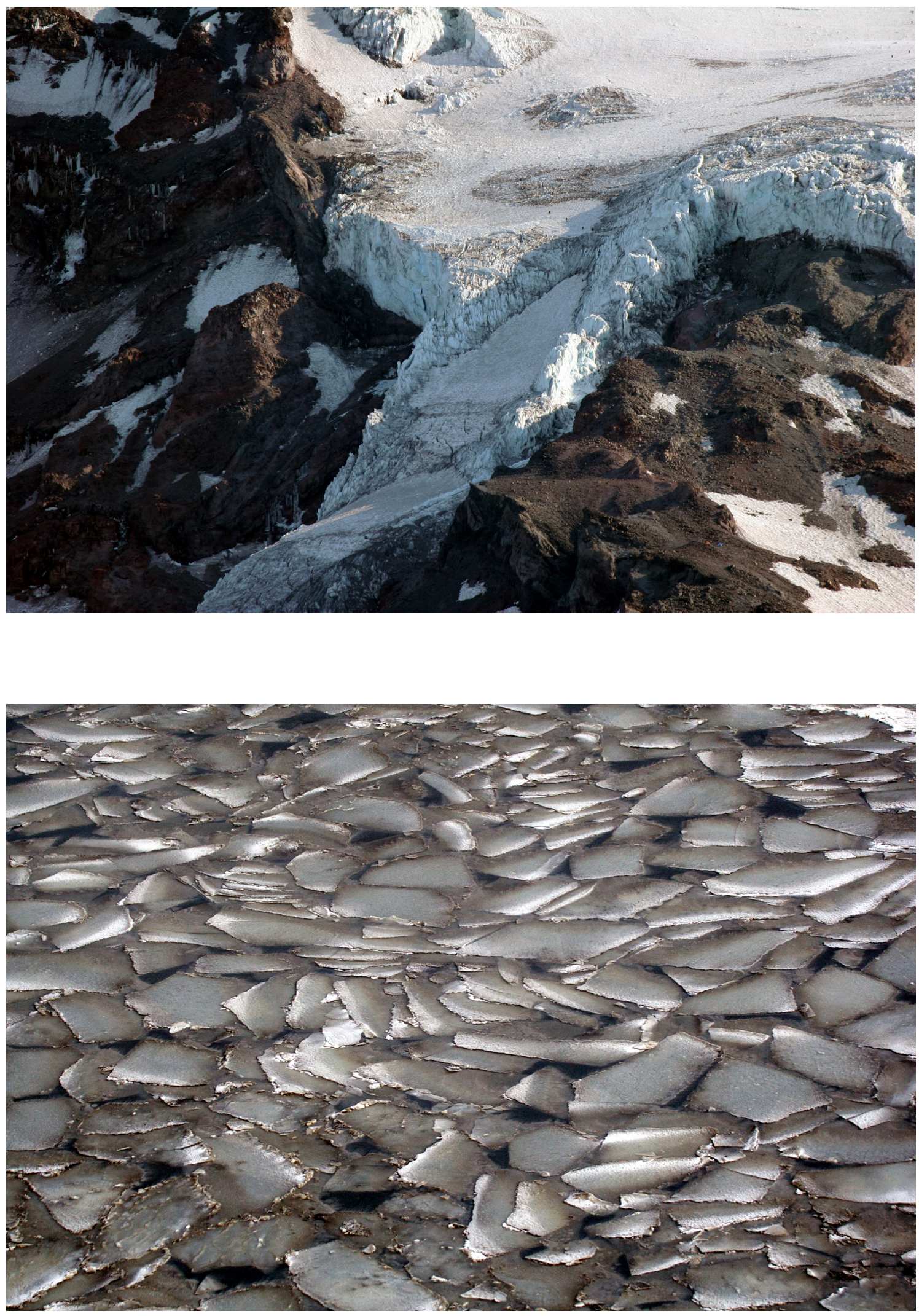


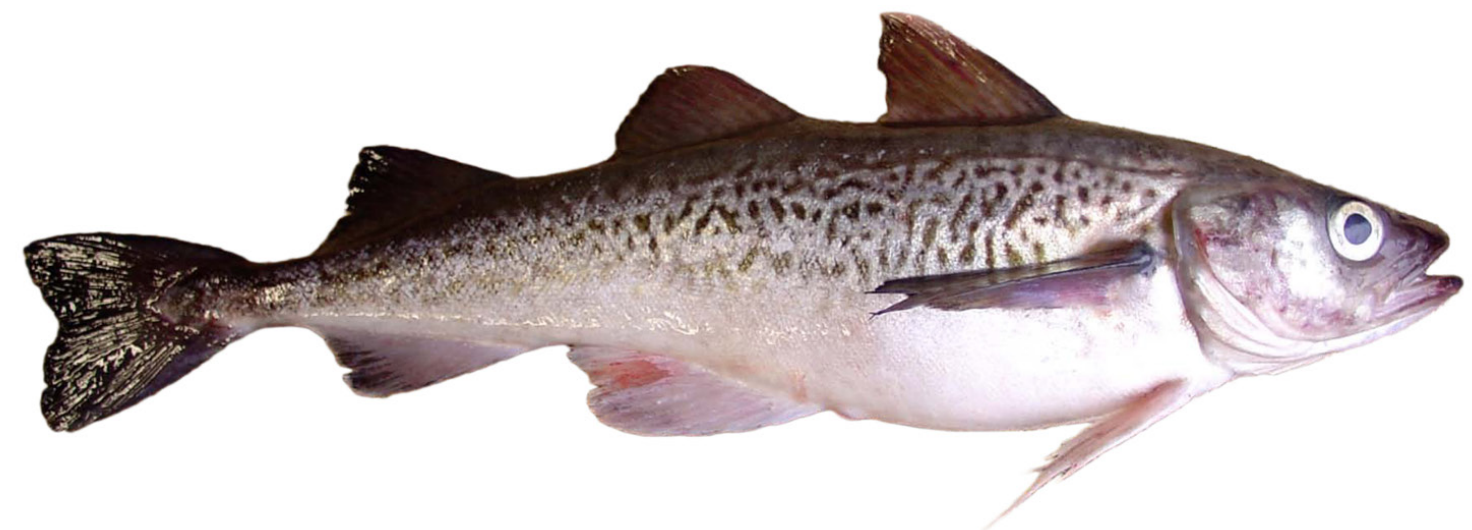

Walleye Pollock, Theragra chalcogramma, are among the species of fish for which there are data regarding consumption rates by its predators and estimates of total natural mortality rates so that the two can be related in a macroecological pattern (photo courtesy of Karna McKinney, NMFS).

question because we are assessing past events rather than seeking guidance for current or future action. As in the examples above, the pattern represented by Figure $1 \mathrm{c}$ is an integral ${ }^{5}$ pattern (as is the case for all such patterns) and objectively accounts for the previous influences of harvesting, all evolutionary dynamics, processes involving extinction, and ecological relationships that contributed to its origin-the infinite set of factors involved in its emergence (App. 3). The pattern involves holistic information (Belgrano and Fowler, 2011b; Fowler and Hobbs, 2011). In this case, the observed harvest was more than 7 times larger than the harvest that would have maximized the biodiversity of the ecosystem (Fowler, 2008).

"How many tons of biomass would have been harvested from the Earth's marine environment in the 1980's, if the harvests had been managed sustainably?" As with the previous three examples, the real-world, holistically integral pattern represented in Figure $1 \mathrm{~d}$ provides the answer. To include humans among the other species in the marine environment (i.e., as-

${ }^{5}$ See Appendix 3 for an explanation of the integral nature of natural patterns - the ways patterns account for the infinite complexity of reality to achieve holism. suming that making ourselves parts of marine ecosystems is a sustainable option), and to maximize the biodiversity of the marine system (insofar as it involves consumption of biomass), harvests would have been managed so that the total take would have been about 4,500,000 $\mathrm{t}$ (rather than the approximately $105,000,000 \mathrm{t}$ taken in the 1990's (Fowler and McCluskey, 2011)). About 23 times too much biomass was extracted from the world's oceans to be holistically sustainable.

The examples reviewed above are objective assessments of cases in which management involved harvests at four different hierarchical levels of complexity. These were four biotic systems of entirely distinct organizational scales: individual species, multispecies groups, ecosystems, and the marine environment. Other such examples abound, all involving the use of macroecological patterns. All serve as examples of systemic management-management that assumes humans are part of the complex interconnected system we often refer to as reality.

In each case above, the research question regarding an assessment of past management could be rephrased as a management question for current application. For example "How many tons of Walleye Pollock would have been taken each year, if taken sustainably from the eastern Bering Sea ecosystem, in the late 1980's?" can be reworded to read "How many tons of Walleye Pollock can be taken sustainably each year from the eastern Bering Sea ecosystem?" As for the case of assessment of past management, consonant empirical patterns, such as those illustrated in Figure 1, serve to address the question and provide guidance.

We now turn to further assessments of past harvests. One case involves data covering several decades and another involves data for numerous species.

\section{Detailed Case-studies}

In this section, we provide previously unpublished examples similar to the single-species case of Walleye Pollock as covered in the last section. In each case, we will be addressing the generic research question: "What would have been a sustainable harvest rate for species X?" Further refinements to this question will involve a variety of issues exemplified by species-specific information such as the body size of humans (as the predator involved in the harvesting). One element of specificity is that of the total natural mortality rate $(M)$ characteristic of the population of the harvested species. This factor provides a convenient starting place for refining the question. 


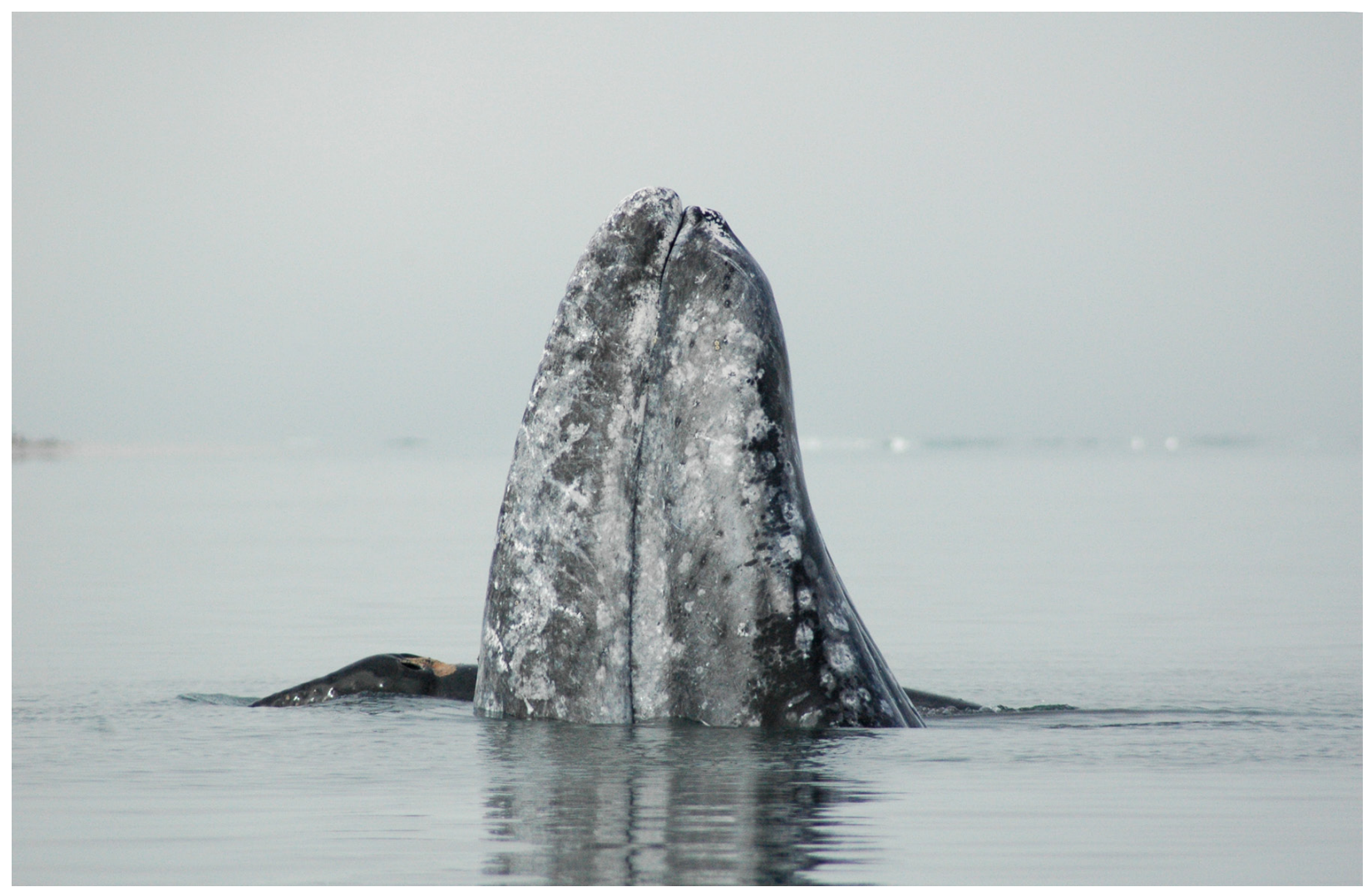

The common gray whale, Eschrichtius robustus, represents a large-bodied species for which data are needed regarding consumption rates by its predators and estimates of total natural mortality rates to better represent the related macroecological pattern (photo courtesy of and copyrighted by Charles Fowler).

"What would have been a sustainable harvest rate for species $\mathrm{X}$, so as to account for its total natural mortality rate?" Figure 2 shows a macroecological pattern relating species-specific consumption rates to natural mortality $(M)$, similar to one presented by Belgrano and Fowler (2011a). In this pattern (see App. 2 ), sustainable harvest rates are related to total natural mortality in a correlative relationship represented by the equation:

$$
F_{e s}=0.095 M,
$$

where $F_{e s}$ is the estimated ecologically sustainable harvest (fishing) rate.

The sustainability of ecologically optimal fishing rates estimated this way involves two parts. First, and most importantly, normal/sustainable ecosystem (and evosystem) integrity, structure, and function are retained to the extent possible. This is done by confining mortality caused by fishing to consumption rates (i.e., the consonant rates) typically observed among other predatory species. These rates are a measure of one aspect of their impact on and within the various systems with which they interact. The resulting pattern among these species is integrative (see App. 3); it represents empirical examples of systemic sustainability to include the sustainability of the ecosystem/evosystem. Second, the resulting integrity of the ecosystem (with its own sustainability) contributes to ensuring a sustainable resource to support fishing that itself can be sustained.

The importance and utility of the macroecological pattern shown in Figure 2 materializes in managing harvests from populations of species for which estimates of natural mortality rates are available. Ideally, estimates of the consumption rates by nonhuman mammalian species of human body size for individual resource species within a particular ecosystem would be preferable as guiding information for the management of harvests (Fowler, 2009, provides other examples), but such information is often lacking.

In the absence of such information, the ecological and evolutionary principles which are accounted for by the pattern illustrated in Figure 2 allow first approximations of sustainable harvests that are far superior to those used in conventional forms of managementsuperior in their holism, objectivity, and the complexity taken into account (Fowler, 2009). Following, we present an example of the use of this pattern for assessing observed historical harvests spanning several decades. 

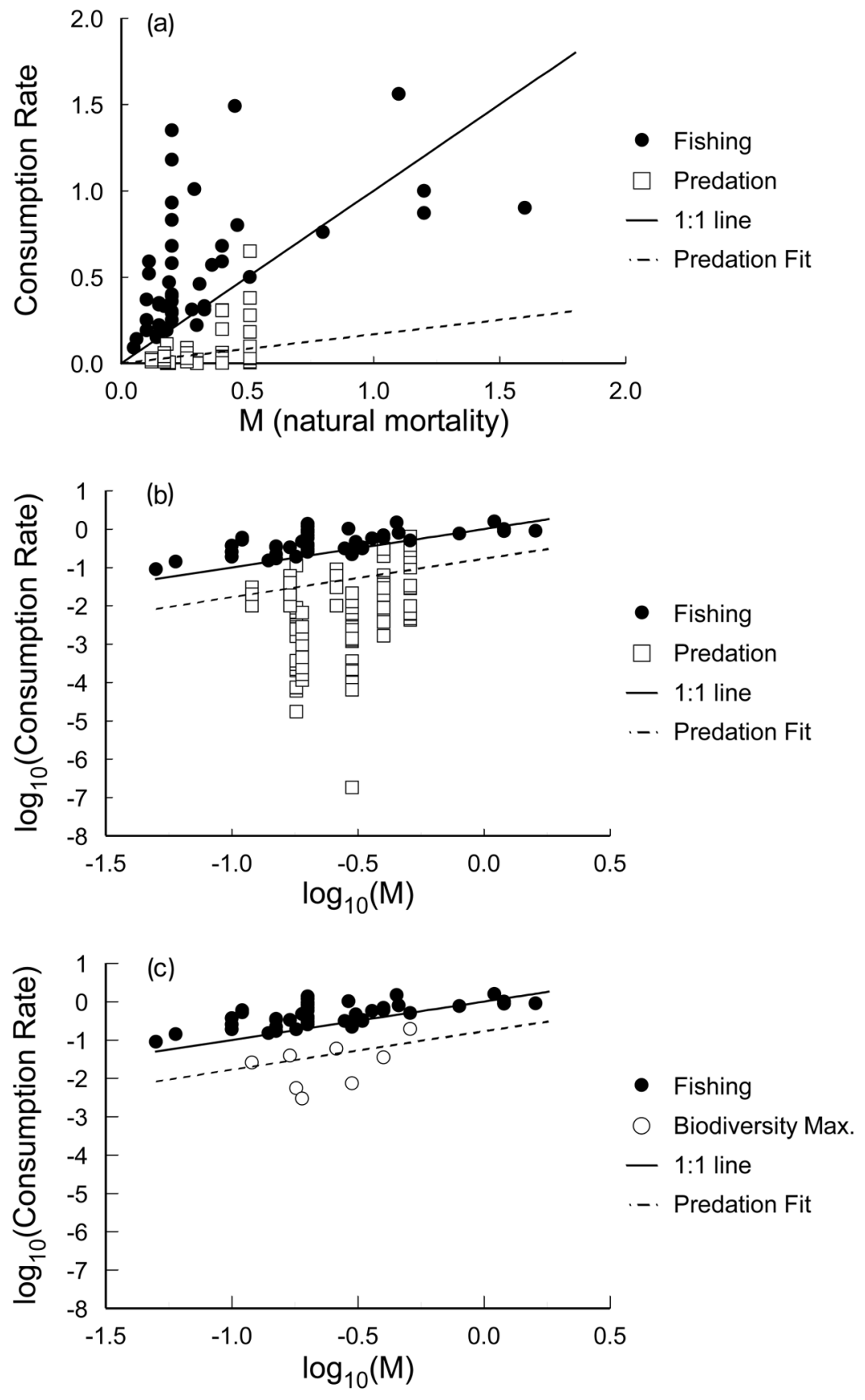

Figure 2.- The macroecological pattern in which sustainable harvest rates (ecologically sustainable, $F_{e s}$ ) are correlated with estimated total natural mortality rates $(M)$. The equation represented by the dashed line (the fit of observed predation rates in relation to $M$; App. 2) is $F_{e s}=0.095 M$ as shown, in the bottom panel, in comparison to the fishing rates that would maximize biodiversity (as exemplified for pollock in Figure 1). The data for observed fishing rates, $F_{o b}$, and total natural mortality are from Mertz and Myers (1998) (see also Belgrano and Fowler, 2011a).
Herring and Sprat

in the Baltic Sea

Both herring and European Sprat, Sprattus sprattus, are harvested in the Baltic Sea and are represented by estimates of their total natural mortality rate for the years 1974-2005 (App. 4). They are also represented by estimates of fishing rates $\left(F_{o b}=\right.$ observed fishing rate) for the same years. As explained in Appendix 4, the natural mortality rate $(M)$ can be converted to an estimate of the corresponding ecologically sustainable fishing rate $\left(F_{e s}=\right.$ ecologically sustainable fishing rate) using the above equation in an application of the macroecological pattern illustrated in Figure 2.

The research question involved in the assessment of historic fishing rates on herring is: "If fishing had been carried out sustainably, what would the fishing rate on herring of the Baltic Sea have been in the years 1974-2005?" The same question can be applied to sprat.

Figure 3 shows the pattern of variation for $F_{o b}$ for herring relative to the pattern of estimated $F_{e s}$, keeping in mind that $F_{e s}$ is based on a macroecological pattern for which the sustainability of the ecosystem (simultaneously seen as an evosystem) is taken into account along with all other factors involved in the complexity of the system (i.e., objectively taking advantage of the integrative nature of the empirical pattern shown in Figure 2).

Figure 4 is similar to Figure 3 in comparing $F_{o b}$ for sprat relative to the pattern of estimated $F_{e s}$. As in the case of assessments depicted in Figure 1, fishing rates historically observed in the harvest of herring and sprat were many times larger than holistically sustainable. Also, in parallel with earlier examples, the question posed to assess past harvesting can be rephrased to represent a management question in regard to current fisheries management (e.g., "To be carried out sustainably, what fishing rate should be applied in the harvest of herring of the Baltic Sea?"). The same kind of consonant pattern would be used for guidance. Management of the harvest of sprat can be guided the same way. 


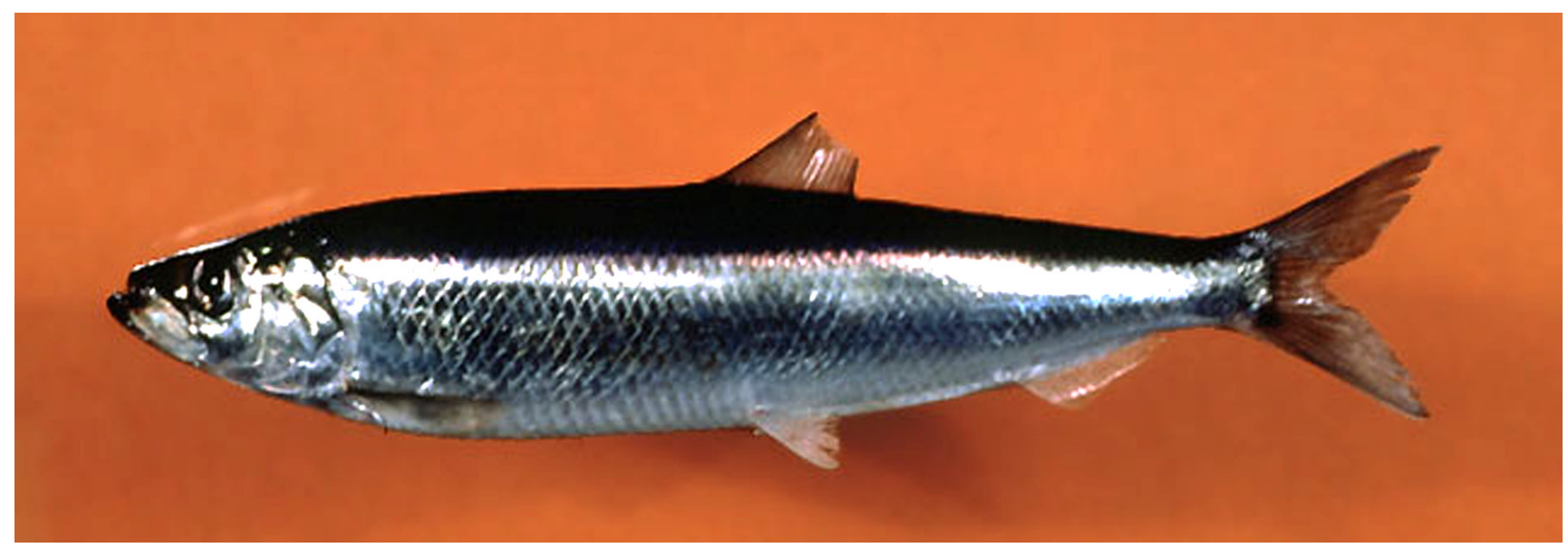

The Atlantic Herring, Clupea harengus, is a species of marine fish for which there are data regarding consumption rates by predators and estimates of total natural mortality rates to contribute to the characterization of the related macroecological pattern (photo courtesy of the NMFS, Northeast Fisheries Science Center).

\section{Evaluating Harvests \\ from Other Species}

The process described above, involving historical data for two species, can be applied generically to assess fishing mortality for any stock or species, worldwide. To exemplify this, we used the data for 44 species of primarily marine fish as published by Mertz and Myers (1998, and listed in Appendix Table A2.3). As above, the information for $M$ can be used to estimate holistically sustainable fishing rates. Across the 44 species, this estimate can be compared to the observed fishing rates. An overfishing index can be calculated for each species as was done above for herring and sprat in the Baltic Sea-in that case as represented by data for several decades. The pattern in the overfishing index for the 44 species is displayed in Appendix Figure A2.14; on average these species are subject to fishing rates that are about 23 -fold too large (App. 2).

With the analysis presented in the last paragraph (and App. 2), it might be tempting to conclude that this is a fully adequate way to proceed toward more holistic management; it is much more holistic than the nonconsonant and limited aspects of empiricism in the evaluation of the use of $M$ by Zhou et al. (2012). It does make a significant step and is clearly preferable to what is being

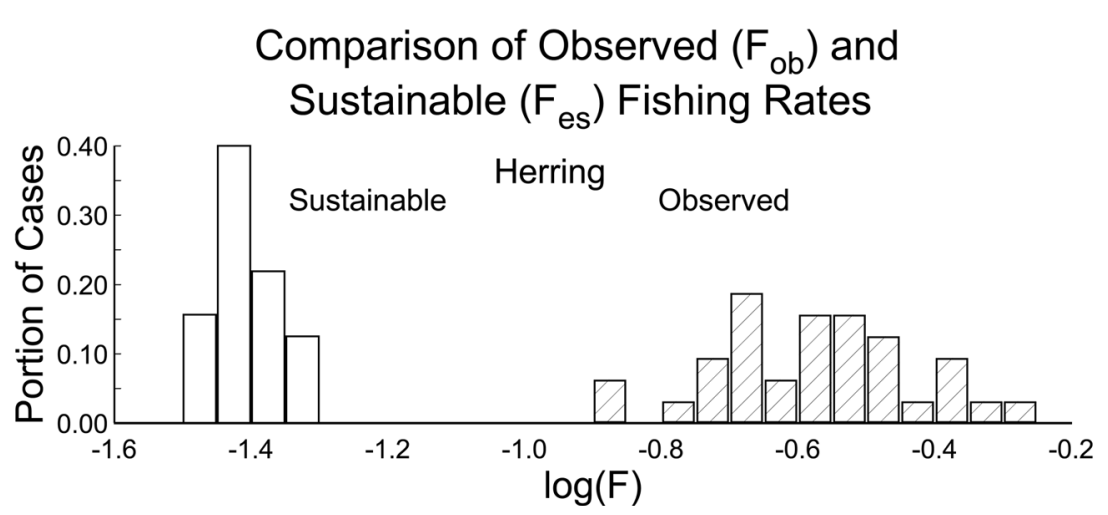

Figure 3.-Frequency distributions showing a comparison of the differences and variance in sustainable and observed fishing rates $\left(F_{e s}\right.$ and $\left.F_{o b}\right)$ estimated for herring of the Baltic Sea from 1974 to 2005.

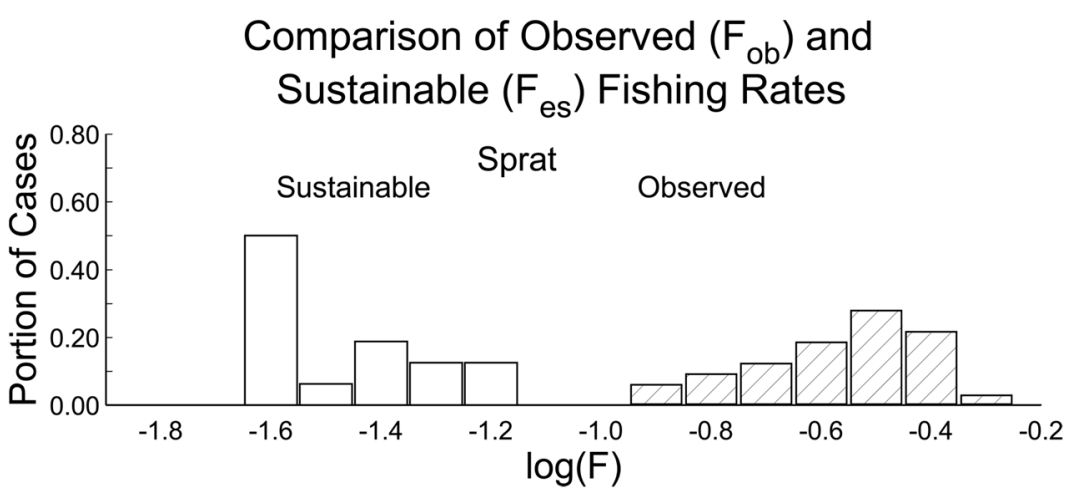

Figure 4.-Frequency distributions showing a comparison of the differences and variance in sustainable and observed fishing rates $\left(F_{e s}\right.$ and $\left.F_{o b}\right)$ estimated for sprat of the Baltic Sea from 1974 to 2005. 
(Right) The common snapping turtle, Chelydra serpentina, is a species from a taxonomic category for which data are needed regarding consumption rates by its predators and estimates of total natural mortality rates to better represent the related macroecological pattern (photo courtesy of and copyrighted by Bruce Fowler).

(Below) Elk, Cervus elaphus, are among the species of large mammals for which there are data regarding consumption rates by its predators and estimates of total natural mortality rates so that the two can be related in a macroecological pattern (photo courtesy of and copyrighted by Charles Fowler).
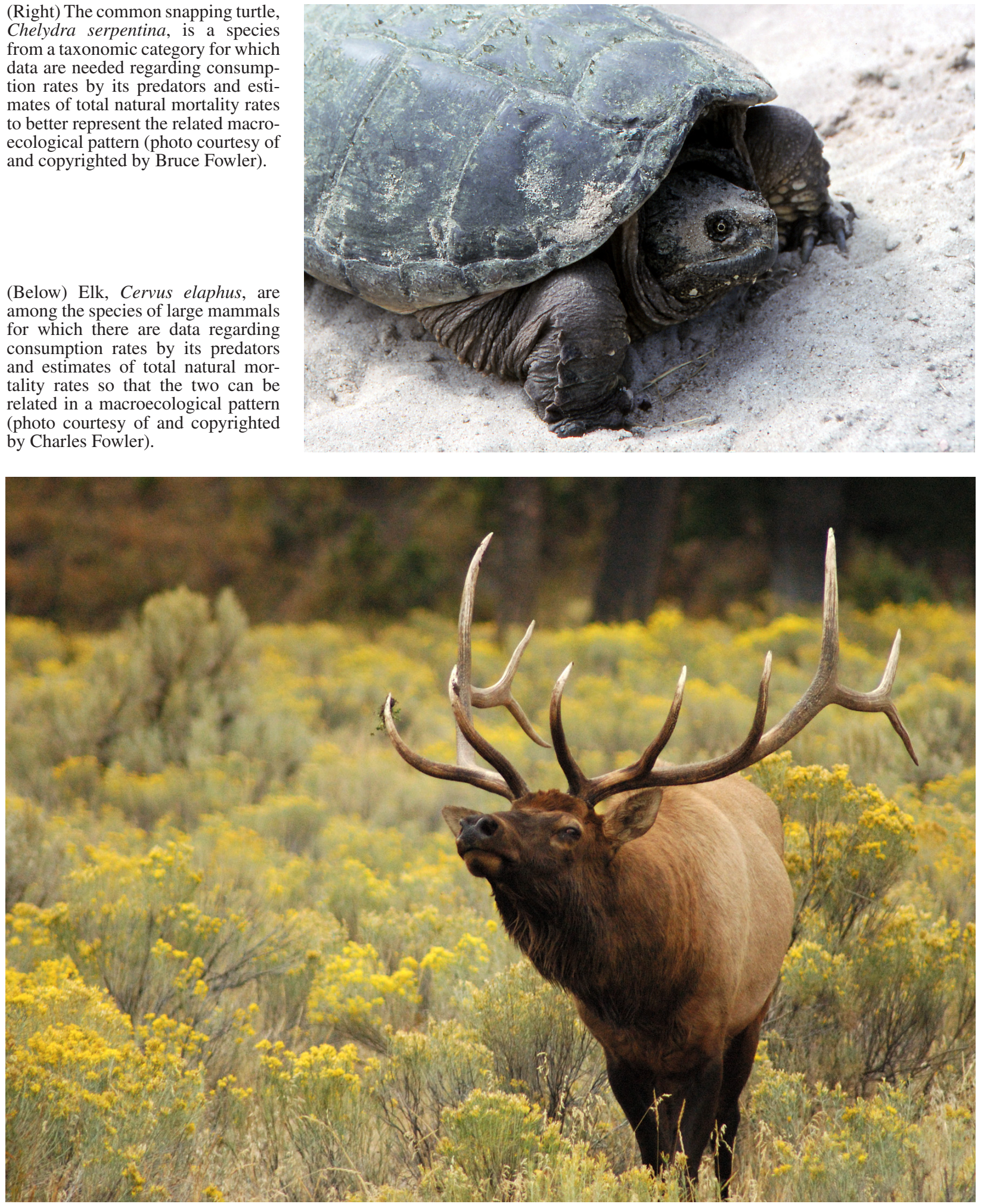


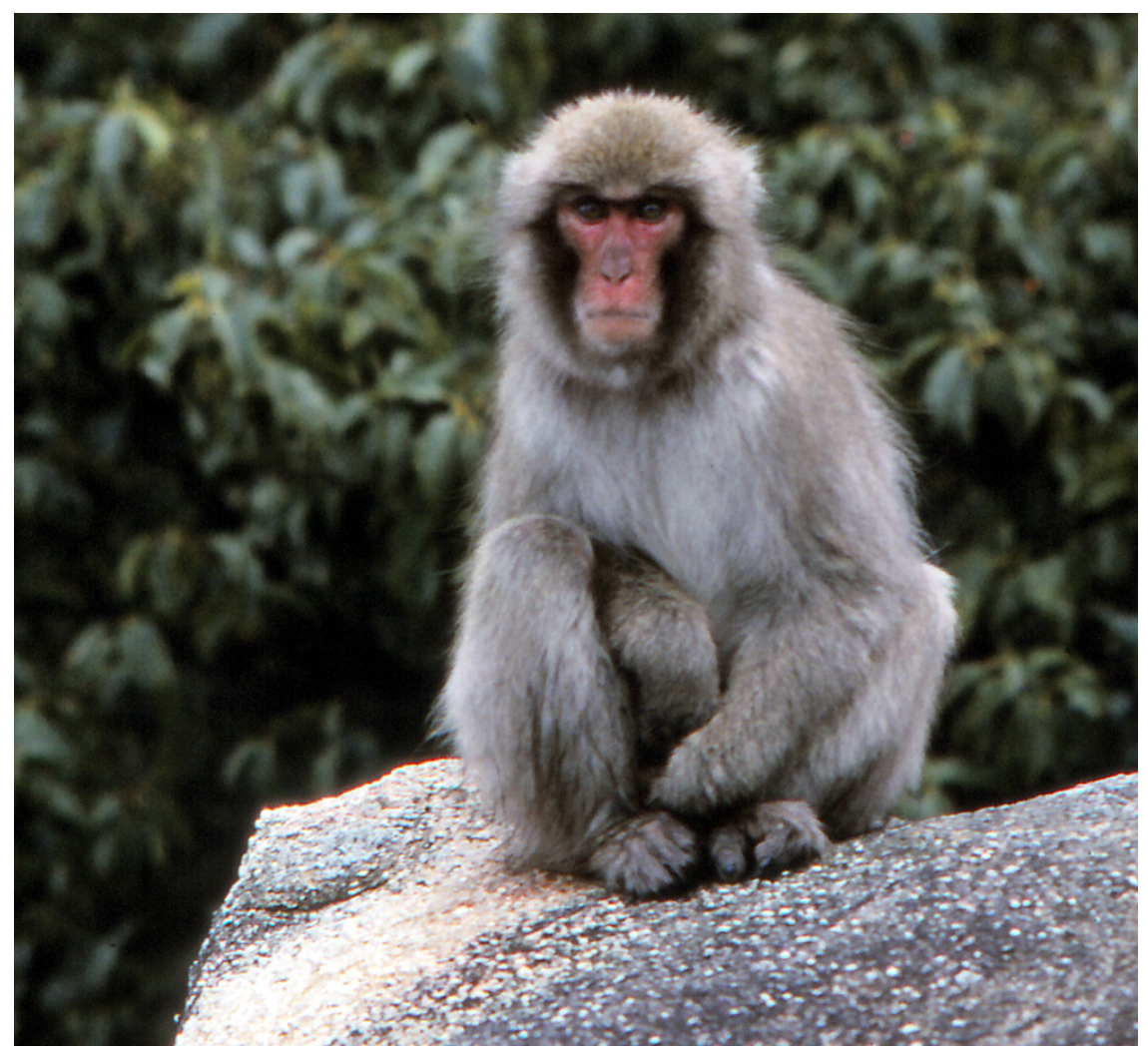

(Left) The Japanese macaque, Macaca fuscata, represents a taxonomic category for which data are needed regarding consumption rates by each species' predators and estimates of the respective total natural mortality rates to better represent the related macroecological pattern (photo courtesy of and copyrighted by Charles Fowler).

(Below) The muskox, Ovibos moschatus, is a species of ungulate for which data are needed regarding consumption rates by predators and estimates of total natural mortality rates to better represent the related macroecological pattern (photo courtesy of and copyrighted by Amy Kennedy, www.Wildkennedy. com).

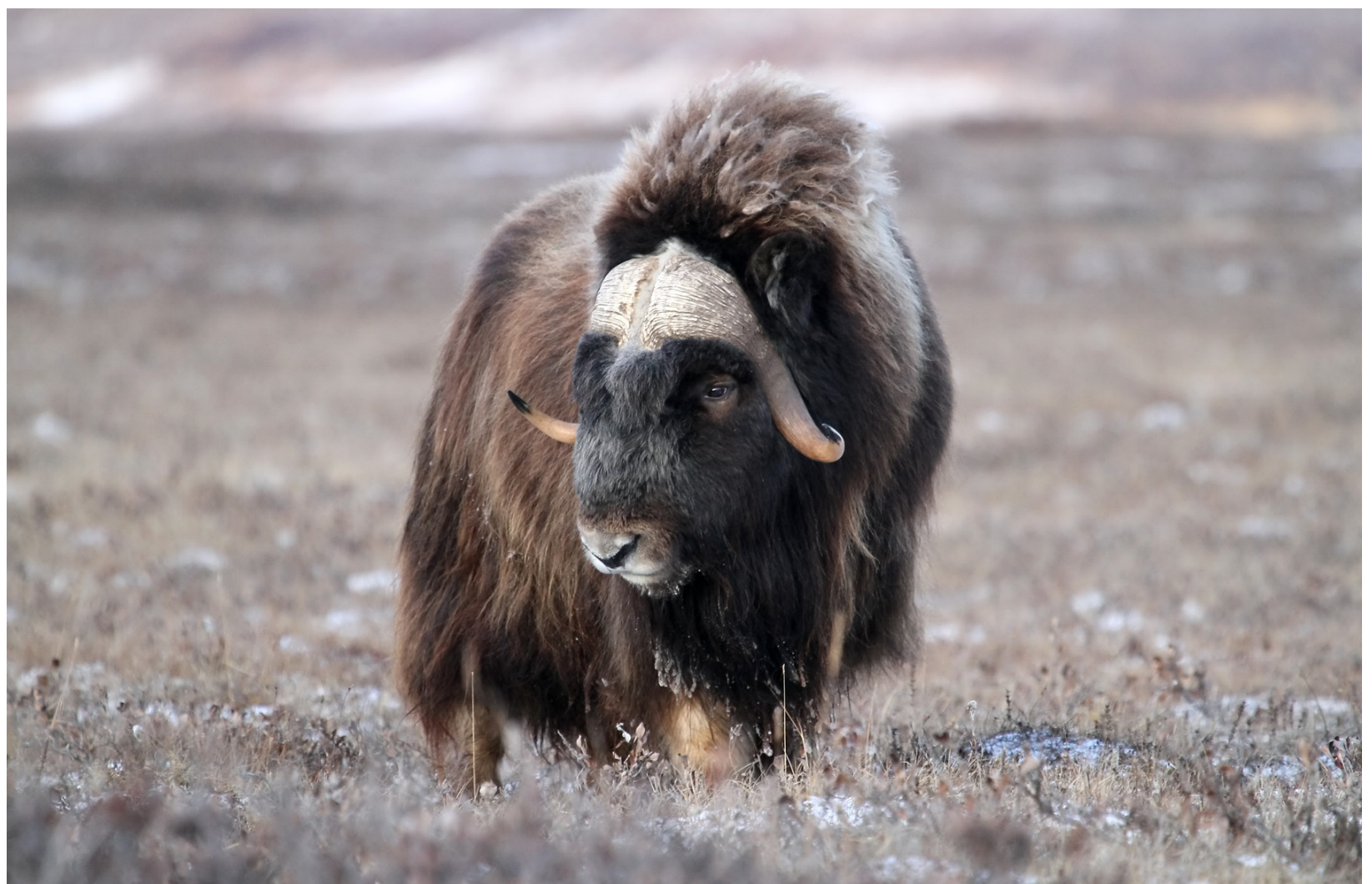




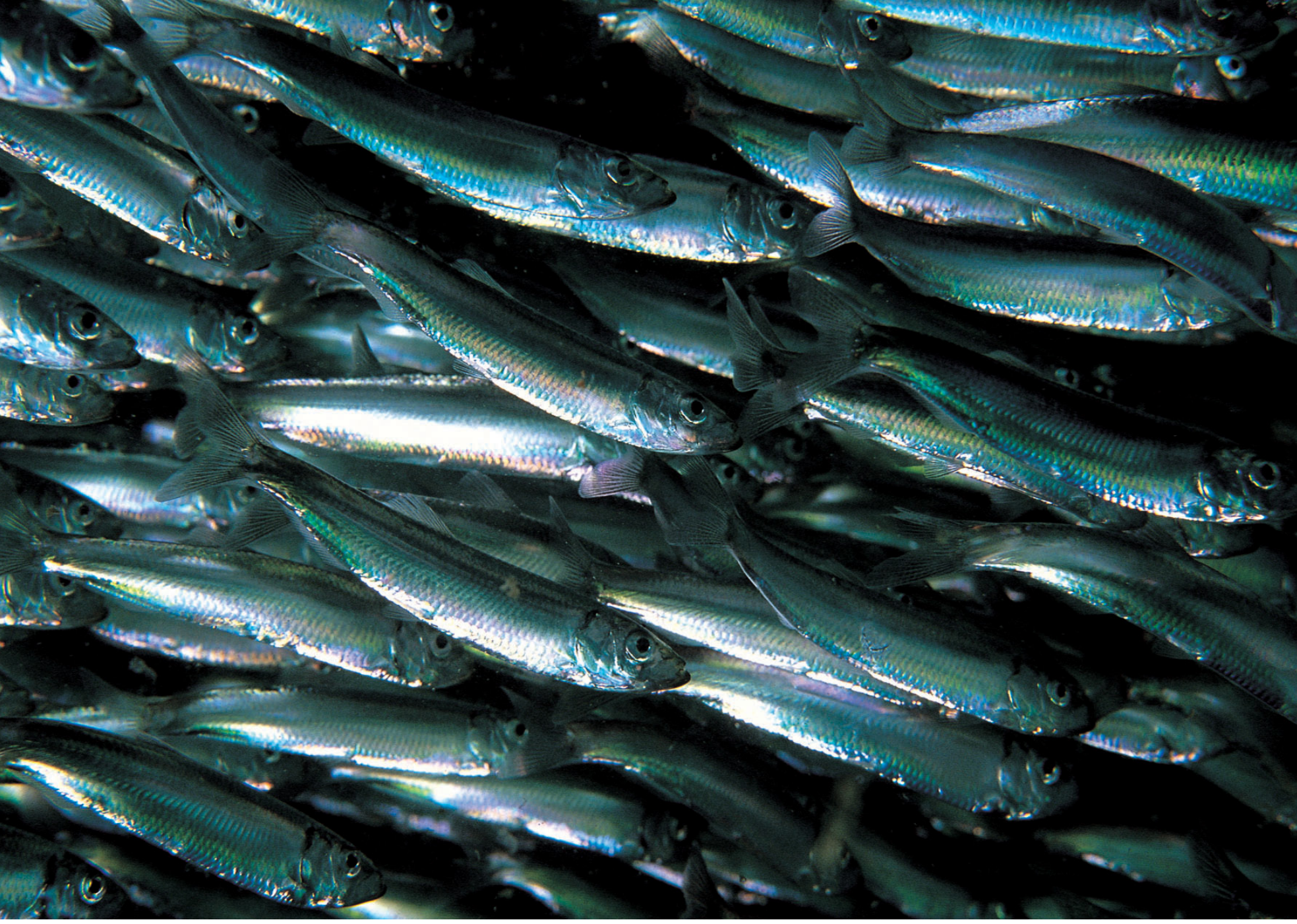

European Sprat, Sprattus sprattus, is a species of marine fish for which historical fisheries management can be evaluated on the basis of a macroecological pattern relating sustainable harvest rates to total natural mortality rate $(M)$ (photo courtesy of Paul Naylor).

done now. It is important, however, to note the advantage of information with greater consonance. For example, when addressing the management question of the sustainability of harvests of herring from the northwest Atlantic, using data from that ecosystem (e.g., $F_{e s}=0.3 \%$ per year for herring) will be preferable to reliance on the macroecological pattern of Figure $2\left(F_{e s}=1.8 \%\right.$ per year - lacking information for $M$ for herring from this specific ecosystem).

Variability among ecosystems is part of what contributes to the variance in the set of data shown in Figure 2. That variability is only partially explained by $M$. Lacking ecosystem-specific in- formation, the macroecological pattern provides valuable and useful information (both the $0.3 \%$ from a specific ecosystem, and the $1.8 \%$ from the macroecological pattern are more precautionary and sustainable than the 5.7\% implemented in conventional management for the specific species/ecosystem combination represented in Appendix Table A2.2). Were data available for predation rates for herring in the Baltic Sea, these data would have been more useful for this particular species/ecosystem combination (as treated in Appendix 4 with information restricted to $M$ ).

Three points emerge from an understanding of Appendix 4, Figures 3 and
4, and Appendix Figure A2.14. First, in all cases, conventional fishery management results in overharvesting that is quite large, often with observed excesses of more than an order of magnitude, when assessed systemically, holistically, and objectively. Second, using the pattern depicted in Figure 2 (and App. Fig. A2.12 and A2.13) to assess past management leads to the use of the same pattern for advising current fishery management. Third, the kind of science involved in the production and analysis of the data representing such patterns is the type that best serves the management process. In addition to the step toward holism achieved in addressing individual 
management questions (for an in-depth treatment of the process of asking questions, see Fowler and Hobbs, 2011), there is the matter of further holism achieved in asking as many management questions as can possibly be asked.

In the preceding sections, various questions were addressed for the purpose of assessing historical management. As we have indicated, finding guidance for current management involves rephrasing these questions. This can be done, for example, to take advantage of the pattern illustrated in Figure 2: "What is the sustainable rate in the harvest of sprat from the Baltic Sea that accounts for our body size and the total natural mortality rate of sprat?" This question can be rephrased for any species in any ecosystem where the species occurs. In the following sections, we discuss several other issues which managers face, along with the relevant questions. These sections provide further illustration of the holism achievable through the variety of applications in which guidance is provided by natural macroecological patterns.

\section{Additional Management Questions}

\section{Selectivity}

"What should be the mean size of fish caught in a sustainable fishery?" This management question relates to the genetic effects of fishing insofar as they involve size selectivity-here selectivity is being addressed directly. The direct aspect of involving selectivity is to be compared to the indirect aspects of this issue as treated in addressing the management questions raised aboveselectivity is part of what is accounted for indirectly in all natural patterns. Thus selectivity is accounted for in addressing other management questions with information from patterns consonant with those questions.

Accounting for selectivity directly is another matter. Etnier and Fowler (2005, 2010) address selectivity directly (the question above) with the consonant macroecological pattern shown in Figure 5. As with previous examples, management has, as one of its primary goals, the objective of rectifying abnormality in

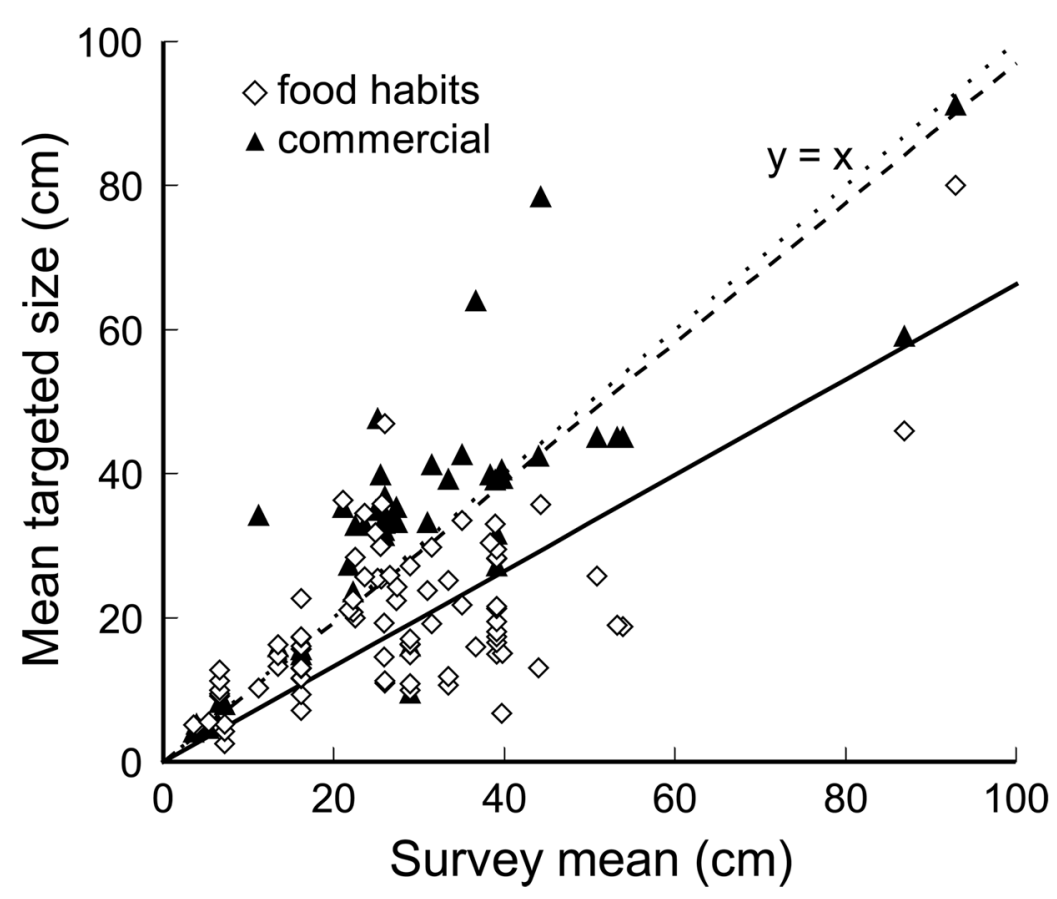

Figure 5.-The macroecological pattern relating the size of fish taken in the diets of marine mammals to the size of the prey available (Etnier and Fowler, 2010).

human impacts on, or relationships with, and within, other systems (species, ecosystems, the biosphere, etc.). To achieve normal ${ }^{6}$ selectivity, the average size for fish taken in commercial harvests would be about $30 \mathrm{~cm}$ but specific applications would naturally depend on the size of prey available (consistent with the correlative pattern represented by the solid line in Figure 5).

As an example of a more specific application, Figure 6 illustrates the abnormality (or the atypical, unusual, aspects of being an outlier) of conventional commercial fishing on Atlantic Cod, Gadus morhua, in the northwest Atlantic as an assessment of the historical selectivity of this fishery. This addresses the selectivity of the harvest

${ }^{6}$ Normal is used here, in the extreme, to avoid being an outlier among other species-to avoid being abnormal or atypical. The most normal selectivity would be that which corresponds to a measure of central tendency (e.g., the mean) in the statistical distribution represented by data characterizing the consonant pattern.

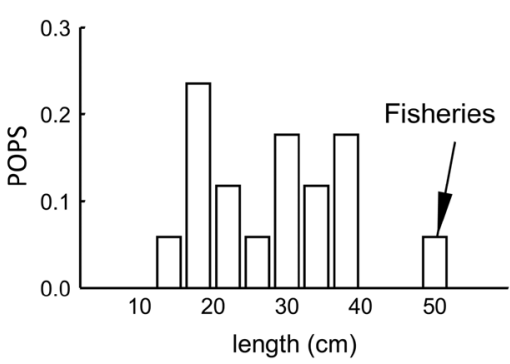

Figure 6.-The macroecological pattern consonant with the question: "What would the mean size of Atlantic Cod, Gadus morhua, taken by the northwest Atlantic fishery have been, had it been taken sustainably?" This pattern involves the mean size of cod taken by 16 species of marine mammal predatory species in their consumption of cod, exposing the abnormality of selectivity by commercial fisheries (representing humans as the 17th species; Etnier and Fowler, 2005, 2010). The height of each bar represents the portion of the 17 predatory species that consumes fish of the size corresponding to its position on the abscissa. 


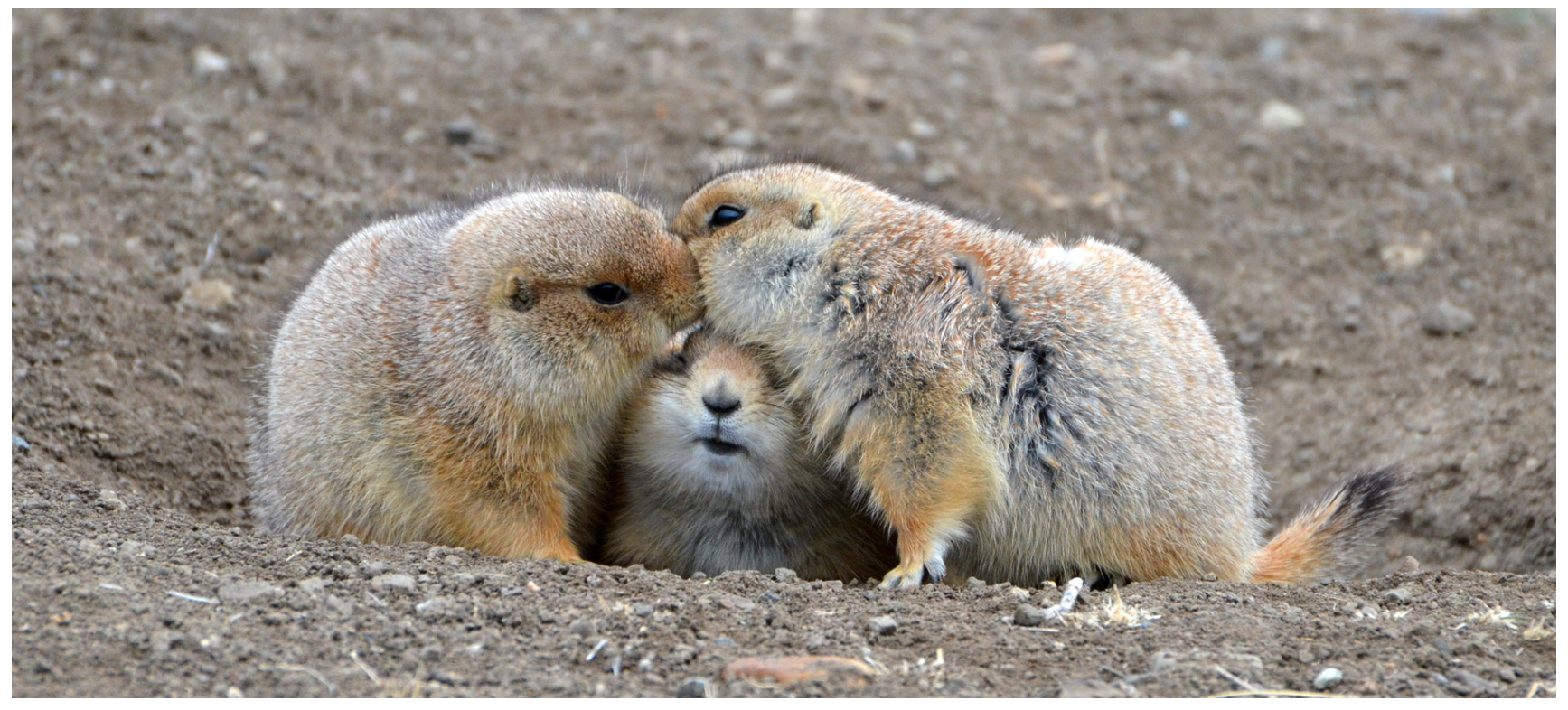

The black-tailed prairie dog, Cynomys ludovicianus, represents a small-bodied mammalian species for which data are needed regarding consumption rates by its predators and estimates of total natural mortality rates to better represent the related macroecological pattern (photo courtesy of and copyrighted by Charles Fowler).

but not the intensity of that selectivity. To achieve normalcy in the intensity associated with any form of selectivity, fishing rates would be guided by information such as that embodied in patterns exemplified by Figure 2, and Appendix Figures A2.12 and A2.13 (i.e., management of the harvest rates themselves - as distinguished from their selectivity).

Advances toward greater holism would be achieved by asking more management questions related to other forms of selectivity. For example, selectivity involves time: "What portion of a sustainable annual harvest of pollock in the eastern Bering Sea should be taken in the month of July?" Such management questions can be asked for any combination of species (replacing pollock in this question), ecosystem (replacing the Bering Sea in this question), and month (replacing July in this question). Other aspects of selectivity for which management questions can be asked include sex, season (period of time of any length), location, behavioral traits, life history traits, and any of the myriad of phenotypes.

True complexity becomes more apparent in asking questions about combinations of such factors (e.g., sex combined with location, or sex combined with location and a particular phenotype). The process then moves on to conducting research to reveal the consonant patterns and managing to achieve normal selectivity according to the patterns revealed. This extends naturally to selectivity (or allocation of harvests) among species (rather than simply within species) to include taxonomic selectivity (Fowler, 1999). It extends further to include selectivity across trophic level, geographic range, or others of a huge number of specieslevel characteristics.

\section{Marine Protected Areas}

Marine protected areas involve portions of an ecosystem that are protected and portions where fishing is allowed. Together, the two portions make up the full ecosystem. To continue with our illustration of the use of consonant patterns we begin with a very generic example (i.e., without regard to season or other extenuating factors).

"What portion of the geographic area of the eastern Bering Sea can be subjected to sustainable fishing?" The issue being addressed here is the advis-

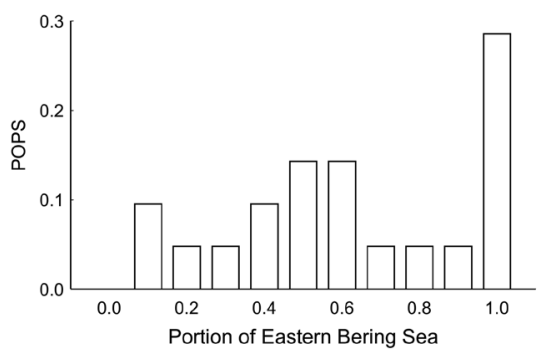

Figure 7.-The macroecological pattern consonant with the question: "What portion of the eastern Bering Sea ecosystem can be subjected to the direct effects of fishing?" This pattern represents the portion of this ecosystem occupied by 20 marine mammal species (see Fig. 2.15 of Fowler, 2009). The height of each bar represents the portion of the 20 predatory species that are found in portions of the eastern Bering Sea corresponding to its position on the abscissa.

able portion of the ecosystem within which fishing would be allowed. The macroecological pattern (Fig. 7) consonant with this management question can be used for guidance (e.g., see also Fowler, 2009: 202-203). The mean for this pattern is 0.67 . This value serves as a first approximation of the portion of 


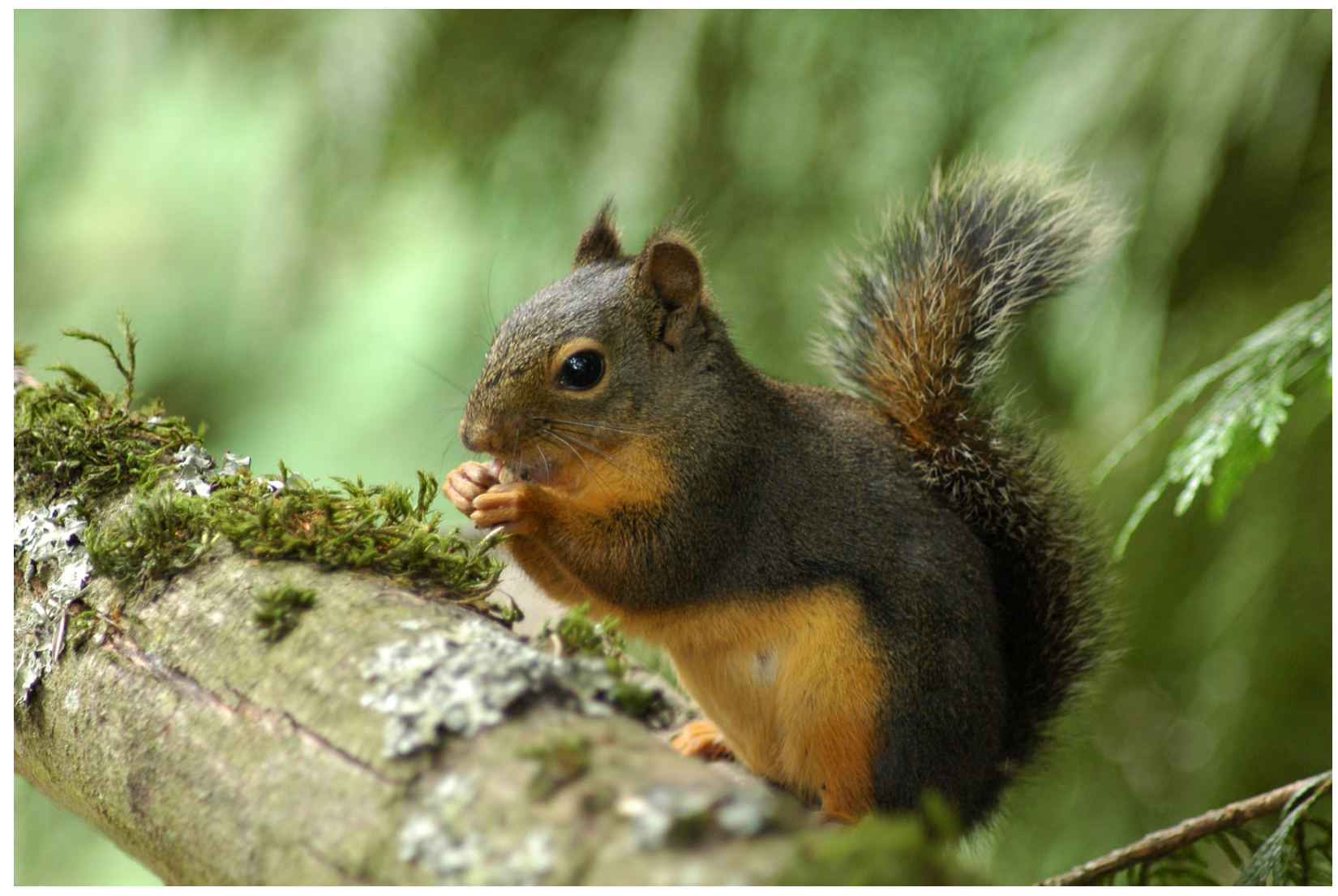

The Douglas squirrel, Tamiasciurus douglasii, represents a small-bodied species of mammal for which data are needed regarding consumption rates by predators and estimates of total natural mortality rates to better represent the related macroecological pattern (photo courtesy of and copyrighted by Charles Fowler).

the ecosystem which can be subjected to the direct effects of fishing sustainably.

Consistent with the examples of the previous sections, the holism brought to bear in addressing the question with an empirical (and consonant) pattern includes an automatic and objective accounting for all contributing factors (evolutionary, ecological, etc.). Of course other management questions need to be asked, and, in particular, this generic question needs to be refined to explicitly address other factors such as season and location.

"What portion of the eastern Bering Sea should be protected from the direct effects of fishing to achieve a sustainable fishery?" Being complementary to the first question of this section, the mirror image of the pattern shown in Figure 7 would provide the needed guidance. The mean of this distribution is 0.33 , indicating that about $33 \%$ of the eastern Bering
Sea needs to be set aside as areas where fishing would not be allowed. Again, location, season, and other important factors have yet to be addressed directly. With these examples, we are illustrating progress. It is obvious that the statistical means of the preceding two paragraphs hide variability. As noted by Fowler (2009), the pattern of unoccupied area (Fig. 7) supports the conclusion that protected areas of almost any size might be permissible with regard to the Bering Sea ecosystem as a whole. If current fishing involves the entire ecosystem, it does not represent being an outlier compared to other species. In contrast to the patterns for harvest rates (e.g., Fig. 1, 3, 4, and App. Fig. A2.14), the current practices of harvesting appear to be very real viable options (are not abnormal) in regard to the portion of the ecosystem involved.
This places emphasis on addressing other management questions, including questions regarding harvesting in the geographic ranges of specific species (e.g., "What portion of the geographic range of northern fur seals, Callorhinus ursinus, in the Bering Sea should be protected from the direct effects of fishing during their breeding season?"). This question can be asked for any species (e.g., the bearded seal, Erignathus barbatus; Fowler 2009). In other words, wide latitude for management in regard to one dimension (in this case, at the ecosystem level) does not guarantee similar freedom regarding other management questions (e.g., at the species level); single-species applications of management remain important. Furthermore, lack of evidence of a problem at the ecosystem level regarding one dimension does not preclude the need to deal with ecosystem-level problems in other 


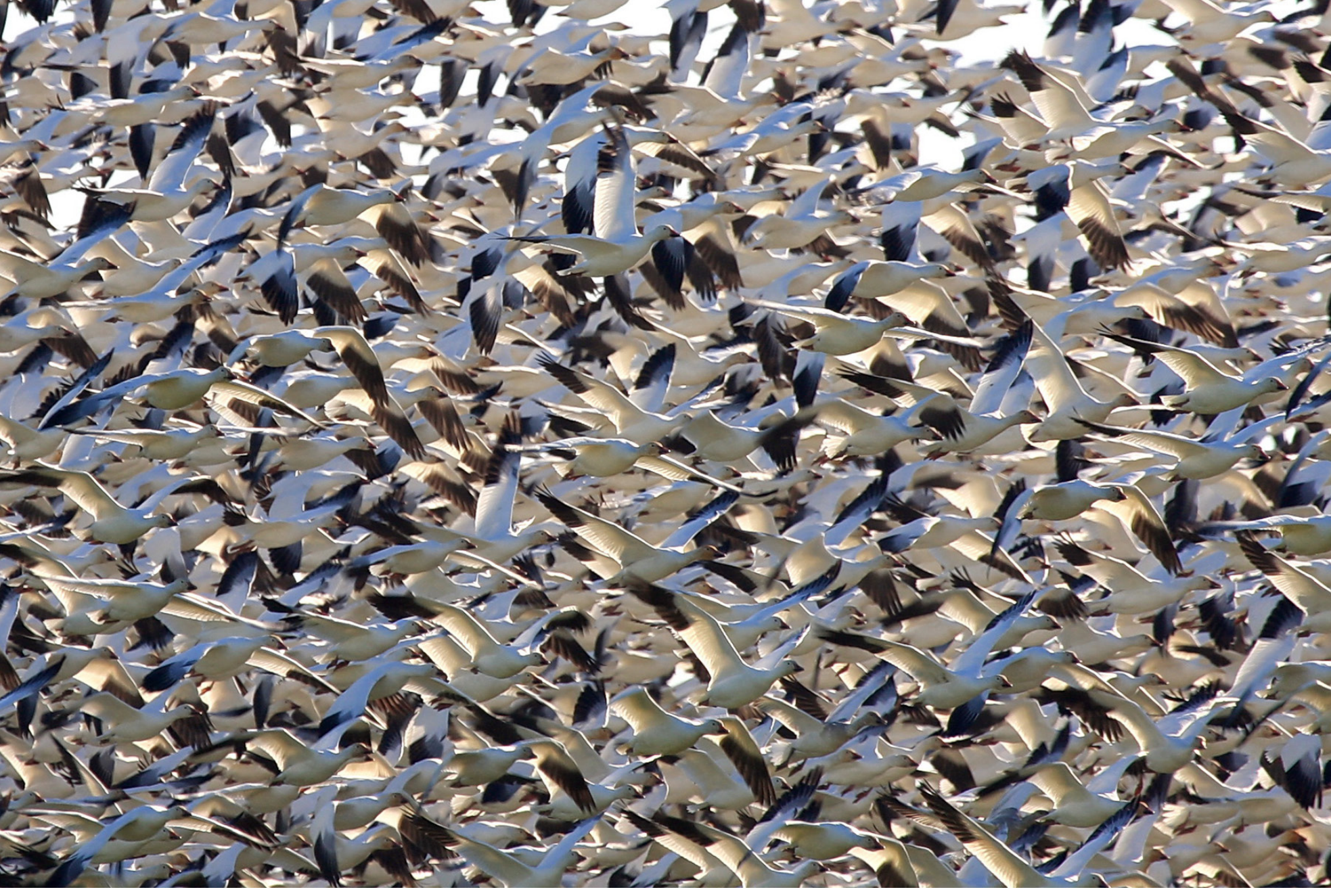

The Snow Goose, Chen caerulescens, is a migratory flocking species of bird for which data are needed regarding consumption rates by its predators and estimates of total natural mortality rates to better represent the related macroecological pattern (photo courtesy of and copyrighted by Amy Kennedy, www.Wildkennedy.com).

dimensions (e.g., reduction of total harvests for the Bering Sea, Fig. 1c).

Much attention is being paid to the issue of size and location of marine protected areas (Côté et al., 2001). In conventional management, questions such as those asked above are rarely asked (Fowler and Hobbs, 2009), and when such questions are asked, they are not addressed with consonant information. Instead, incomplete reductionistic explanatory or predictive models are explored based on known principles-all relevant, but never consonant. Unknown principles are all excluded, as are a number of known principles (e.g., many evolutionary principles, including the selectivity of extinction and speciation). The more holistic approach of using macroecological patterns is again a viable option.

\section{Discussion}

In systemic management, management questions are addressed realistically. ${ }^{7}$ Not only can questions that are not being addressed currently be answered (to the extent that consonant research can be funded and conducted),

${ }^{7}$ By "realistically" we mean, first and foremost, that the questions are actually asked. Second, they are questions that are addressed essentially free of the errors in logical typing (and other fallacies), which are characteristic of most conventional management. Third, they are addressed so as to achieve objectivity (i.e., so as to prevent, to the extent possible, opinions, human values, politics, and other human limitations from interfering in the management decision; Fowler, 2003, 2009). Fourth, management is confined to the regulation of human endeavor (avoid controlling things that cannot be controlled). Fifth is adherence to various other principles and tenets of management (e.g., accounting for complexity holistically and maintaining humans in a sustainable role in complex systems). but holism can be brought to situations where it is lacking today. The questions that we face are numerous and of varying importance, whether they involve human relationships with the biosphere, ecosystems, evosystems, or any of their components. The information used to address these questions can holistically and objectively account for the complexity involved when based on natural, empirically observed patterns-exemplified by the macroecological patterns we have illustrated above.

Ecosystem-based management is part of our quest for holism in management. Influencing ecosystems is a part of what we (and all other species) do; without management of our influence to achieve normalcy, management cannot be considered holistic. Likewise, if we neglect managing our interactions with evosystems, we fail at the task of achiev- 
ing holism. If we fail to ask and answer questions regarding the selectivity of our influence (at all levels), and fail to manage based on holistic information, we fail to achieve holism.

The examples presented in this paper illustrate how this can be done. Managers and scientists are unable to conceptualize all management questions because of their infinite variety. Those questions that we can ask are questions that can be answered consistently, holistically, and objectively when guidance takes advantage of integrative information in the pattern (often macroecological) that is consonant with the management question (systemic management; Fowler, 2009).

There is more to do than to ask more questions and correct problems of human abnormality as revealed by consonant information. Including the field of macroecology in management involves research of a magnitude beyond anything realized in management today. ${ }^{8}$ As one small isolated example, the very limited sample size behind the relationship depicted in Figure 2 (and App. Fig. A2.10-A2.13) needs to be increased with additional data from numerous ecosystems and species. ${ }^{9}$ The pattern shown in Figure 2 included explicit consideration of only natural mortality as a correlative variable; with more data there is the promise of directly accounting for

${ }^{8}$ For example, we have the management question, "To achieve holistically sustainable fisheries globally, what portion of the world's oceans (the entire marine environment) should be closed to fishing?" The consonant research question (to explicitly account for human body size and the fact that we are mammals) is: What portion of the Earth's oceans are free of the effects of consumption by each individual marine mammal species of human body size? These questions can be refined to be asked in regard to time (season or month). Determining the geographic ranges of marine mammals, and their temporal dynamics, is a huge challenge for research.

${ }^{9}$ Many macroecological patterns are not easily recognized without a large sample size, often involving hundreds of species (see Brown, 1995; Gaston and Blackburn, 2000) covering a wide range for each independent variable (e.g., body size; Petchey and Belgrano, 2010). The data behind the middle panel of Figure 2 involves only 49 cases of estimated consumption rates by individual populations of predators on individual populations of prey (all confined to eight preyecosystem combinations).

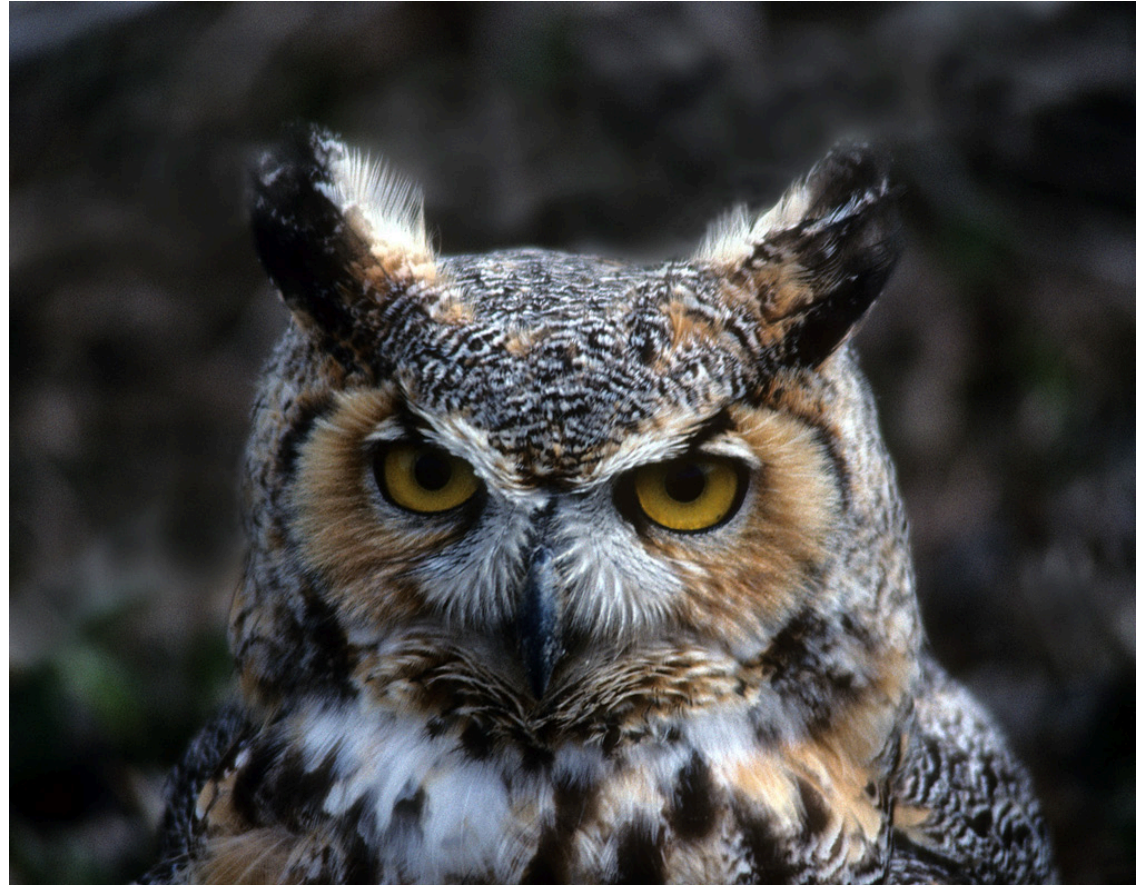

The Great Horned Owl, Bubo virginianus, is a predatory nocturnal bird as a species for which data are needed regarding consumption rates by predators and estimates of total natural mortality rates to better represent the related macroecological pattern (photo courtesy of and copyrighted by Bruce Fowler).

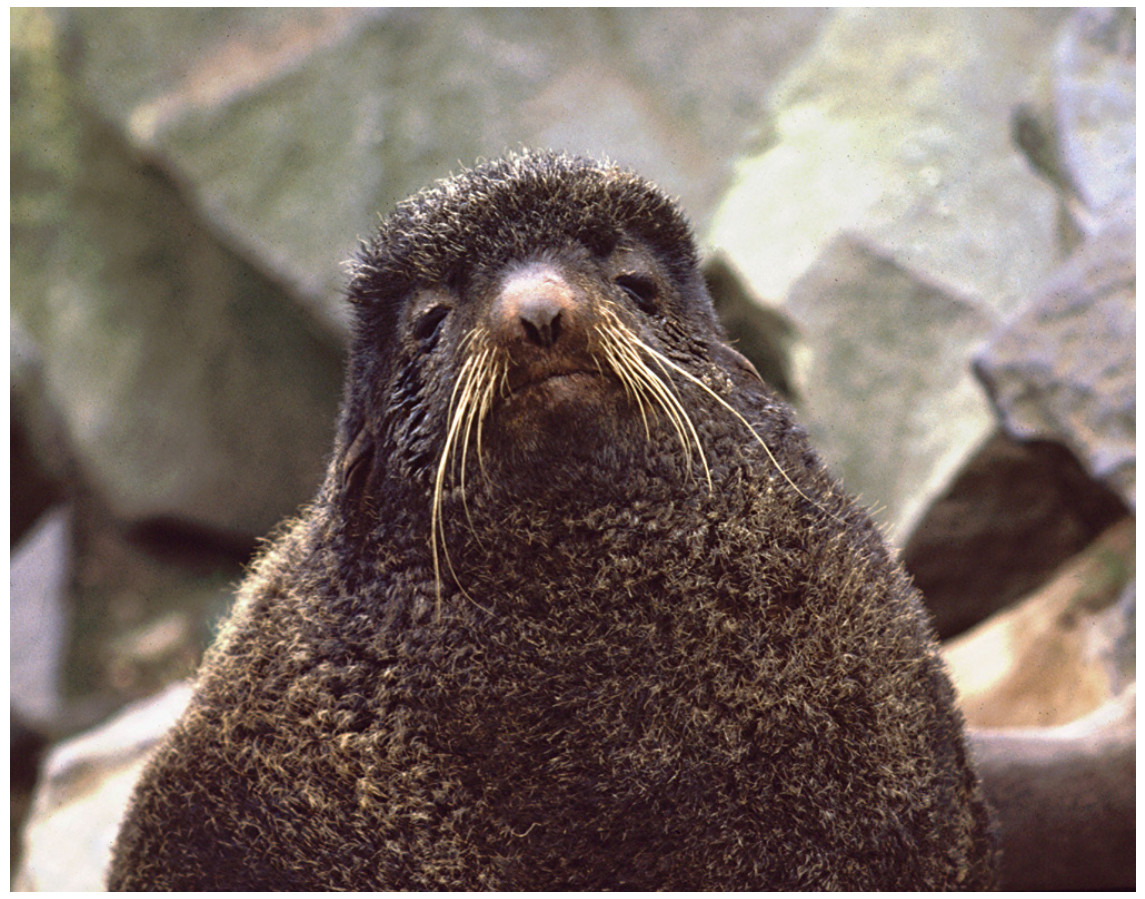

The northern fur seal, Callorhinus ursinus, is a species of predator that feeds on walleye pollock, Theragra chalcogramma, and for which predation rates would be monitored to help reflect current circumstances-especially the effects of fishing in related ecosystems (photo courtesy of Charles Fowler). 


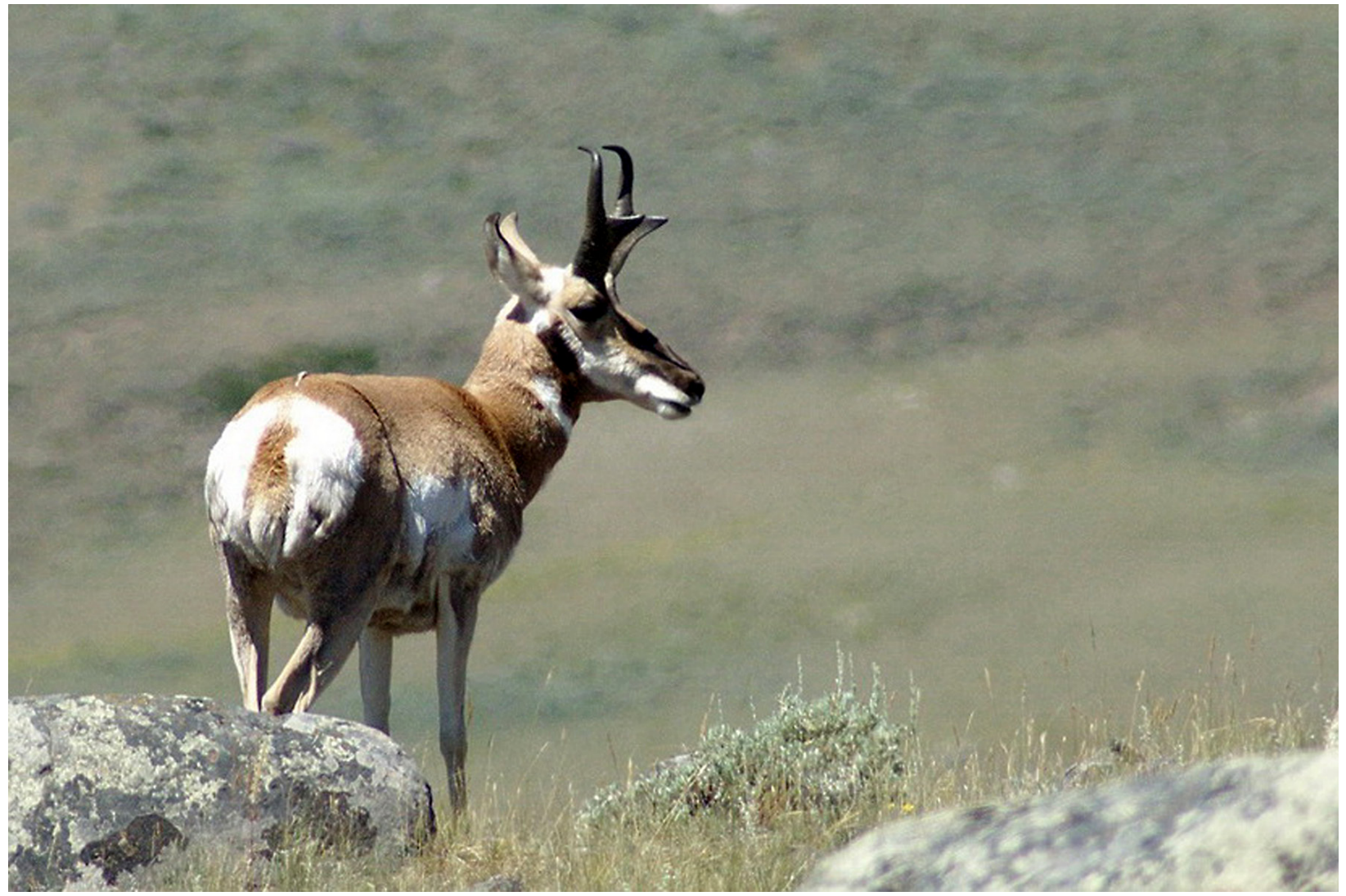

The pronghorn antelope, Antilocapra americana, represents a large mammal species for which data are needed regarding consumption rates by its predators and estimates of total natural mortality rates to better represent the related macroecological pattern (photo courtesy of and copyrighted by Charles Fowler).

other factors such as other life-history characteristics (e.g., generation time, intrinsic rate of population increase, and rate of increase per generation), environmental factors (such as latitude or mean temperature), and ecosystem variables (such as the number of predator species, the number of prey species, or trophic level-see Fowler et al., 2009, for an example wherein the count of predatory species helps define sustainable consumption rates).

In spite of the preliminary nature of the pattern shown in Figure 2, however, further research is unlikely to do more than refine the relationship; systemic measures of overfishing are likely to remain quite large and probably increase (see the effect of directly accounting for body size in Appendix 2). This is likely, in spite of the potential for increases in the consumption rates by other mammalian predators in reaction to the release of excessive competitive effects by extreme fishing rates (increases to be revealed by carrying out systemic management in the framework of adaptive management; see App. 1:fn A1.1).

Perhaps of greatest value in achieving holism and objectivity in management is the use of integrative empirical patterns. It is important that the patterns used to guide management are consonant with the questions they are used to answer (Fowler and Hobbs, 2011); without doing so we fail. Even though there are more critical components to achieving holism, the essential point here is that such patterns are integral parts of reality. They are not simply parts of ecosystems or of evosystems. Such patterns are integral parts of both; they are holistically integrative of everything that contributed to their origin, including evosystems and ecosystems (App. 3).
In other words, being integral parts of reality means that patterns account for all of the complexity involved in their origin or emergence (holism, including the risks, influences, and consequences of the patterns and all components) nothing is ignored. If we could replicate reality in a model, the patterns replicated would be a function of the infinite set of factors and history involved in the reality behind their origins (Belgrano and Fowler, 2011a). Instead of models, we have reality to work with when we use the empirical patterns consonant with our management questions (Fowler, 2009).

It is important to recognize the element of change; change characterizes the reality with which we are dealing (Basurto and Coleman, 2010). In part, as mentioned above, and in Appendices 1 and 3 , systems are responsive to human influence (fishing, pollution, etc.). The 
patterns used to guide management (e.g., Fig. 1; App. Fig. A2.1-A2.8) reflect human influence, and, in particular, the effects of fishing in the extremes revealed. In other words, reductions to maximize biodiversity on the basis of the historic patterns will result in new patterns.

As laid out in Fowler (2009), systemic management embraces adaptive management (Holling, 1978); this requires research to produce data of the kind illustrated in Figures 1 and Appendix Figures A2.1-A2.8 (consonant with the management question). Such data would be representative of circumstances imposed by systemic management (rather than conventional management). In the spirit of adaptive management, continuous monitoring and estimates of consumption rates by other predators is essential for being responsive to current circumstances (rather than simply historical information).

For our purposes, however, it is very important to distinguish between conventional and systemic forms of adaptive management. An important part of the distinction lies in the systemic interpretation of natural systems as having components (such as species) that reflect eons of adaptation through what are often referred to as a "trial-anderror process." This is a concept that is generally confined to the human realm in conventional forms of adaptive management (Basurto and Coleman, 2010; Ostrom and Basurto, 2011). More holistically, or on larger temporal, spatial, and hierarchical scales, as accommodated in systemic thinking, this concept also promotes the option of mimicry (or imitation; Ostrom and Basurto, 2011) at the species level; it is a matter of consistently making use of natural examples of sustainability. The failure of conventional adaptive management to deal with biodiversity (Schultz et al., 2011) is a problem for which we have illustrated a solution: the direct approach of systemic management takes advantage of options for maximizing biodiversity (App. 1). In the process, the integrative nature of natural patterns (App. 3) means that economic issues are taken into account inherently; in other words, every aspect

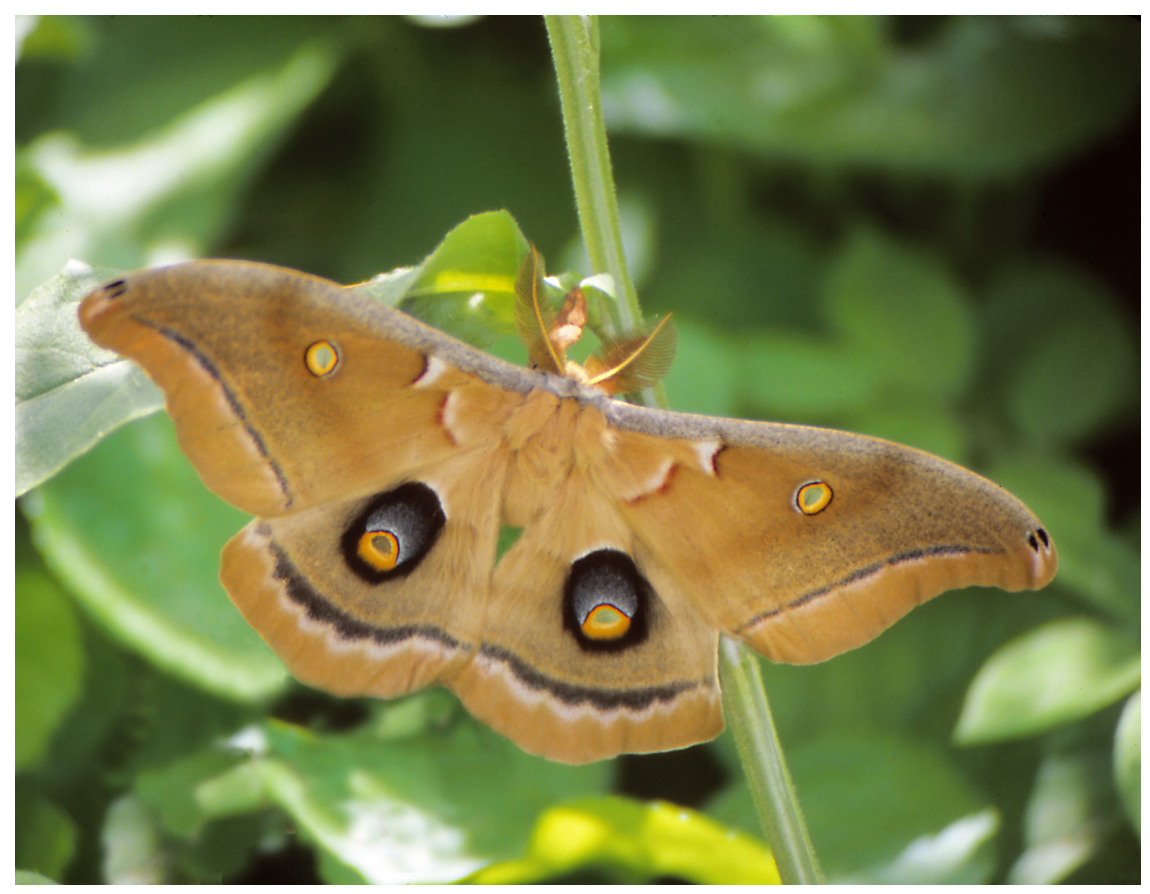

The polyphemus moth, Antheraea polyphemus, is a species of insect for which data are needed regarding consumption rates by predators and estimates of total natural mortality rates to better represent the related macroecological pattern and account for its taxonomic group (photo courtesy of and copyrighted by Bruce Fowler).

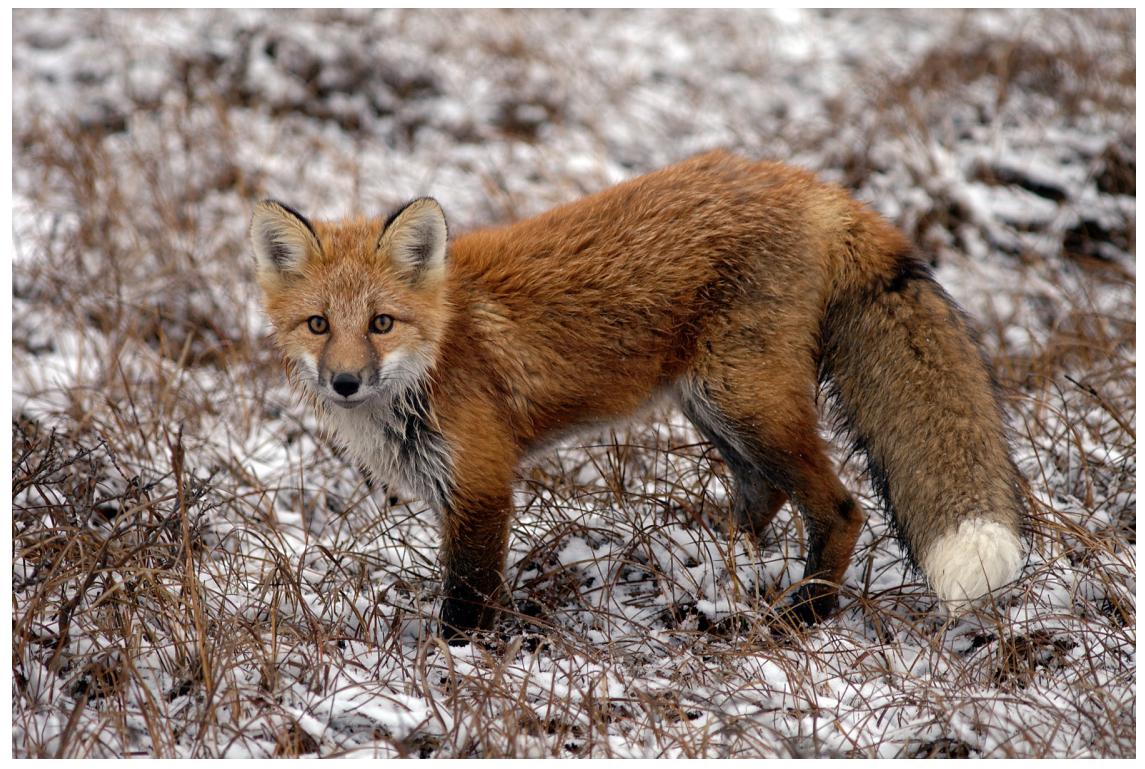

The red fox, Vulpes vulpes, is a predatory species of mammal for which data are needed regarding consumption rates by its own predators and estimates of total natural mortality rates to better represent the related macroecological pattern (photo courtesy of and copyrighted by Amy Kennedy, www.Wildkennedy.com). 
of all economic systems (factors important in works such Basurto and Coleman (2010) and Ostrom and Basurto (2011)) are all taken into account completely. ${ }^{10}$

One aspect of maximizing biodiversity deserves further attention. In theory, there is the option of concluding that we should harvest everything because that would lead to increased measures of biodiversity such as that of the Shannon-Weiner information index (App. 2). This fails to address the complexity behind the overriding element of achieving healthy natural systems; there are innumerable management questions to be addressed, such as: "From how many species can we sustainably consume resources?" The word "species", in this question, can be replaced with any entity that serves as a potential source of resources. Once we have decided it is a realistic option to harvest from any particular species (or species group, community, predator/ prey pair, or ecosystem), there is then the option of maximizing biodiversity as a means of establishing how large that harvest should be. Maximizing biodiversity in our consumption of resources on a global scale is part of the process (Fowler, 2008). Sustainability in all facets of human existence (in all scales of time, space, and complexity) is the objective of systemic management (Fowler, 2009); maximizing biodiversity is an option in many cases but is not the overarching singular goal. Achieving sustainability is the primary goal within which achieving maximum biodiversity is a special case; standards for avoiding the abnormal include both statistical measures (e.g., measures of central tendency and confidence limits) and, occasionally, the option of maximizing

\footnotetext{
${ }^{10}$ It should be kept in mind that, although the three papers cited in this paragraph are primarily conventional (rather than systemic) in their approach, they, like almost all scientific papers, contribute to the substantiation of general principles (such as the interconnectedness, complexity, and the dynamic and changing nature of natural systems - including human systems). These principles include the occurrence of limits to natural variation (Belgrano and Fowler, 2008). Such principles, however, do not constitute management advice. Systemically, as exemplified in this paper, it is the information in patterns consonant with specific management questions that provides guidance by revealing what works.
}

biodiversity.

It is important to reiterate that several of the examples above illustrate the application of macroecological patterns to assess past management. The same process can be used to provide advice for achieving sustainability through the many management questions we face today. Such questions include the following: "At what rate can we sustainably harvest herring in the Baltic Sea?" "How many tons of herring and sprat (the multispecies combination) can be sustainably harvested annually from the Baltic Sea?" "How many tons of biomass can be sustainably harvested annually from the Baltic Sea?" Research on the harvest (consumption) rates observed for other species of mammalian predators in the Baltic Sea would provide information to answer the management questions. Restricting harvests to the sustainable levels indicated by such information would account for the virtually infinite set of consequences wherein normal ecosystem dynamics count among the intended results. As such, not only are all of the factors that give rise to emergent patterns objectively taken into account by the use of macroecological patterns, but also all of the consequences of management action. This is a significant advance toward the objectives of holism and objectivity - far beyond the simplicity of conventional management.

\section{Summary}

On the path to holistic management, ecosystem-based management is but one essential element. On this path, adding evosystem-based management is also essential. This would account not only for ecosystems and all of their complexity, but also coevolutionary systems or evosystems - all parts of the ultimate reality we face. The increasing number of fields of science that are included represents significant progress toward greater holism. The role of macroecology in management can be seen in the examples we have provided, examples that apply to ecosystems in being evosystem-based as well as ecosystembased.

Through systemic management, with its use of empirical patterns to guide management objectively, we bring holism to every management question we can ask - through the integral nature of empirical patterns. This holism involves not only the complete set of factors accounted for through the emergence of the patterns, but also the complete set of ramifications of our management actions. As such, both ecosystems and evosystems (along with the biosphere) are taken into account. Such management is far more holistic and objective than the management being carried out today. Based on the cases we have used to exemplify this approach, it is clear that overfishing is much more extensive, and much more extreme, than has been recognized previously.

\section{Acknowledgments}

We thank Robyn Angliss, Christine Baier, Jim Clark, Shawn Dahle, Gary Duker, Jean Fowler, Steve Ignell, Jim Lee, Alec MacCall, Erin Moreland, Randy Morris, Luciana Santos, and several anonymous reviewers for their very helpful reviews and comments on previous versions of this paper.

\section{Literature Cited}

Basurto, X., and E. Coleman. 2010. Institutional and ecological interplay for successful selfgovernance of community-based fisheries. Ecol. Econ. 69:1094-1103.

Belgrano, A., and C. W. Fowler. 2008. Ecology for management: pattern-based policy. In S. I. Munoz (Editor), Ecology research progress, p. 5-31. Nova Sci. Publ., Hauppauge, N.Y. and 2011a. On the path to holistic management: ecosystem-based management in marine systems. In A. Belgrano and C. W. Fowler (Editors), Ecosystem-based management for marine fisheries: an evolving perspective, p. 337-356. Camb. Univ. Press, Camb., U.K. and (Editors). 2011b. Ecosystem-based management for marine fisheries: an evolving perspective. Camb. Univ. Press, Camb., U.K., 384 p.

Brown, J. H. 1995. Macroecology. Univ. Chicago Press, Chicago, Ill., 304 p.

Côté, I. M., I. Mosqueira, and J. D. Reynolds. 2001. Effects of marine reserve characteristics on the protection of fish populations: a meta-analysis. J. Fish Biol. 59:178-189.

Damuth, J. D. 2007. A macroevolutionary explanation for energy equivalence in the scaling of body size and population density. Am. Nat. 169:621-631.

Eikeset, A. M., A. P. Richter, F. K. Diekert, D. J. Dankel, and N. C. Stenseth. 2011. Unintended consequences sneak in the back door: making wise use of regulations in fisheries management. In A. Belgrano and C. W. 
Fowler (Editors), Ecosystem-based management for marine fisheries: an evolving perspective, p. 183-217. Camb. Univ. Press, Camb., U.K.

Etnier, M. A., and C. W. Fowler. 2005. Comparison of size selectivity between marine mammals and commercial fisheries with recommendations for restructuring management policies. NOAA Tech. Memo. NMFSAFSC-159, 274 p. and 2010. Size selectivity in marine mammal diets as a guide to evolutionarily enlightened fisheries management. N. Am. J. Fish. Manage. 30:588-603.

FAO. 2009. The state of world fisheries and aquaculture, 2008. Food Agric. Organ. U.N., Rome. Avail. at www.fao.org/docrep/011/ i0250e/i0250e00.htm. Last accessed 13 Sept. 2010

Fowler, C. W. 1999. Management of multi-species fisheries: from overfishing to sustainability. ICES J. Mar. Sci. 56:927-932.

. 2003. Tenets, principles, and criteria for management: the basis for systemic management. Mar. Fish. Rev. 65(2):1-55.

2008. Maximizing biodiversity, information and sustainability. Biodivers. Conserv. 17:841-855.

2009. Systemic management: sustainable human interactions with ecosystems and the biosphere. Oxford Univ. Press, Oxford, U.K., 295 p.

and L. Hobbs. 2009. Are we asking the right questions in science and management? U.S. Dep. Commer., NOAA Tech. Memo. NMFS-AFSC-202, 59 p. and 2011. Science and management: matching the questions. In $\mathrm{A}$. Belgrano and C. W. Fowler (Editors), Ecosystem-based management for marine fisheries: an evolving perspective, p. 279-396. Camb.
Univ. Press, Camb., U.K.

and S. M. McCluskey. 2011. Sustainability, ecosystems and fishery management. In A. Belgrano, and C. W. Fowler (Editors), Ecosystem-based management for marine fisheries: an evolving perspective, p. 307336. Camb. Univ. Press, Camb., U.K. , T. E. Jewell, and M. V. Lee. 2009. Harvesting young-of-the-year from large mammal populations: an application of systemic management. U.S. Dep. Commer., NOAA Tech. Memo. NMFS-AFSC-192, 65 $\mathrm{p}$.

Gaston, K. J., and T. M. Blackburn. 2000. Patterns and process in macroecology. Blackwell Sci., Oxford, U.K., 377 p.

Holling, C. S. (Editor). 1978. Adaptive environmental assessment and management. John Wiley and Sons, N.Y., 377 p.

Jackson, J. B. C. 2008. Ecological extinction and evolution in the brave new ocean. Proc. Natl. Acad. Sci. 105:11458-11465.

Jørgensen, C., K. Enberg, E. S. Dunlop, R. Arlinghaus, D. S. Boukal, K. Brander, B. Ernande, A. Gårdmark, F. Johnston, S. Matsumura, H. Pardoe, K. Raab, A. Silva, A. Vainikka, U. Dieckmann, M. Heino, and A. D. Rijnsdorp. 2007. Managing evolving fish stocks. Science 318:1247-1248.

Livingston, P. A. 1993. Importance of predation by groundfish, marine mammals and birds on walleye pollock, Theragra chalcogramma, and Pacific herring, Clupea pallasi, in the eastern Bering Sea. Mar. Ecol. Prog. Ser. 102:205-215.

Mertz, G., and R. A. Myers. 1998. A simplified formulation for fish production. Can. J. Fish. Aquat. Sci. 55:478-484.

NRC. 2004. Improving the use of the "best scientific information available" standard in fisheries management. Natl. Res. Counc., Natl.
Acad. Press, Wash., D.C., 106 p.

Okasha, S. 2006. Evolution and the levels of selection. Clarendon Press, Oxford, U.K., $288 \mathrm{p}$.

Ostrom, E., and X. Basurto. 2011. Crafting analytical tools to study institutional change. J. Inst. Econ. 7:317-243.

Overholtz, W. J., S. A. Murawski, and K. L. Foster. 1991. Impact of predatory fish, marine mammals, and seabirds on the pelagic fish ecosystem of the northeastern USA. ICES Mar. Sci. Symp. 193:198-208.

Petchey, O. L., and A. Belgrano. 2010. Bodysize distributions and size-spectra: universal indicators of ecological status? Biol. Lett. 6:434-437.

Pielou, E. C. 1974. Population and community ecology. Gordon Breach Sci. Publ., N.Y., $432 \mathrm{p}$.

Pitcher, T. J., and M. E. Lam. 2010. Fishful thinking: rhetoric, reality, and the sea before us. Ecol. Soc. 15:12.

Schultz, L., A. Duit, and C. Folke. 2011. Participation, adaptive co-management, and management performance in the world network of biosphere reserves. World Dev. 39:662-671.

Swain, D. P., A. F. Sinclair, and J. M. Hanson. 2007. Evolutionary response to size-selective mortality in an exploited fish population. Proc. R. Soc. Biol. Sci. 274:1015-1022.

Tamura, T., and S. Ohsumi. 1999. Estimation of total food consumption by cetaceans in the world's oceans. Inst. Cetacean Res., Tokyo, Jpn., $16 \mathrm{p}$.

Woese, C. R. 2004. A new biology for a new century. Microbiol. Mol. Biol. Rev. 68:173-186.

Zhou, S. Z., S. Yin, J. T. Thorson, A. D. M. Smith, and M. Fuller. 2012. Linking fishing mortality reference points to life history traits: an empirical study. Can. J. Fish. Aquat. Sci. 69:1292-1301. 


\section{Appendix 1: Frequency Distributions, Information, and Diversity}

Among the goals of management are the objective and effective use of information to guide management toward healthy biotic systems. A primary mode for achieving these and other goals is sustainable anthropogenic impact on species, communities, ecosystems, evosystems, and the biosphere. The biodiversity underlying such systems is of essential importance to health and sustainability.

This appendix contains an explanation of the graphic representation and interpretation of natural patterns, such as those represented by text Figure 1patterns that are informative and serve as sources of guidance for sustainable human participation in the various systems represented. The construction of such illustrations involves two parts: the histogram (the upper panels of each of the four parts of Figure 1, each depicting a frequency distribution) and the maximization of biodiversity (the lower panels in each part of Figure 1). Interpretation includes the assessment of any abnormality revealed. This is especially important in regard to any human abnormality as it serves as an indication of the extent to which biodiversity, normalcy/health, and sustainability can be improved through management defined as action to alter human influence.

\section{Histograms}

The construction of a histogram involves, as a first step, the collection of a set of values, numbers, or measurements often referred to as observations. Such observations are exemplified by the estimated number of metric tons $(\mathrm{t})$ of biomass consumed annually from a specific stock of fish by its predatorsspecifically Walleye Pollock, Theragra chalcogramma, populations as consumed by various predators in the eastern Bering Sea in the late 1980's (Fig. 1a; see also Appendix 2 for treatment of the same information in units of portion of the standing stock harvested each year).

As explained in Fowler and Perez (1999), the frequency distribution of these estimates can then be presented in the form of a histogram representing an empirical pattern with its statistical properties, including the limits to observed variation. This process involves following the instructions found in basic statistical texts such as that of Alder and Roessler (1964). Thus, in the case of Figure 1a, we humans, as one of the seven predators, consumed an estimated 1.17 million $t$ of pollock per year for the time period covered by the data. Thus, our species (commercial fisheries) is represented by a bar positioned on the abscissa to correspond to values encompassing the rate at which we harvested pollock (1.17 million $t$ per year as shown in $\log _{10}$ scale). The height of this bar represents our portion of the overall total of seven species; this height (or POPS: the portion of the predatory species) is about $0.143=1 / 7$, because we are one of seven species.

Three species (spotted seals, Phoca largha; harbor seals, P. vitulina; and ringed seals, Pusa hispida) are represented by the tallest bar which has a height of about 0.429 (POPS =3/7). This bar, in its representation of $42.9 \%$ of the species, is positioned on the abscissa to correspond to estimated consumption rates of between about 17,783 and 56,234 t per year (a range in $\log _{10}$ values falling between 4.25 and 4.75 ) which is the range that encompasses the consumption rates estimated for these three species.

The other three bars represent, by their position on the abscissa, the estimated consumption rates for each of the other three species of marine mammals; each bar has a height of 0.143 in representing one species (see Table A2.1 for a full list of the species involved). That is, each rate falls in a separate, nonoverlapping, adjacent range of estimated consumption rates involving limits separated by 0.5 in $\log _{10}$ scale-often referred to as "bins" distributed along the length of the abscissa.

The other three histograms (Fig. 1b, 1c, and 1d) were constructed in exactly the same way. The upper panel of Figure $1 \mathrm{~b}$ represents the frequency distribution of estimated consumption rates from three species of fish by 10 species of predatory marine mammals in the northwest Atlantic (plus that by commercial fisheries) during the late 1980's (see Table A2.1 for a list of the species involved). In this case, the vertical bars represent the 11 species of consumers, positioned horizontally to represent estimated consumption rates (e.g. 165,000 t per year for humans).

In each case, the height of the bar represents the corresponding portion of the sample of 11 species (POPS = $0.091=1 / 11$ for humans and the three other individual species alone in their category of consumption rates). Thus, the upper panel of Figure 1c represents estimated consumption rates by 20 species of marine mammals (and fisheries) from the eastern Bering Sea ecosystem during the late 1980's. The upper panel of Figure 1d represents estimated consumption rates by 16 species of small cetaceans (and fisheries) from the world's oceans during the late 1990's. The sources of the estimated consumption rates in each case are listed in the legend of Figure 1; these sources also lead to the methods used to produce the estimates.

\section{Maximizing Biodiversity}

The bottom panels of each of the four parts of Figure 1 are a representation of the biodiversity of the respective consumer/resource system, specifically as this diversity would vary in response to changing harvest rates by humans (i.e. commercial fishing, as explained in Fowler (2008), keeping in mind the need to be responsive to real-world changes in current applications). ${ }^{\mathrm{A} 1.1}$ The index of

\footnotetext{
A1.1 It is important to emphasize that the patterns of all four panels of Figure 1 are, to some very real extent, products of (or influenced by) the role of humans as depicted in the position of the bar/line representing commercial harvesting. Change, through management, would undoubtedly result in change in the consumption rates by other species (and the position of bars representing them in respective histograms). In the spirit of adaptive management (see: Holling (1978) and the many subsequent references to this work), management to maximize the biodiversity of the system reflective of reduced harvesting would, of necessity, require research to determine estimates of consumption rates by marine mammals under the circumstances resulting from those reduced harvests. This is an example of both overt and inherent (holistic) aspects of systemic management as
} it accounts for itself. 
diversity $(D I)$ in each case is measured by the equation:

$$
D I=-\sum_{j} p_{j} \log p_{j} .
$$

This is known as the Shannon-Weiner measure of diversity and information (alternatively known as the ShannonWeaver or the Shannon index, based on a substantial history and body of information theory; e.g. see Pielou, 1974), $p_{j}$ is the portion of a sample falling in the $j$ th category. Using this metric explicitly brings the field of information theory into the fold of interdisciplinary approaches to science that are brought to bear in the form of management explained and exemplified in this paper (see also Fowler, 2003, 2009).

To obtain the value of the ShannonWeiner index for the observed commercial harvest of pollock (lower panel of Figure 1a), the $p_{j}$ for the harvest by humans was calculated as the ratio of the commercial catch to the total biomass estimated to have been consumed by all seven species. The $p_{j}$ for the other six species were calculated the same way; their estimated rate of consumption was divided by the total for all seven species (this total, in the denominator, was thus the same for each $p_{j}$ ). Substituting all seven of these values for $p_{j}$ (the six for nonhuman species and that for humans) in the above equation resulted in a calculated value for $D I$ of about 0.302 - the value plotted as the black dot at the lower end of the gray line which itself corresponds to the observed harvest by humans (in its position in the abscissa of both panels).

This process was repeated for different (assumed) values for the harvest by commercial fisheries (and thus different total harvests as well). Each was represented by a different black filled circle corresponding to values for that harvest in the $\log _{10}$ scale of the abscissa. Thus, each calculated value of $D I$ corresponds to a different value for the consumption rate by humans, only one of which was a value that was actually observed (that corresponding to the gray line).

This process leads to the observation of a curve representing the biodiversity and information content of the collec- tion of seven species as a function of the harvest rate by humans. In other words, the curve represents humans with our (hypothetically) varying harvest levels and the six other species represented by constant observed levels of estimated consumption. Thus, both the calculated diversity index and the total consumption rate for all seven species (the denominator for each $p_{j}$ ) were made to vary only by changing the consumption rate for humans (the harvest by commercial fisheries). This curve is represented by the full collection of black dots in the lower panel of Figure 1a. Again, this is representative of the circumstances imposed by the effects of observed fishing rates, at the time these data were collected; adjustments would be required as other species respond to management action undertaken to reduce harvest rates.

Obviously, this curve has a maximum, and finding that maximum results in an estimate of the harvest by the commercial fisheries that would have maximized the biodiversity of this system (i.e., the system of seven species of predators and their common prey: Walleye Pollock). For present purposes, this maximum was determined using iterative calculations of $D I$ to find the corresponding commercial harvest (which would have been about 69,200 t).

As with the case of our construction of the frequency distributions (discussed above), this procedure was repeated for the other three elements of Figure 1 to obtain the values plotted in the lower panels for each consumer/resource system. In all cases, the observed values of $D I$ for the respective system are represented by the black dot at the lower end of the gray line that, in its position on the abscissa, represents the magnitude of the commercial harvest. Also, in each case, the maximum value of $D I$ for the respective consumer/resource system is plotted by the black dot at the lower end of the dashed line positioned on the abscissa to correspond to the harvest rate that would result in that maximized biodiversity.

It should be noted that the ShannonWeiner information index responds to a variety of factors of importance to its interpretation (covered in the next section). Generically, the index increases with an increasing number of species (or other components of $D I$, measured by $p_{j}$ ). Thus, the diversity and information of Figures 1a through 1d increases with the numbers of species involved; in increasing order of diversity are: Figure 1a (seven species), Figure 1b (11 species), Figure 1d (17 species), and Figure 1c (21 species).

The index also responds negatively to variance; the greatest information content would be found in cases for which the $p_{j}$ are all the same; this maximum is a function of the number of species $\left(D I_{\text {max }}=\log (N)\right.$ where $N$ is the number of species). In this regard, the index is most sensitive to $p_{j}$ that are large (e.g., monopolies or monocultures) compared to the more common $p_{j}$. This explains why each of the curves in the lower panels of Figure 1 has its lowest values of $D I$ representing the larger alternative harvest rates by humans; any species showing such extremes so heavily dominate the system as to result in greatly reduced diversity/ information.

\section{Interpretation}

The calculations involved in finding the information depicted in Figure 1 lead to finding and measuring abnormality in the respective systems. Specifically, not only will any abnormality in the impact caused by humans on the respective system be revealed, but also made obvious is an indication of the magnitude of change necessary to rectify the associated pathology with its impacts and ripple effects throughout the larger systems.

For example, in the case of the harvest of pollock in the eastern Bering Sea, observed harvests were almost 17 times too large to maximize the biodiversity (the harvest rate represented by the gray line is nearly 17 times larger than that represented by the dashed line) - a value very similar to overharvesting indices measured for our harvests of other species of fish (App. Table A2.3 and App. Fig. A2.14).

Similar overharvesting indices apply to the other three systems represented in Figure 1. The commercial harvest 
from three species of fish in the northwest Atlantic during the late 1980's was over 14 times too large to be sustainable. The commercial harvests of biomass from the eastern Bering Sea ecosystem during the late 1980's were about 7 times too large to be sustainable. And finally, the commercial harvests of biomass from the world's oceans during the late 1990's were over 23 times too large.

These values represent indications of the magnitude of changes (changes by humans as management) necessary to maximize biodiversity where such biodiversity is most directly under our control. Such changes would simultaneously rectify all of the pathological effects of overharvesting (including those involving all of the evosystems involved). As part of such changes would be reactions seen in the estimated consumption rates by other species; changes that would have to be taken into account directly through research to reveal such responses. Solving the problems caused by observed abnormality would promote health for the respective systems and their subsystems as well as for the systems for which they serve as components. Harvesting at levels that maximize biodiversity would involve an impact that is sustainable by the system providing resources and sustainability of the systems themselves.

\section{Literature Cited}

Alder, H. L., and E. B. Roessler. 1964. Introduction to probability and statistics. Freeman Co., San Francisco, 313 p.

Fowler, C. W. 2003. Tenets, principles, and criteria for management: the basis for systemic management. Mar. Fish. Rev. 65(2):1-55.

2008. Maximizing biodiversity, information and sustainability. Biodiv. Conserv. 17:841-855.

2009. Systemic management: sustainable human interactions with ecosystems and the biosphere. Oxford Univ. Press, Oxford, U.K., 295 p. and M. A. Perez. 1999. Constructing species frequency distributions-a step toward systemic management. U.S. Dep. Commer., NOAA Tech. Memo. NMFSAFSC-109, $59 \mathrm{p}$.

Holling, C. S. (Editor). 1978. Adaptive environmental assessment and management. John Wiley Sons, N.Y., 377 p.

Pielou, E. C. 1974. Population and community ecology. Gordon Breach Sci. Publ., N.Y., 432 p. 


\section{Appendix 2: Management to Maximize Biodiversity in Harvesting from Individual Species}

Diversity, resource extraction from individual species, and information are all essential elements of managementseveral among many. Biodiversity is heavily emphasized in the literature regarding the management of human influence on nonhuman biotic systems. Our impacts on other species contribute to the complexity of such systems, especially our consumption from species that serve as resources.

In this appendix, we present information concerning the biodiversity among consumption rates by predators which consume from populations of eight different species of prey-species which also serve as resources for consumption by humans. Thus, the information we present includes estimates of consumption from these prey species by both other mammalian predators and harvests by humans (for details, see App. 1). This makes it possible to compare the rates at which we humans consume a particular resource with the rates at which that resource is consumed by other predatory species.

We use the combination of this information, across all eight prey species, to illustrate a macroecological pattern in consumption rates as a function of the total natural mortality rate for the prey species $(M)$ - a pattern similar to one first described by Belgrano and Fowler (2011). This pattern can be used to both evaluate historical/current harvest rates by humans and to provide guidance for harvests from species for which there are estimates of $M$.

\section{Patterns in Predation Rates for Individual Prey Species}

We begin with estimated predation rates for predators consuming from a population of white-tailed deer, Odocoileus virginianus, in western Montana, as presented by Kunkel and Pletscher (1999). The top panel of Figure A2.1 illustrates the pattern in consumption rates estimated for five species of predators (including humans) in their take of deer from this
Table A2.1.-A list of the predatory species, and their estimated consumption rates, in their predation on eight species of prey (from Overholtz et al., 1991; Fowler, 1999a,b; Fowler and Perez, 1999; and Kunkle and Pletscher, 1999).

\begin{tabular}{|c|c|c|c|}
\hline Prey species & Predator species & Scientific name & Consumption rate $(\% / y r)$ \\
\hline \multirow[t]{5}{*}{ White-tailed deer } & & Odocoileus virginianus & \\
\hline & Cougar & Puma concolor & 9.000 \\
\hline & Wolf & Canis lupus & 6.000 \\
\hline & Grizzly bear & Ursus arctos & 3.000 \\
\hline & Coyote & Canis latrans & 1.000 \\
\hline \multirow[t]{5}{*}{ Elk } & & Cervus elaphus & \\
\hline & Cougar & Puma concolor & 6.000 \\
\hline & Wolf & Canis lupus & 4.000 \\
\hline & Black bear & Ursus americanus & 1.000 \\
\hline & Grizzly bear & Ursus arctos & 2.000 \\
\hline \multirow[t]{4}{*}{ Moose } & & Alces alces & \\
\hline & Wolf & Canis lupus & 3.000 \\
\hline & Black bear & Ursus americanus & 1.000 \\
\hline & Grizzly bear & Ursus arctos & 3.000 \\
\hline \multirow[t]{7}{*}{ Walleye Pollock } & & Theragra chalcogramma & \\
\hline & Northern fur seal & Callorhinus ursinus & 1.460 \\
\hline & Steller sea lion & Eumetopias jubatus & 0.594 \\
\hline & Harbor seal & Phoca vitulina & 0.187 \\
\hline & Spotted seal & Phoca largha & 0.117 \\
\hline & Ringed seal & Pusa hispida & 0.299 \\
\hline & Bearded seal & Erignathus barbatus & 0.036 \\
\hline \multirow[t]{8}{*}{ Silver Hake } & & Merluccius bilinearis & \\
\hline & Bottlenose dolphin & Tursiops truncatus & 0.380 \\
\hline & Gray grampus & Grampus griseus & 0.666 \\
\hline & Harbor seal & Phoca vitulina & 0.898 \\
\hline & Harbor porpoise & Phocoena phocoena & 1.908 \\
\hline & $\begin{array}{l}\text { Short-beaked common } \\
\text { dolphin }\end{array}$ & Delphinus delphis & 3.596 \\
\hline & Atlantic white-sided dolphin & Lagenorhynchus acutus & 3.968 \\
\hline & Long-finned pilot whale* & Globicephala melas & 6.260 \\
\hline \multirow[t]{8}{*}{ Atlantic Herring } & & Clupea harengus & \\
\hline & Minke whale* & Balaenoptera acutorostrata & 0.024 \\
\hline & Harbor porpoise & Phocoena phocoena & 0.046 \\
\hline & Harbor seal & Phoca vitulina & 0.096 \\
\hline & Atlantic white-sided dolphin & Lagenorhynchus acutus & 0.099 \\
\hline & Humpback whale* & Megaptera novaeangliae & 0.187 \\
\hline & Long-finned pilot whale* & Globicephala melas & 0.188 \\
\hline & Fin whale ${ }^{\star}$ & Balaenoptera physalus & 0.664 \\
\hline \multirow[t]{9}{*}{ Sand eel } & & Ammodytes marinus & \\
\hline & Atlantic white-sided dolphin & Lagenorhynchus acutus & 0.428 \\
\hline & Harbor porpoise & Phocoena phocoena & 0.470 \\
\hline & Minke whale* & Balaenoptera acutorostrata & 0.607 \\
\hline & $\begin{array}{l}\text { Short-beaked common } \\
\text { dolphin }\end{array}$ & Delphinus delphis & 0.633 \\
\hline & Long-finned pilot whale* & Globicephala melas & 2.834 \\
\hline & Harbor seal & Phoca vitulina & 2.952 \\
\hline & Humpback whale* & Megaptera novaeangliae & 9.907 \\
\hline & Fin whale* & Balaenoptera physalus & 37.932 \\
\hline \multirow[t]{11}{*}{ Atlantic mackerel } & & Scomber scombrus & \\
\hline & Bottlenose dolphin & Tursiops truncatus & 0.022 \\
\hline & $\begin{array}{l}\text { Short-beaked common } \\
\text { dolphin }\end{array}$ & Delphinus delphis & 0.590 \\
\hline & Fin whale* & Balaenoptera physalus & 0.666 \\
\hline & Gray grampus & Grampus griseus & 0.021 \\
\hline & Harbor porpoise & Phocoena phocoena & 0.007 \\
\hline & Harbor seal & Phoca vitulina & 0.030 \\
\hline & Humpback whale* & Megaptera novaeangliae & 0.162 \\
\hline & Minke whale* & Balaenoptera acutorostrata & 0.007 \\
\hline & Long-finned pilot whale ${ }^{\star}$ & Globicephala melas & 0.894 \\
\hline & Atlantic white-sided dolphin & Lagenorhynchus acutus & 0.037 \\
\hline
\end{tabular}

*See text for analysis omitting species marked with a star to illustrate the process of directly accounting for body size.

population. This pattern is presented as a frequency distribution (see Appendix 1 regarding the construction of a frequency distribution) to illustrate the limits observed in the variability among these rates (shown numerically for individual predators in Table A2.1 along with the identity of each of the corresponding predators).

The bottom panel of Figure A2.1 shows a curve representing a measure ${ }^{\mathrm{A} 2.1}$

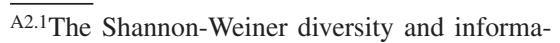
tion index as explained in Appendix 1; see Pielou (1974). 


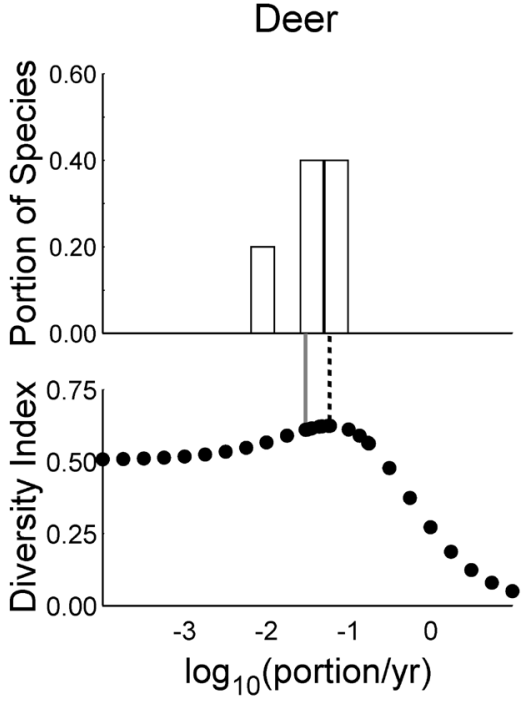

Figure A2.1.- The pattern in mammalian predation rates on whitetailed deer, Odocoileus virginianus, in western Montana (from Kunkel and Pletscher, 1999) showing the information and diversity (based on the Shannon-Weiner information index) resulting from variable harvest levels by humans. The solid gray vertical line represents $F_{o b}$ (the observed harvest rate by humans) and the dashed vertical line represents $F_{m b}$ (the harvest rate by humans which would maximize the diversity for this predator/prey system). The height of bars in the top panel represents the portion of predatory species (i.e., the same metric as POPS in text Figure 1) that consumes deer at the rate corresponding to its position on the abscissa (see App. 1).

of the diversity and information $(D I$ in text Figure 1, as explained in Appendix 1) in the predation rates of the predator/prey system involving this deer population and the five species of predators represented in the top panel. These five species include humans plus the four species listed as predators for deer in Table A2.1.

The biodiversity represented by the curve in the bottom panel is that corresponding to a variable harvest rate for humans as explained in Appendix 1 . Thus, the point at the lower end of the solid gray line is the measured diversity of the system in which humans harvested about $3.0 \%$ of the deer popu-

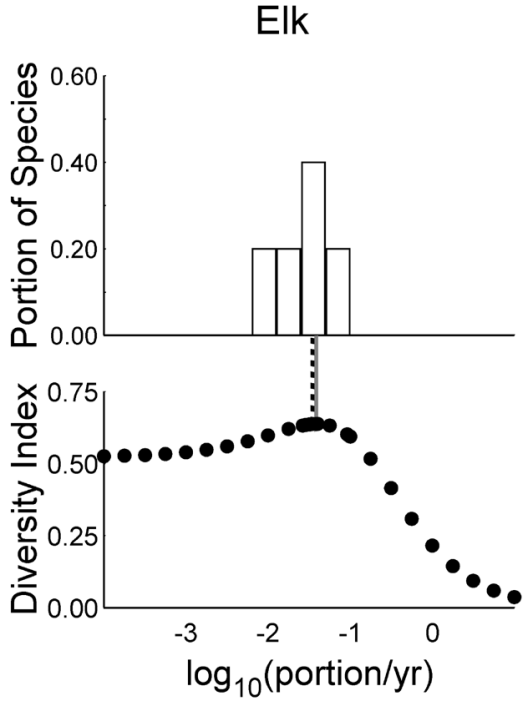

Figure A2.2.- The pattern in mammalian predation rates on elk, Cervus elaphus, in western Montana (from Kunkel and Pletscher, 1999) showing the same kinds of information as depicted in Figure A2.1.

lation each year as observed by Kunkel and Pletscher (1999). The other points represent a set of alternative harvest rates by humans covering the range of rates represented by the graph. This sampling was carried out to explore resulting variation in the diversity and information inherent to this system as it responds to the harvest rate by humans.

Managing to achieve a specific diversity within the system can be carried out by directly managing the harvest rate by humans (Fowler, 2008). The process just described allows for calculating (iteratively) the harvest rate by humans that would maximize the biodiversity of this predatory prey complex. As in Figure 1, this maximum is represented by the dashed vertical line. Based on the set of data for the nonhuman predators listed in Table A2.1, the harvest rate to achieve maximum diversity is estimated to be about $5.9 \%$ of the deer population per year (about twice as much as actually taken in the sport harvest reported by Kunkel and Pletscher, 1999).

Figure A2.2 represents the predator/ prey system in which the prey species is elk, Cervus elaphus, with the preda-

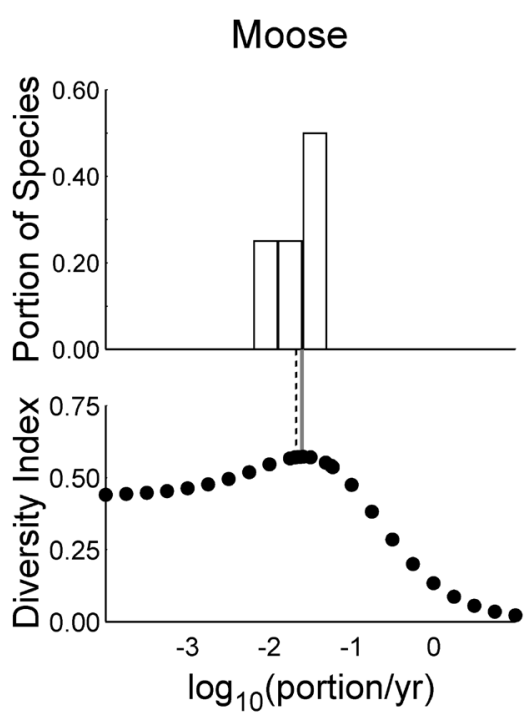

Figure A2.3.- The pattern in mammalian predation rates on moose, Alces alces, in western Montana (from Kunkel and Pletscher, 1999) showing the same kinds of information as depicted in Figures A2.1 and A2.2.

tors and their predation rates identified in Table A2.1; otherwise this figure is identical to Figure A2.1. In this case, the biodiversity and information content of the system would be maximized with a harvest by humans of about $3.90 \% / y r$ (the harvest rate observed by Kunkel and Pletscher (1999) was about 4.0\% per year-nearly the same as that for maximized biodiversity).

Figure A2.3 is again similar to Figures A2.1 and A2.2, but represents the predator/prey system in which the prey species is moose, Alces alces, with the predators and their predation rates identified in Table A2.1. In this case, the biodiversity and information content of the system would be maximized with a harvest by humans of about $2.56 \%$ (the harvest rate observed by Kunkel and Pletscher (1999) was about 2.0\%) per year.

In Figure A2.4, we turn to marine systems. In this figure the prey species is Walleye Pollock, Theragra chalcogramma, with predators and their predation rates identified in Table A2.1. For pollock, the biodiversity and information within the system would have been maximized with a harvest by humans (or 
Pollock

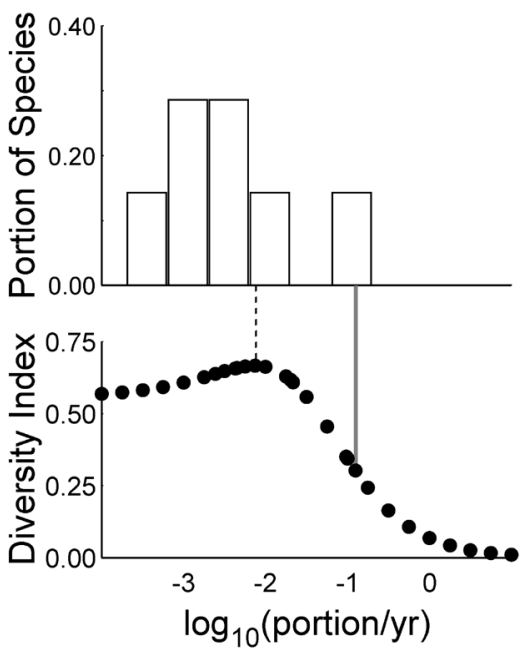

Figure A2.4.- The pattern in mammalian predation rates on Walleye Pollock, Theragra chalcogramma, from the eastern Bering Sea (from Livingston, 1993; Fowler and Perez, 1999) showing the same kinds of information as depicted in Figures A2.1-A2.3.

a fishing rate, $F_{m b}$ ) of about $0.74 \%$ of the standing stock per year (the observed harvest rate was about $12.5 \%$ per year: Livingston, 1993; Fowler and Perez, 1999). This system is also represented in Figure 1a, and explained in terms of harvests expressed in units of biomass in Appendix 1.

Figures A2.5-A2.8 are based on data from Overholtz et al. (1991; see also Fowler, 1999a, b). These graphs also represent marine systems wherein the prey species are Atlantic Herring, Clupea harengus; Silver Hake, Merluccius bilinearis; Sand Eel, Ammodytes marinus; and Atlantic Mackerel, Scomber scombrus. As with the previous graphs, the predators and their predation rates are identified in Table A2.1. The values of $F_{m b}$ (fishing rates that maximize biodiversity and information inherent to the system as represented by vertical dashed lines) are $0.30 \%, 3.48 \%, 17.78 \%$, and $0.55 \%$ per year, respectively (compared to harvest rates by humans of about $5.7 \%$, $30.8 \%, 0.05 \%$, and $19.0 \%$ per year as represented by the vertical gray lines).
Herring

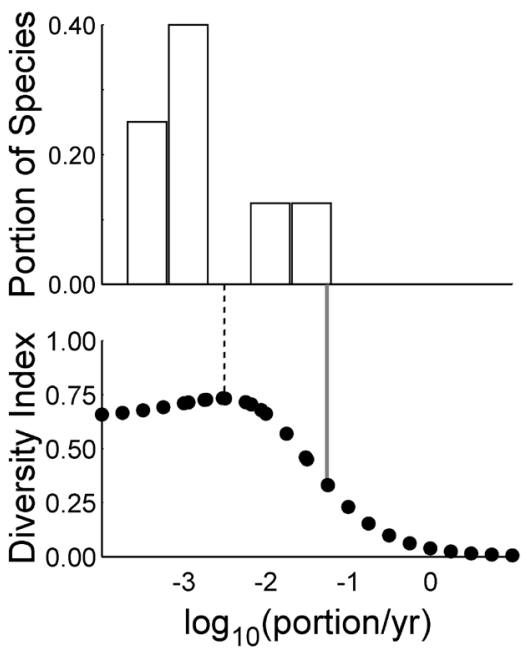

Figure A2.5.- The pattern in mammalian predation rates on Atlantic Herring, Clupea harengus, from the northwest Atlantic (from Overholtz et al., 1991, and Fowler, 1999a, b) showing the same kinds of information as depicted in Figures A2.1A2.4.

\section{Sandeel}

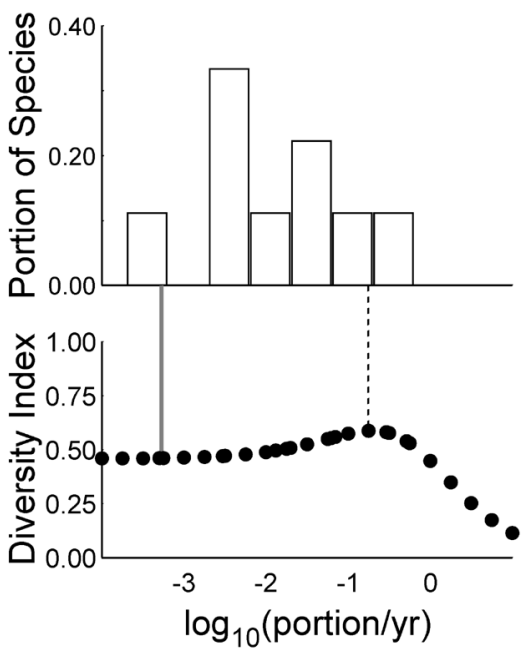

Figure A2.7.- The pattern in mammalian predation rates on Sand Eel, Ammodytes marinus, from the northwest Atlantic (from Overholtz et al., 1991, and Fowler, 1999a, b) showing the same kinds of information as depicted in Figures A2.1A2.6.

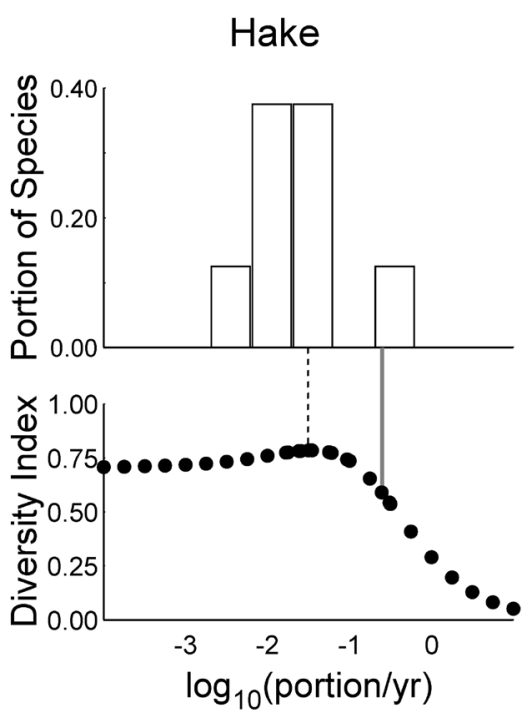

Figure A2.6.- The pattern in mammalian predation rates on Silver Hake, Merluccius bilinearis, from the northwest Atlantic (from Overholtz et al., 1991, and Fowler, 1999a, b) showing the same kinds of information as depicted in Figures A2.1A2.5.

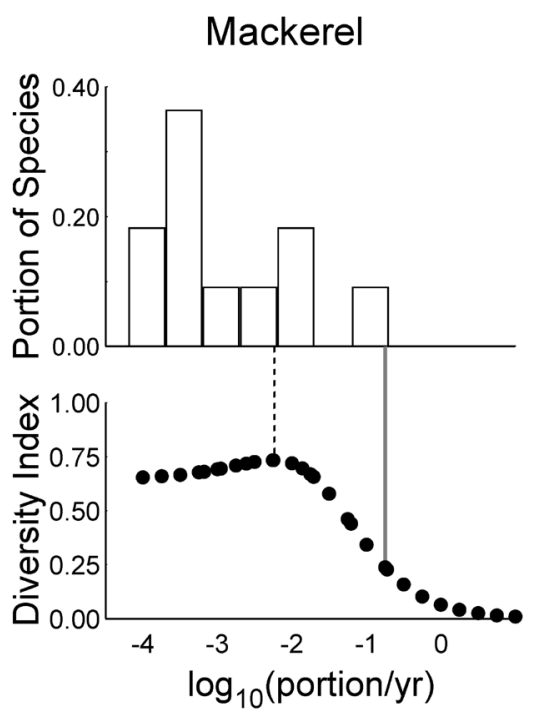

Figure A2.8.- The pattern in mammalian predation rates on Atlantic Mackerel, Scomber scombrus, from the northwest Atlantic (from Overholtz et al., 1991, and Fowler, 1999a, b) showing the same kinds of information as depicted in Figures A2.1A2.7. 
Table A2. 2 contains a summary of the values for harvest rates that would maximize biodiversity $\left(F_{m b}\right)$ as compared to $F_{o b}$ (the observed harvest rate) as determined for the sets of data presented in Figures A2.1-A2.8.

Note that in each case reviewed above, the management question that was addressed was specific to a particular species and a particular ecosystem. "What portion of species (i) can sustainably be harvested annually within ecosystem $(j)$ (where $i$ is deer, elk, moose, pollock ... etc., and $j$ is the ecosystem studied by Kunkel and Pletscher (1999), the ecosystem studied by Livingston (1993), and the ecosystem studied by Overholtz et al., 1991)?" This directly accounts for each specific ecosystem and prey species.

\section{A Macroecological Pattern in Predation Rates}

We now turn to the macroecological pattern seen in the combination of data represented by Figures A2.1-A2.8 and shown numerically in Table A2.1. Figure A2.9 displays this combination as related to total natural mortality rates (from Table A2.2) in comparison to a line representing the case wherein $F_{o b}$ is equal to $M$ (the 1:1) line. As described by Fowler and McCluskey (2011) (see also Mertz and Myers, 1998; Zhou et al., 2012), measures of $M$ have often been used to evaluate $F_{o b}$, and fishing rates in excess of $M$ are considered to be examples of overfishing.

As can be seen, empirical examples of what works ${ }^{\mathrm{A} 2.2}$ in these predator/ prey systems indicate that long-term sustainable fishing rates are much less than $M$; they are much less than estimated by Zhou et al. (2012) who take into account a few (but necessarily limited number of) relevant factors to show that they are less than $M$. Because $M$ is the total natural mortality, a sustainable $F$ to mimic what works in the ecological/evolutionary systems in which these predator/prey systems are component systems has to be, on the average, less than $M / N_{p}$, where $N_{p}$ is the number of predatory species consuming from the resource species. How do we find an estimate of $F_{e s}$,

\footnotetext{
A2.2As laid out in Appendix 3, empirical information such as this (regarding what works) reflects and accounts for all factors, such as the ecosystem in which they are embedded, the influence of evolution and extinction, existing and past management practices, and the belief systems, values, and opinions behind management (Belgrano and Fowler, 2008; Fowler, 2009). This achieves holism in addressing each management question when using consonant empirical patterns for guidance (Belgrano and Fowler, 2011).
}

where $F_{e s}$ is the ecologically/evolutionarily sustainable harvest rate, or a rough measure of what is systemically sustainable—holistically sustainable?

A first approximation involves fitting a model to the pattern represented by the data displayed in Figure A2.9. Such a model is represented by the dashed line. This model is a linear model in which it is assumed that, when $M$ is zero, all consumption rates (including fishing rates) must also be zero. This model is represented by the simple equation:

$$
F_{e s}=a M .
$$

An ordinary least squares fit of this model to the data for consumption rates in Table A2.1, using the estimates of $M$ from Table A2.2, resulted in an estimate of 0.095 for the coefficient $(a)$. Thus, with information for $M$, an estimate of $F_{e s}$ can be obtained with the equation:

$$
F_{e s}=0.095 \mathrm{M} .
$$

Figure A2.10 shows the same set of data and relationships, in $\log _{10}$ scale for both $F$ and $M$. Again, the above equation is represented by the dashed line (predation fit).

How well does this relationship rep-

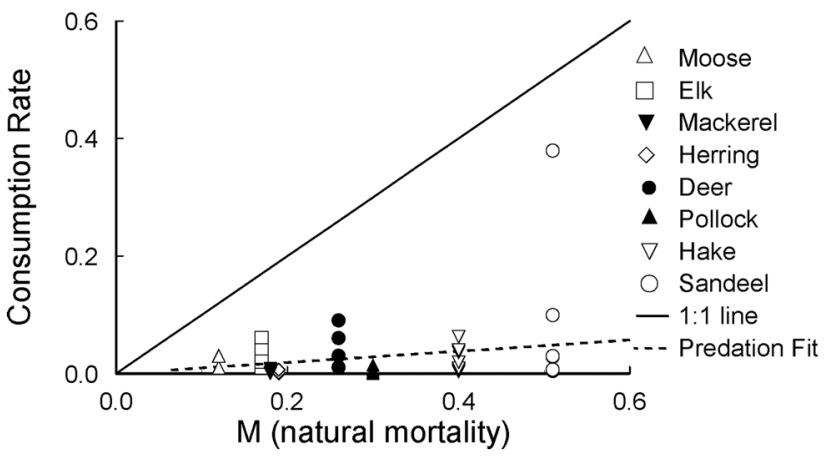

Figure A2.9.- The macroecological pattern of the combined information from Figures A2.1-A2.8 representing the data for consumption rates from Table A2.1 plotted as a function of the total natural mortality rates for each of the eight prey species from Table A2.2. The solid line represents the relationship wherein consumption rates (e.g., fishing rates) are equal to the total natural mortality $(M)$. The dashed line is the linear model for the macroecological pattern, as a least squares fit to observed consumption rates forced through the origin.

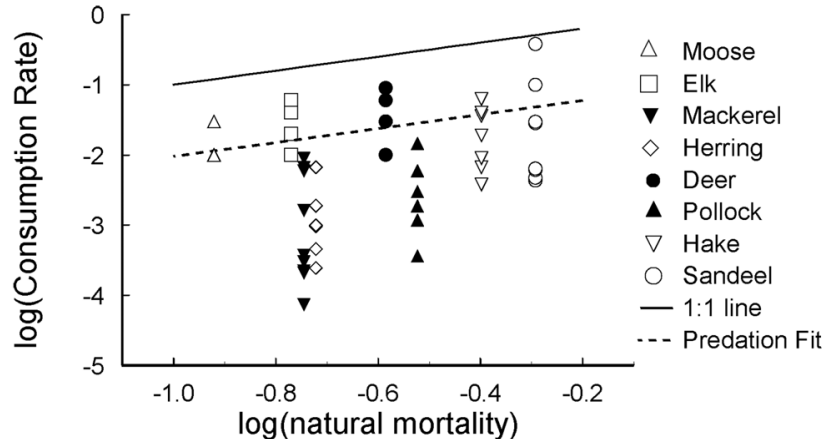

Figure A2.10.- The macroecological pattern of Figure A2.9 plotted in log scale. 
resent the maximized biodiversity of the eight predator/prey systems illustrated in Figures A2.1-A2.8? Figure A2.11 shows the relationship between the $F_{m b}$ and the corresponding $M$ of Table A2.2 (again in log scale). A linear least squares fit of a line parallel to that in Figure A2.11 results in an estimate of 0.08925 for the coefficient (a)-very close to 0.095 (only $5.84 \%$ different). Owing to the similarity of these estimates of the coefficient, and the preliminary and limited nature of the sets of data with which we are working, we selected the above equation $\left(F_{e s}=0.095\right.$ $M)$ to use in demonstrating the use of the macroecological pattern illustrated in Figures A2.9-A2.11.

Alternative models could have been chosen. One of the first presentations of the macroecological patterns we are describing here is found in Belgrano and Fowler (2011). In that paper we presented the model $F_{e s}=0.168 M$ with which estimates of $F_{e s}$ would be almost twice those produced by the equation we are using in this paper (about 1.77 times larger). One of the necessities of good management is to frame the management question so as to explicitly account for relevant factors (exemplified by the specific prey species and ecosystems in eight sets of data treated above). Other such factors include taxonomy, body size, and trophic level. The data for predation rates used to derive the equation presented in Belgrano and Fowler (2011) included predation by species that taxonomically do not match ours; some of the predator species were birds (we are not birds), and others were fish (we are not fish). For this reason (along with the close fit to the estimated $F_{m b}$ ), we are opting to use $F_{e s}=0.095 \mathrm{M}$ as the model for demonstrating the use of the macroecological pattern of Figure A2.9.

We hasten to point out, however, that the preliminary nature of this model is emphasized by further refinement of the questions we are addressing. Above, we have progressed to the point of addressing the management question: "Given that we are mammals, what portion of the standing stock of a resource species characterized by a measured value of $M$ can we harvest sustainably

Table A2.2.-List of prey species represented by Figures A2.1-A2.8, listing the harvesting/fishing rate $\left(F_{m b}\right)$ that would maximize the biodiversity of the respective predator/prey system, compared to the observed harvest/fishing rate $\left(F_{o b s}\right)$, and $M$, the total natural mortality rate for each prey species (from Kunkel and Pletscher, 1999; Mertz and Meyers, 1998).

\begin{tabular}{|c|c|c|c|c|}
\hline Common name & Scientific name & $F_{m b}$ & $F_{o b s}$ & $M$ \\
\hline White-tailed Deer & Odocoileus virginianus & 0.0593 & 0.0300 & 0.26 \\
\hline Elk & Cervus elaphus & 0.0390 & 0.0400 & 0.17 \\
\hline Moose & Alces alces & 0.0256 & 0.0200 & 0.12 \\
\hline Walleye Pollock & Theragra chalcogramma & 0.0074 & 0.1251 & 0.30 \\
\hline Atlantic Herring & Clupea harengus & 0.0030 & 0.0567 & 0.19 \\
\hline Silver Hake & Merluccius bilinearis & 0.0348 & 0.3082 & 0.40 \\
\hline Sand Eel & Ammodytes marinus & 0.1778 & 0.0005 & 0.51 \\
\hline Atlantic Mackerel & Scomber scombrus & 0.0055 & 0.1900 & 0.18 \\
\hline
\end{tabular}

each year?" All of the predatory species of Table A2.1 are mammals - this achieves a limited degree of consonance (see Fowler and Hobbs, 2011) in making use of the pattern represented by the information in Figures A2.9-A2.11. All of the species involved are mammals; as mammals we are comparing ourselves to other mammals.

However, body size remains an issue that is not yet accounted for explicitly. ${ }^{\mathrm{A} 2.3}$ If we refine the management question to: "Given that we humans are mammals, what portion of the standing stock of a resource species with a natural mortality rate of $M$ can we harvest sustainably each year to directly account for our characteristic body size?" To achieve more consonance in following this refinement of the management question, we can remove the large whales from the analysis (those marked with stars in Table A2.1). This results in an estimate of 0.0478 for the coefficient $(a)$ to result in estimates of $F_{e s}$ that are about $50 \%$ less than those we use in this paper (based on 0.095 as the coefficient).

Further refinement would involve both management and further ques-

\footnotetext{
${ }^{\text {A2.3 }}$ Taking complexity into account involves both the implicit aspects of the integrative nature of natural patterns (App. 3), and the explicit (or overt) aspect of the correlative nature of factors seen in the characteristics of natural patterns. Taxonomic category is exemplified as an explicitly considered factor in the choice of mammals in this question. The management question is being refined here to account for body size owing to the prevalence of macroecological patterns for which body size is increasingly recognized as a major factor (Peters, 1983; see also Fowler, 2009:ch. 2). This is an example that might seem counterintuitive, but reversal of the burden of proof requires that any skepticism lead to proving that there is not a relationship before we abandon taking it into account when and where we can.
}

tions - a form of adaptive management (see App. 1:fn A1.1). To account directly for systemic management, harvest rates would be reduced through guidance provided by Figures A2.3A2.8 followed by research to reveal patterns reflective of the effects of such harvests. The resulting patterns would be used to provide guidance, and potentially result in further adjustments among harvest rates. The continuing iterative aspect of this process would be adaptive in its response to change, not only that of fishing, but of environmental circumstances in general (including other human influences such as our contribution to the $\mathrm{pH}$ of ocean waters).

\section{Assessing Fisheries Globally}

In this section we demonstrate the use of the macroecological pattern illustrated in Figures A2.9 and A2.10 to provide assessments of fishing rates applied in conventional management to a variety of species of fish for which values of $M$ are found in the published literature. Table A2.3 is a list of 44 species of fish with their corresponding species-specific estimated total natural mortality rates $(M)$ and fishing rates $\left(F_{o b}\right)$ that applied to each species as documented in Mertz and Myers (1998).

Figure A2.12 shows the observed fishing rates (dots) for these species plotted against the corresponding $M$. Also shown are the 1:1 line $(F=M)$, the line (dashed) representing the macroecological pattern of Figure A2.9, and the points (circles) representing the consumption/ fishing rates that maximize the biodiversity of the predator/prey systems for the eight prey species discussed above. Figure A2.13 shows the same sets of information in log scale. 


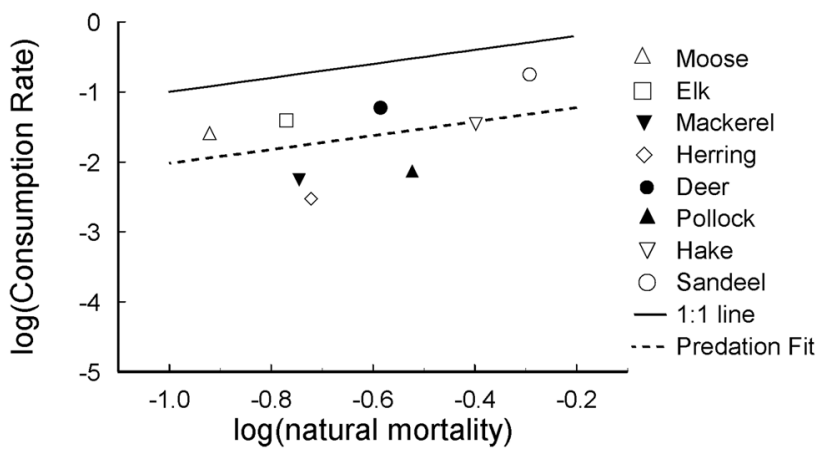

Figure A2.11. - The macroecological pattern of Figure A2.9 represented by the consumption rates for hunting or fishing by humans that would maximize the diversity of the respective predator/prey systems, in log scale.

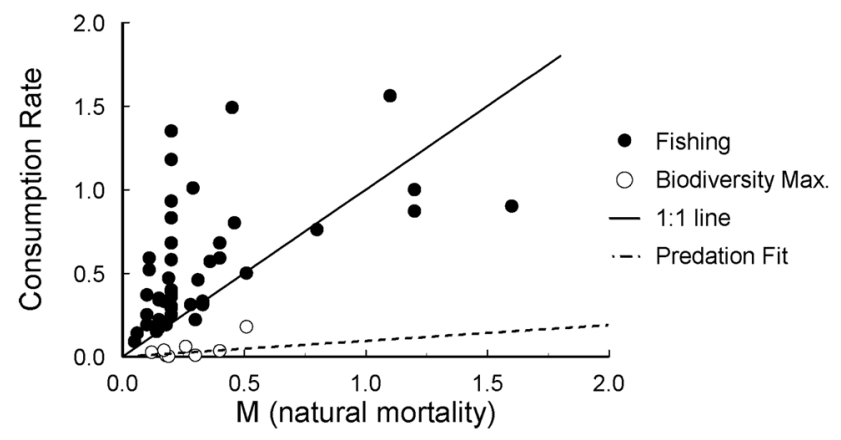

Figure A2.12.-The observed fishing rates (dots; from Mertz and Myers, 1998) for 44 species of fish plotted against $M$, the corresponding total natural mortality rate as compared to the macroecological pattern of Figure A2.9 represented by the consumption rates for hunting or fishing by humans that would maximize the diversity of the respective predator/prey systems (circles and dashed line).

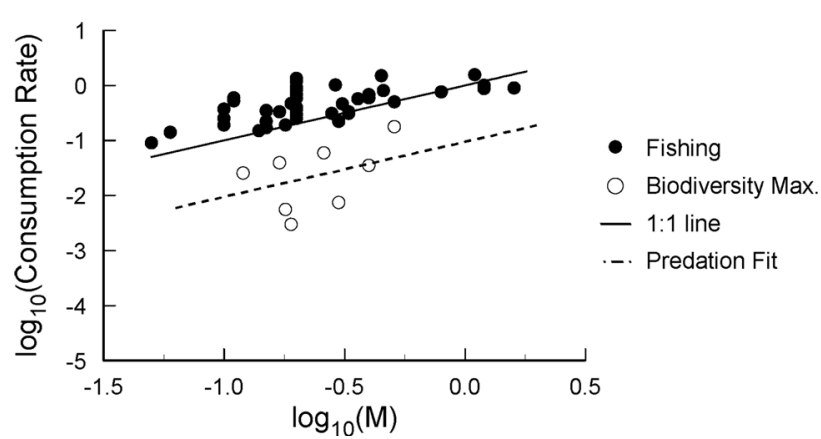

Figure A2.13.- The information of Figure A2.12 plotted in $\log$ scale.

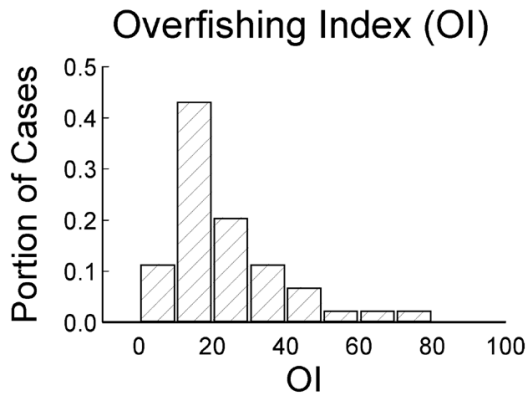

Figure A2.14.- The pattern in overfishing among the 44 species of fish listed in Table A2.3 expressed as the ratio $(O I)$ of observed fishing rates $\left(F_{o b}\right)$ to the systemically (or ecologically) sustainable fishing rates $\left(F_{e s}\right)$ based on information from the macroecological pattern shown in Figures A2.9-A2.11 and represented by the equation $F_{e s}=0.095 \mathrm{M}$.
Table A2.3 also shows the estimated ecologically sustainable fishing rate $\left(F_{e s}=0.095 \mathrm{M}\right)$ for each of the 44 species. With these values in hand, an overfishing index $\left(O I=F_{o b} / F_{e s}\right)$ can then be calculated for each species. The last column of Table A2.3 contains this index for each species. Figure A2.14 shows a histogram representing the pattern in overfishing for all 44 species. Note that overfishing ranges from nearly six-fold at a minimum to over seventy-one-fold at the maximum. The mean of the overfishing indices from this set of data is 23.4.

As noted by Fowler and McCluskey (2011), there has been a history of attempts and advice to reduce advisable fishing rates from the standard of $M$ (total natural mortality rate). How much of a reduction should be involved?

In addition to reviewing its history, Zhou et al. (2012) review the continuing prevalence of the assumption that a sustainable fishing rate is equivalent to $M$. To make progress toward finding a multiplier that can be applied to $M$, these authors use empirical data to find that a value of 0.85 helps understand the degree to which the direct use of $M$ results in overfishing. Their use of empirical data exemplifies the conventional use of nonconsonant information, however, and the prog- ress made in their work is limited by a lack of holism-something largely overcome with consonant information. The multiplier of our work (0.095) is far more holistic in that all of the factors taken into account by Zhou et al. (2012) are inherently accounted for, along with all other evolutionary and ecological factors (owing to the integrative nature of the consonant pattern; App. 3).

Thus, on the basis of the information from the macroecological pattern we are demonstrating, all of the 44 species of Table A2.3 are overfished. This conclusion is to be compared to that of conventional assessments in which it is often claimed that only 
Table A2.3.-A list of 44 species of fish (from Mertz and Meyers, 1998) with their corresponding species-specific estimated total natural mortality rates $(M)$, observed fishing rates $\left(F_{o b s}\right)$, ecologically sustainable fishing rate $\left(F_{e s}\right)$, and ecological overfishing index $\left(\mathrm{OI}=F_{o b s} / F_{e s}\right)$.

\begin{tabular}{|c|c|c|c|c|}
\hline Scientific and common names & M & $F_{o b s}$ & $F_{e s}$ & $\mathrm{OI}$ \\
\hline Brevoortia patronus, Gulf Menhaden & 1.10 & 1.56 & 0.104 & 15.0 \\
\hline Brevoortia tyrannus, Atlantic Menhaden & 0.45 & 1.49 & 0.043 & 34.9 \\
\hline Clupea harengus, Atlantic Herring & 0.19 & 0.47 & 0.018 & 26.1 \\
\hline Sardina pilchardus, Iberian Sardine & 0.33 & 0.33 & 0.031 & 10.5 \\
\hline Sardinella brasiliensis, Orangespot Sardine & 1.20 & 0.87 & 0.114 & 7.60 \\
\hline Sardinops sagax, Pacific Sardine & 0.46 & 0.80 & 0.044 & 18.3 \\
\hline Sprattus sprattus, European Sprat & 0.33 & 0.31 & 0.031 & 9.90 \\
\hline Engraulis encrasicolus, European Anchovy & 0.80 & 0.76 & 0.076 & 10.0 \\
\hline Engraulis ringens, Peruvian Anchoveta & 1.20 & 1.00 & 0.114 & 8.80 \\
\hline Gadus morhua, Atlantic Cod & 0.20 & 0.68 & 0.019 & 35.9 \\
\hline Melanogrammus aeglefinus, Haddock & 0.20 & 0.58 & 0.019 & 30.6 \\
\hline Merlangius merlangus, Whiting & 0.20 & 0.93 & 0.019 & 49.1 \\
\hline Merluccius bilinearis, Silver Hake & 0.40 & 0.68 & 0.038 & 17.9 \\
\hline Merluccius gayi, Peruvian Hake & 0.36 & 0.57 & 0.034 & 16.7 \\
\hline Merluccius merluccius, European Hake & 0.20 & 0.29 & 0.019 & 15.3 \\
\hline Micromesistius australis, Southern Blue Whiting & 0.20 & 0.25 & 0.019 & 13.2 \\
\hline Micromesistius poutassou, Blue Whiting & 0.20 & 0.36 & 0.019 & 19.0 \\
\hline Pollachius virens, Pollock or Saithe & 0.20 & 0.39 & 0.019 & 20.6 \\
\hline Theragra chalcogramma, Walleye Pollock & 0.31 & 0.46 & 0.029 & 15.7 \\
\hline Trisopterus esmarkii, Norway Pout & 1.60 & 0.90 & 0.152 & 5.90 \\
\hline Ammodytes marinus, Sand Eel & 0.51 & 0.50 & 0.048 & 10.3 \\
\hline Trachurus symmetricus murphyi, Chilean Jack Mackerel & 0.40 & 0.59 & 0.038 & 15.6 \\
\hline Trachurus trachurus, Horse Mackerel & 0.15 & 0.22 & 0.014 & 15.5 \\
\hline Sander vitreus, Walleye & 0.30 & 0.22 & 0.028 & 7.70 \\
\hline Genyonemus lineatus, White Croaker & 0.29 & 1.01 & 0.027 & 36.7 \\
\hline Scomber scombrus, Atlantic Mackerel & 0.18 & 0.19 & 0.017 & 11.1 \\
\hline Scomberomorus cavalla, King Mackerel & 0.17 & 0.33 & 0.016 & 20.5 \\
\hline Thunnus thynnus, Bluefin Tuna & 0.14 & 0.15 & 0.013 & 11.3 \\
\hline Pagrus auratus, New Zealand Snapper & 0.06 & 0.14 & 0.006 & 24.6 \\
\hline Pagrus pagrus, Red Porgy & 0.28 & 0.31 & 0.027 & 11.7 \\
\hline Paralichthys dentatus, Summer Flounder & 0.20 & 1.35 & 0.019 & 71.2 \\
\hline Hippoglossoides platessoides, American Plaice & 0.20 & 0.83 & 0.019 & 43.8 \\
\hline Platichthys flesus, European Flounder & 0.20 & 0.40 & 0.019 & 21.1 \\
\hline Limanda ferruginea, Yellowtail Flounder & 0.20 & 1.18 & 0.019 & 62.2 \\
\hline Pleuronectes platessa, European Plaice & 0.11 & 0.59 & 0.010 & 56.6 \\
\hline Reinhardtius hippoglossoides, Greenland Halibut & 0.15 & 0.34 & 0.014 & 23.9 \\
\hline Lepidorhombus whiffiagonis, Megrim & 0.20 & 0.30 & 0.019 & 15.8 \\
\hline Solea vulgaris, Sole & 0.10 & 0.37 & 0.009 & 39.0 \\
\hline Salvelinus namaycush, Lake Trout & 0.11 & 0.52 & 0.010 & 49.9 \\
\hline Anoplopoma fimbria, Sablefish & 0.10 & 0.19 & 0.009 & 20.0 \\
\hline Sebastes alutus, Pacific Ocean Perch & 0.05 & 0.09 & 0.005 & 19.0 \\
\hline Sebastes entomelas, Widow Rockfish & 0.15 & 0.35 & 0.014 & 24.6 \\
\hline Sebastes mentella, Deepwater Redfish & 0.10 & 0.25 & 0.009 & 26.4 \\
\hline Sebastes paucispinis, Bocaccio & 0.15 & 0.17 & 0.014 & 12.0 \\
\hline
\end{tabular}

about $28 \%$ are overfished (e.g., FAO, 2009). The thinking and belief systems behind such appraisals are part of what is reflected in (accounted for by; App. 3 ) the empirical patterns we observe (e.g., all of the patterns represented by the figures of this appendix; Belgrano and Fowler, 2008, 2011; Fowler, 2009). perspective, p. 337-356. Camb. Univ. Press, Camb., U.K.

FAO. 2009. The state of world fisheries and aquaculture, 2008. Food Agric. Organ., U.N. Avail. at www.fao.org/docrep/011/i0250e/i0250e00. htm. Last accessed 13 Sept. 2010.

Fowler, C. W. 1999a. Management of multi-species fisheries: from overfishing to sustainability. ICES J. Mar. Sci. 56:927-932. 1999b. Nature's Monte Carlo experiments in sustainability. In V. R. Restrepo (Editor), Proceedings of the fifth NMFS Stock Assessment Workshop: providing scientific advice to implement the precautionary approach under the Magnuson Stevens Fishery Conservation and Management Act, p. 25-32. U.S. Dep. Commer., NOAA Tech. Memo. NMFS-F/SPO-40.

2008. Maximizing biodiversity, information and sustainability. Biodivers. Conserv. 17:841-855.

2009. Systemic management: sustainable human interactions with ecosystems and the biosphere. Oxford Univ. Press, Oxford, U.K., 295 p. and L. Hobbs. 2011. Science and management: matching the questions. In A. Belgrano and C. W. Fowler (Editors), Ecosystem-based management for marine fisheries: an evolving perspective, p. 279-396. Camb. Univ. Press, Camb., U.K. and S. M. McCluskey. 2011. Sustainability, ecosystems and fishery management. In A. Belgrano and C. W. Fowler (Editors), Ecosystem-based management for marine fisheries: An evolving perspective, p. 307336. Camb. Univ. Press, Camb., U.K. and M. A. Perez. 1999. Constructing species frequency distributions-a step toward systemic management. U.S. Dep. Commer., NOAA Tech. Memo. NMFSAFSC-109, $59 \mathrm{p}$.

Kunkel, K., and D. H. Pletscher. 1999. Speciesspecific population dynamics of cervids in a multipredator ecosystem. J. Wildl. Manage. 63:1082-1093.

Livingston, P. A. 1993. Importance of predation by groundfish, marine mammals and birds on walleye pollock Theragra chalcogramma and Pacific herring Clupea pallasi in the eastern Bering Sea. Mar. Ecol. Prog. Ser. 102:205215.

Mertz, G., and R. A. Myers. 1998. A simplified formulation for fish production. Can. J. Fish. Aquatic Sci. 55:478-484.

Overholtz, W. J., S. A. Murawski, and K. L. Foster. 1991. Impact of predatory fish, marine mammals, and seabirds on the pelagic fish ecosystem of the northeastern USA. ICES Mar. Sci. Symp. 193:198-208.

Belgrano, A., and C. W. Fowler. 2008. Ecology for management: pattern-based policy. In S. I. Munoz (Editor), Ecology research progress, p. 5-31. Nova Sci. Publ., Hauppauge, N.Y.

and 2011. On the path to holistic management: ecosystem-based management in marine systems. In A. Belgrano and C. W. Fowler (Editors), Ecosystem-based management for marine fisheries: an evolving
Peters, R. H. 1983. The ecological implications of body size. Camb. Univ. Press, N.Y., 329 p.

Pielou, E. C. 1974. Population and community ecology. Gordon Breach Sci. Publ., N.Y., 432 p.

Zhou, S. Z., S. Yin, J. T. Thorson, A. D. M. Smith, and M. Fuller. 2012. Linking fishing mortality reference points to life history traits: an empirical study. Can. J. Fish. Aquat. Sci. 69:1292-1301. 


\section{Appendix 3: The Integrative Nature of Natural Patterns}

We treat here the concept that natural patterns are sources of information that holistically accounts for the complexity of reality (see Appendix 1 regarding the related role of information theory). This complexity includes all of reality, and its complete history, along with that of all its components, as well as the full set of dynamics, impacts, and risks associated with all of the ways the elements of reality are interconnected.

Natural patterns are integrative through their emergence as products of the full suite of factors that contribute to their origin, current characteristics, and dynamics (Fowler, 2009). Patterns include those that are observed in the limits to variation seen in the measures of any of a variety of processes, relationships, and interactions within natural systems (e.g., the process of consumption illustrated in text Figure 1 and selectivity as shown in text Figures 5 and 6). Patterns are also observed in physical structure; they are observed in the variation seen in the dimensions of such structure as we measure them.

All such patterns (including their dynamics) are reflective of the complete set of factors involved in the history of their origin; being infinitely integrative, nothing is excluded (Belgrano and Fowler, 2008). This can be understood from the point of view of experience in the construction of models; a completely holistic model would include the infinite set of factors involved in simulating the origin of any pattern (Belgrano and Fowler, 2011).

In practice, this is something that is obviously impossible. However, the reality one would be attempting to represent with such a model remains a reality (a set of real factors and real history that is infinite in its complexity). This reality is completely reflected in each observed pattern-nothing is excluded. The reality behind each pattern has all of its elements in common with that for every other pattern-the interconnected nature of reality (as a matter of principle) is included in what gets taken into account.
In essence, a pattern represents information far beyond the capacity of science/scientists to synthesize, integrate, or account for in any other way; the integration involved is essentially complete compared to the necessarily very limited potential of what scientists can achieve (e.g., through procedures such as Integrated Ecosystem Assessment; Levin et al., 2008). ${ }^{\mathrm{A} 3.1}$ In biotic systems this includes the information contained in genetic code as one part of the full set of information. Physicists often think of the full set of information in real-world systems as indestructible (even in passing through black holes; e.g., see: Susskind, 2008; Barbón, 2009; this persistence is occasionally referred to as the "law of information conservation"). In interpersonal communication, the kind of information characterized as nonverbal is understood to account for the majority of the message-as information much like that provided by natural patterns.

Empirically observed patterns can be understood as the result of natural Bayesian integration wherein the infinite set of factors involved are all taken into account-completely, accurately, and objectively (Fowler, 2009). As we have pointed out elsewhere (Belgrano and Fowler, 2011), the integrative nature of natural patterns involves their being what Goethe called urphänomen or ". . . laws which do not reveal themselves through words and hypotheses to the understanding, but through phenomena to the perception" (Williams, 1998).

The integration involved is akin to that behind the understanding that individual species can serve as indicators of ecosystem status (e.g., Moore, 2008, who, along with others uses the term "sentinels" in this regard); other

A3.1 As presented in detail in Fowler and Hobbs (2011), human limitations (including our ignorance) are brought to bear directly in our construction of simulation models, meetings of experts, and involvement of stakeholders while attempting to account for complexity (e.g., to integrate information). This is accomplished automatically within, and as a product of, the reality with which we are dealing, and specifically for each pattern consonant with our management questions. These patterns function as integrators in the same way indicators are assumed to function in Integrated Ecosystem Assessment. species reflect the condition, nature, and dynamics of their ecosystems (see Levin et al., 2008, for use of such indicators in Integrated Ecosystem Assessment-although lacking in consonance with a management question). Like such "canaries in the coal mine," natural patterns provide information about things that are unseen-even unknowable; as indicators, they provide information concerning what is sustainable when consonant with a management question.

An important aspect of the integrative nature of natural patterns is that they reflect the impact of human influence (Belgrano and Fowler, 2008, 2011). This can be appreciated easily in noting that the patterns in text Figures 3 and 4 have conventional management as a significant explanatory factor; the harvest rates resulting in overharvesting are those implemented in current forms of management.

Worldwide, such harvest rates contribute (perhaps quite significantly) to observed patterns in the consumption rates by other species. ${ }^{\mathrm{A} 3.2}$ As MacCall (2011) pointed out, most current attempts to achieve sustainability are efforts to maintain the status quo. Resistance to reducing harvest rates to conform to what is empirically evident as more sustainable (e.g., resistance to reducing the mean overfishing index derived from Appendix Figure A2.14) exemplifies the maintenance of the status quo; the factors behind such resistance also contribute heavily to the pattern of overfishing and the effects of overfishing on other species, ecosystems, and the biosphere.

Thus, owing to the interconnected nature of reality, all patterns reflect human influence in general. As such, the patterns of text Figures 3 and 4 account for human endeavors. The fact

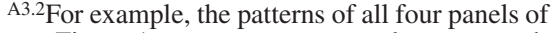
text Figure 1 are, to some very real extent, products of human influence. Altered human impact, through management, would undoubtedly result in changes among other species (see App. 1:fn A1.1). In the spirit of adaptive management (Holling, 1978), research would be required to determine estimates of consumption rates by marine mammals under circumstances of varying harvest rates.
} 
that natural patterns account for human influence (including our policies, laws, belief systems, values, economic policies, etc.) solves an important dilemma faced in conventional management: the need to manage so as to account for management itself.

Using natural patterns as a source of guiding information takes into account management-management involving all human influence (that is, all human influences are reflected in the fully integrative nature of empirical patterns). Systemic management (Fowler, 2003, 2009) uses empirical patterns so as to fill the need to undertake management that is based on information (see Appendix 1 regarding information theory). In the process, such management accounts for itself (much like a transcendental equation/function wherein a variable is a function of itself). As developed by Belgrano and Fowler (2011), systemic management accounts for itself (see Appendix 2 regarding ways in which this can be done more directly/overtly as an implementation of adaptive management).

One particular aspect of human endeavor is worthy of specific attention with regard to its being taken into account through guidance provided by natural patterns. This anthropogenic component of reality is economics, or economic systems. It is quite easy to understand the economic hardship of implementing the extensive reductions in harvest rates that would be required of management based on guidance provided by macroecological patterns. Lobbyists, lawyers, and fishermen, along with scientists, environmentalists, and other human stakeholders would all agree that the economic burden of reducing the harvest rates in commercial fishing by more than $90 \%$ would be very close to economic suicide. For some, an initial understanding of the utility of macroecological patterns as guiding information might give rise to advice to try convincing the world of the importance of such information on the basis of economic benefits (to find a way to "sell systemic management with economic arguments"). All such reactions represent recognition of the connection of economics to decisionmaking and the ways these factors contribute to management. The point of this appendix is that all economic factors are, along with all other aspects of human endeavor, inherently reflected in (accounted for by) empirically observable natural patterns. Thus, all such factors are already taken into account (automatically) by the guiding macroecological patterns themselves.

Therefore, rather than allowing economic factors to be the driving force that they are in conventional management, systemic management involves a full consideration of such factors (and meets legislative requirements that economic factors be taken into account). Such factors are taken into account with respect to all associated risks-including those of future losses exemplified by those involving ecosystem services, extinction (including the risk of our own), and collapses in the populations of resource species. The interdisciplinary aspect of involving economists in decision-making helps clarify that there are, among the interconnected aspects of reality, connections that involve the cause-and-effect impacts of economic factors (all of which are subsumed, inherently, in the very nature of natural patterns). The transdisciplinary aspect of systemic management guarantees that all such factors are taken into account. Information inherent to natural patterns includes such things as the resistance to, the failure to implement, and the lack of understanding of, systemic management. These are especially prominent in the pattern of human abnormality seen in a wide variety of metrics applied to human relationships with the nonhuman (Fowler, 2009), specifically those involving our harvest of fish as presented in this paper.

Evolution, coevolution, and natural selection at all levels are elements that are also within the reality behind every empirical pattern. As such, these count among the infinite set of factors that get taken into account by natural patterns. So are all of the elements, components, and processes of ecosystems and the biosphere. Thus, when natural patterns are used as information to guide management, the guidance is not only ecosystem-based, it is simultaneously and consistently evosystem-based and biosphere-based-it is reality based (holistic).

These systems, processes, and dynamics are all taken into account as part of the information inherent to natural patterns. Beyond the "automatic" accounting of such complexity (complexity inherent to natural patterns) is the option of proceeding to account for such factors directly/overtly in the way we ask and refine management questions (as exemplified by the questions posed and addressed in this paper).

Legal mandates often require accounting for economic factors, social issues, and the values and opinions of stakeholders. As specified earlier, these are already accounted for in natural patterns; such factors are among those that contribute to the formation of such patterns and are thus inherent to the patterns. This is true for all belief systems, legislation, thinking, politics, policies, and values brought to the management process. They are all elements of reality from which natural patterns emerge. They are all involved in the process of "dependent co-arising" clearly recognized in Buddhist philosophy (Macy, 1979).

\section{Literature Cited}

Barbón, J. L. F. 2009. Black holes, information and holography. J. Phys.: Conf. Ser. 171:1-6.

Belgrano, A., and C. W. Fowler. 2008. Ecology for management: Pattern-based policy. In S. I. Munoz (Editor), Ecology research progress, p. 5-31. Nova Sci. Publ., Hauppauge, N.Y.

and

2011. On the path to holistic management: ecosystem-based management in marine systems. In A. Belgrano and C. W. Fowler (Editors), Ecosystem-based management for marine fisheries: An evolving perspective, p. 337-356. Camb. Univ. Press, Camb., U.K.

Fowler, C. W. 2003. Tenets, principles, and criteria for management: the basis for systemic management. Mar. Fish. Rev. 65(2):155.

2009. Systemic management: sustainable human interactions with ecosystems and the biosphere. Oxford Univ. Press, Oxford, U.K., 295 p. and L. Hobbs. 2011. Science and management: matching the questions. In A. Belgrano and C. W. Fowler (Editors), Ecosys- 
tem-based management for marine fisheries: an evolving perspective, p. 279-396. Camb. Univ. Press, Camb., U.K.

Holling, C. S. (Editor). 1978. Adaptive environmental assessment and management. John Wiley Sons, N.Y., 377 p.

Levin, P. S., M. J. Fogarty, G. C. Matlock, and M. Ernst. 2008. Integrated ecosystem assessments. U.S. Dep. Commer., NOAA Tech.
Memo. NMFS-NWFSC-92, 20 p.

MacCall, A. 2011. Foreword. In A. Belgrano and C. W. Fowler (Editors), Ecosystem-based management for marine fisheries: An evolv-

ing perspective, p. xiii-xvi. Camb. Univ. Press, Camb., U.K.

Macy, J. 1979. Dependent co-arising: the distinctiveness of Buddhist ethics. J. Relig. Ethics $7: 38-52$
Moore, S. E. 2008. Marine mammals as ecosystem sentinels. J. Mammal. 89:534-540.

Susskind, L. 2008. The black hole war: my battle with Stephen Hawking to make the world safe for quantum mechanics. Little Brown Co., N.Y., $480 \mathrm{p}$.

Williams, J. R. 1998. The life of Goethe: a critical biography. Blackwell Publ., Oxford, U.K., $352 \mathrm{p}$. 


\section{Appendix 4: An Assessment of Single-Species Fisheries of the Baltic Sea}

Here, we present a detailed application of the information involved in the macroecological pattern described in Appendix 2 (and represented in text Figure 2 and Appendix Figures A2.9A2.12). Specifically, we evaluate the history of fishing as it involved two species of fish in the Baltic Sea. This represents the first systemic assessment of a multi-year fishery.

"What would the fishing rate have been in the harvest of Atlantic Herring, Clupea harengus, from the Baltic Sea each year from 1974-2005, if the harvest had been managed sustainably to directly account for the total natural mortality rate of this population?"

Figure A4.1 is an illustration of estimated total natural mortality rates for herring in the Baltic Sea from 1974-2005 (ICES, 2006), involving the case of an ecosystem where there are historical estimates of the natural mortality rate $(M)$ for a number of consecutive years. We used the equation from Appendix $2\left(F_{e s}=0.095\right.$ $M)$ to convert $M$ to an estimate of the ecologically sustainable harvest rate $\left(F_{e s}\right.$, with sustainability of systemic proportions, as explained in the main text). This was done rather than using $M$ itself as a standard of reference for sustainable harvest rates for commercial fishing (as commonly done historically, and an example of using information that is not consonant with the manage-

\section{Total Natural Mortality (M)}

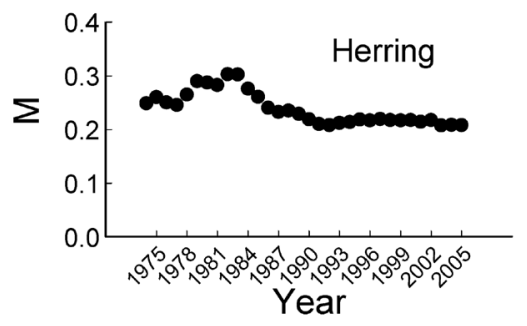

Figure A4.1.-The estimated total natural mortality rate $(M)$ for Atlantic Herring in the Baltic Sea from 1974 to 2005 (ICES, 2006). ment questions; Fowler and McCluskey, 2011). Thus, we are estimating sustainable harvest rates based on the macroecological pattern shown in text Figure 2 and Appendix Figure A2.12, as explained in Appendix 2.

Figure A4.2 shows a temporal comparison of observed harvest rates $\left(F_{o b}\right.$; i.e., harvest rates applied through conventional management, wherein politics, economic factors, and other nonconsonant factors are heavily influential; ICES, 2007) with the ecologically/evolutionarily sustainable harvest rates $\left(F_{e s}\right.$, wherein all factors are treated objectively, keeping in mind that other management questions have yet to be addressed, specifically those regarding selectivity).

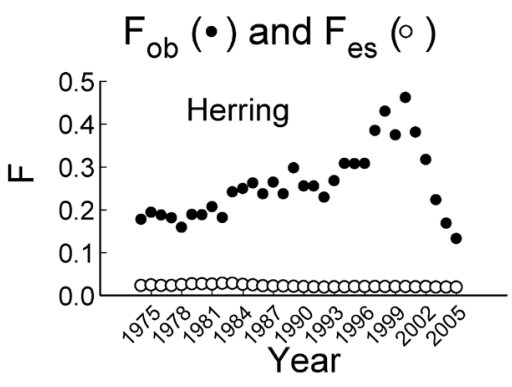

Figure A4.2.-The observed fishing rates $\left(F_{o b}\right.$; ICES, 2006) for Atlantic Herring in the Baltic Sea from 1974 to 2005 and the corresponding estimated sustainable harvest rates $\left(F_{e s}\right.$ $=0.095 \mathrm{M}$; ecologically, evolutionarily, empirically sustainable fishing rates) based on $M$ from Figure A4.1 for the same years.

\section{Overfishing Index (OI)}

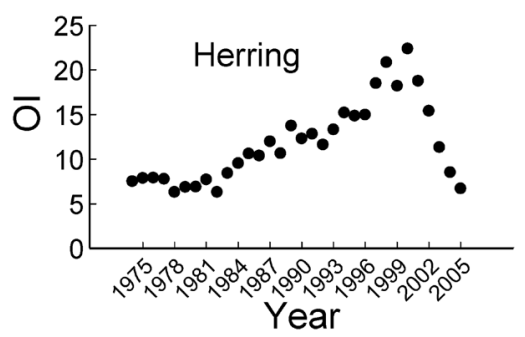

Figure A4.3.- The overfishing index $\left(O I=F_{o b} / F_{e s}\right)$ for Atlantic Herring of the Baltic Sea as it varied over time from 1974 to 2005.
A simple overharvesting index (OI) can be calculated, for any species, as the ratio of the observed harvest rate $\left(F_{o b}\right)$ to the more holistically sustainable harvest rate $\left(F_{e s}\right)$. The temporal dynamics of this ratio $\left(O I=F_{o b} / F_{e s}\right)$ are illustrated for herring in the Baltic Sea in Figure A4.3. The mean overharvesting index for this species, in this ecosystem, and for the period from 1974 to 2005 , is 11.8 (with a minimum of 6.3 times too much taken in 1982 and maximum of 22.4 taken in 2000) (Fig. A4.4). This fishery is similar to the fisheries represented in Appendix Figure A2.14 in significantly overharvesting - in this case, over the span of more than three decades.

"What would the fishing rate have been in the harvest of European Sprat, Sprattus sprattus, from the Baltic Sea each year (from 1974 to 2005), if the harvest had been managed sustainably to account directly

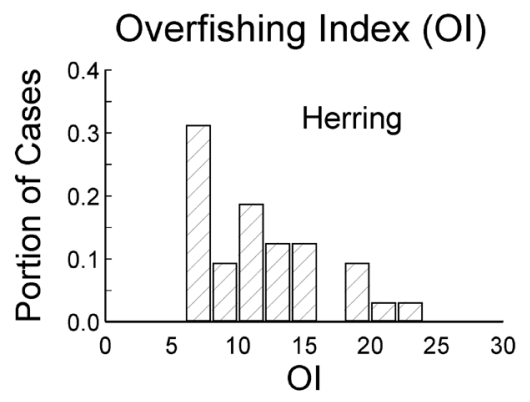

Figure A4.4.- The overfishing index $\left(O I=F_{o b} / F_{e s}\right)$ for Atlantic Herring of the Baltic Sea in its pattern of variability for the years 1974-2005.

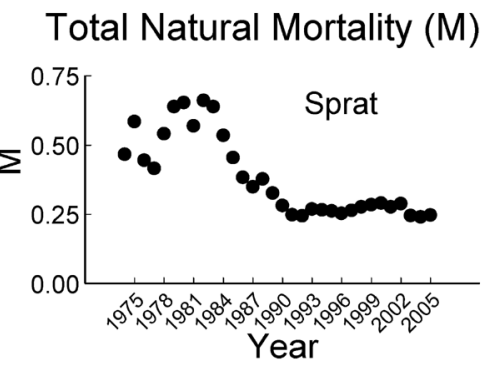

Figure A4.5.- The estimated total natural mortality rate $(M)$ for European Sprat in the Baltic Sea from 1974 to 2005 (ICES, 2006). 


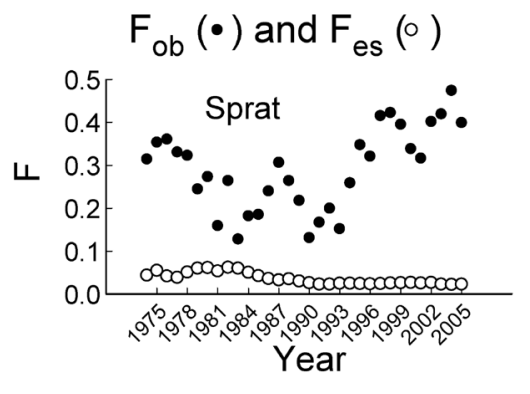

Figure A4.6.-The observed fishing rates $\left(F_{o b}\right.$; ICES, 2006) for European Sprat in the Baltic Sea from 1974 to 2005 and the corresponding estimated sustainable harvest rates $\left(F_{e s}\right.$ $=0.095 \mathrm{M}$; ecologically, evolutionarily, empirically sustainable fishing rates) based on $M$ from Figure A4.5 for the same years.

for the total natural mortality rate of this population?"

Figures A4.5-A4.8 are similar to Figures A4.1-A4.4, respectively. In this case, the data are for sprat. Again, the overharvesting index (and its variation over time, Fig. A4.7) is consistent with that of most conventionally managed

\section{Overfishing Index (OI)}

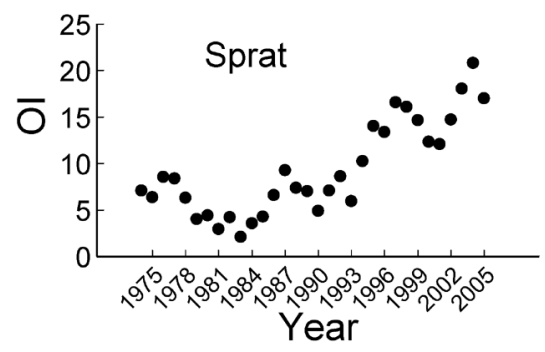

Figure A4.7.- The overfishing index $\left(O I=F_{o b} / F_{e s}\right)$ for European Sprat of the Baltic Sea as it varied over time from 1974 to 2005 .

fisheries (App. Fig. A2.14), showing a minimum of 2.12 (1983) and a maximum of 20.8 (2004) with a mean of 9.36 (Fig. A4.8).

\section{Literature Cited}

Fowler, C. W., and S. M. McCluskey. 2011. Sustainability, ecosystems and fishery management. In A. Belgrano and C. W. Fowler

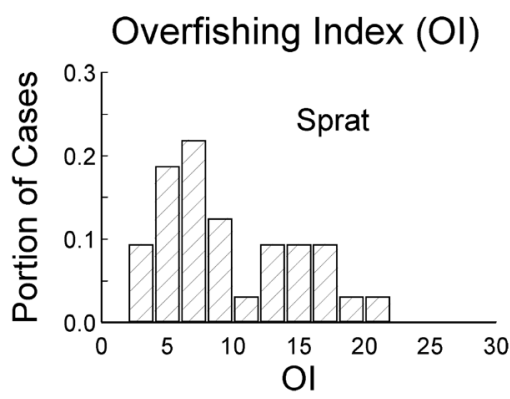

Figure A4.8.- The overfishing index $\left(O I=F_{o b} / F_{e s}\right)$ for European Sprat of the Baltic Sea in its pattern of variability for the years 1974-2005.

(Editors), Ecosystem-based management for marine fisheries: an evolving perspective, $\mathrm{p}$. 307-336. Camb. Univ. Press, Camb., U.K. ICES. 2006. Report of the study group on multispecies assessment in the Baltic (SGMAB), 2-7 November 2006, Helsinki, Finland. Copenhagen, Denmark, 114 p. 2007. Report of the Baltic Fisheries Assessment Working Group (WGBFAS), 17-26 April 2007, ICES Headquarters, Copenhagen, Denmark, 735 p. 